\title{
Hospital midwives
}

Citation for published version (APA):

Cronie, D. J. (2019). Hospital midwives: an examination of the role, diversity and practice conditions of Dutch hospital midwives. [Doctoral Thesis, Maastricht University]. Gildeprint Drukkerijen. https://doi.org/10.26481/dis.20191003dc

Document status and date:

Published: 01/01/2019

DOI:

10.26481/dis.20191003dc

Document Version:

Publisher's PDF, also known as Version of record

\section{Please check the document version of this publication:}

- A submitted manuscript is the version of the article upon submission and before peer-review. There can be important differences between the submitted version and the official published version of record.

People interested in the research are advised to contact the author for the final version of the publication, or visit the DOI to the publisher's website.

- The final author version and the galley proof are versions of the publication after peer review.

- The final published version features the final layout of the paper including the volume, issue and page numbers.

Link to publication

\footnotetext{
General rights rights.

- You may freely distribute the URL identifying the publication in the public portal. please follow below link for the End User Agreement:

www.umlib.nl/taverne-license

Take down policy

If you believe that this document breaches copyright please contact us at:

repository@maastrichtuniversity.nl

providing details and we will investigate your claim.
}

Copyright and moral rights for the publications made accessible in the public portal are retained by the authors and/or other copyright owners and it is a condition of accessing publications that users recognise and abide by the legal requirements associated with these

- Users may download and print one copy of any publication from the public portal for the purpose of private study or research.

- You may not further distribute the material or use it for any profit-making activity or commercial gain

If the publication is distributed under the terms of Article $25 \mathrm{fa}$ of the Dutch Copyright Act, indicated by the "Taverne" license above, 


\section{Hospital Midwives: an examination of the role, diversity and practice conditions of Dutch hospital midwives.}

Douglas John Cronie 
Financial support from M aastricht University and Zuyd University (Research Center Midwifery Science) for the publication of: "Are midwives in the Netherlands satisfied with their jobs? A systematic examination of satisfaction levels among hospital and primary-care midwives in the Netherlands" (chapter 4) and: "How good is collaboration between maternity service providers in the Netherlands?" (chapter 6) is gratefully acknowledged.

Financial support by the Royal Dutch Organisation of Midwives for the publication of this thesis is gratefully acknowledged.

Author: $\quad$ D.J. Cronie

Cover: Jaimie Doak, www.okdoakdesign.com

Lay-out: Ilse Modder, www.ilsemodder.nl

Printed by: $\quad$ Gildeprint - Enschede, www.gildeprint.nl

\section{ISBN: 978-94-6323-796-3}

(c) Copyright, D. J. Cronie, 2019.

All rights reserved. No part of this thesis may be reproduced or transmitted in any form or by any means, electronic or mechanical, including photocopy, recording or any information storage or retrieval system, without prior permission of the author. 


\title{
Hospital Midwives: an examination of the role, diversity and practice conditions of Dutch hospital midwives.
}

To obtain the degree of Doctor at M aastricht University on the authority of the Rector Magnificus, Prof. dr. Rianne M. Letscherft, in accordance with the decision of the Board of Deans to be defended in public on Thursday the $3^{\text {rd }}$ of October 2019 at 12.00 o'clock.

\author{
By \\ Douglas John Cronie
}

Date of birth: $9^{\text {th }}$ November 1965 in Johnstone, Scotland. 
Supervisors:

Co-supervisors:

Assessment Committee:
Prof. Dr. R. de Vries.

Prof. Dr. S.E. Buitendijk, Imperial College London

Dr. M. Rijnders, TNO Leiden

Dr. S. Jans, TNO Leiden

Prof. Dr. P. Teunissen, Chairman

Prof. Dr. J. de Jong

Prof. Dr. F. Stevens

Prof. Dr. P. Lewis, Bournemouth University

Dr. M. Smit, LUMC 


\section{Table of Contents}

\section{Chapter 1}

General Introduction

\section{Chapter 2}

Diversity in the Scope and Practice of Hospital-Based Midwives in the Netherlands

J Midwifery Women's Health 2012, 57 (5): 469-475.

\section{Chapter 3}

M aking Evidence Available for Hospital-Based Midwives: A Systematic Examination of the Content and M ethodological Quality of Three Protocols Used in Maternity Hospitals in the Netherlands International Journal of Childbirth 2014, 4 (4): 208-218.

\section{Chapter 4}

Are midwives in the Netherlands satisfied with their jobs? A systematic examination of satisfaction levels among hospital and primary-care midwives in the Netherlands

Accepted by: BM C Health Service Research, M ay 2019.

\section{Chapter 5}

Experienced job autonomy among maternity care professionals in the Netherlands

Birth 2015, 42 (2): 156-64.

\section{Chapter 6}

How good is collaboration between maternity service providers in the Netherlands?

Journal of Multidisciplinary Healthcare 2019, 12: 21-30. 


\section{Chapter 7}

General Discussion

\section{Chapter 8}

Summary

\section{Chapter 9}

Nederlandse samenvatting

\section{Chapter 10}

List of publications and contributions authors

\section{Chapter 11}

About the Author

Chapter 12

Word of thanks 


\section{This thesis is dedicated to:}

My Mum, from whom I was lucky enough to receive unconditional love Our daughter, for whom I strive with every fibre of my being to give unconditional love

And for my husband without whose love and support this long and sometimes difficult journey would have been infinitely harder.

Thank you! 
1

General Introduction 


\section{General introduction:}

\section{Advent of the hospital midwife.}

The primary care midwife has long been the cornerstone of Dutch maternity care; the hospital midwife is a relatively new and increasingly important caregiver for pregnant and birthing women in the Netherlands. Twenty-five years ago, fewer than ten percent of midwives in the Netherlands were identified as hospital midwives (known as 'clinical midwives' in Dutch) ${ }^{1}$; today according to the latest available numbers - one in three midwives are employed in hospitals, making this the fastest growing segment of the profession ${ }^{2}$. In spite of their growing numbers, and in spite of the fact that they are frequently called upon to care for women with complex care needs - often without direct supervision by an obstetrician ${ }^{3}$ - we know very little about the practice of hospital midwives and what they contribute to maternity care in the Netherlands.

\section{The changing face of maternity care in the Netherlands.}

M aternity care in the Netherlands is organized in echelons: primary, secondary and tertiary care. All physiological (sometimes called "low-risk") pregnancy and birthing-related care occurs in the primary care setting with the primary care midwife - or (rarely) a general practitioner - as the lead professional. Primary care midwives are independent, autonomous professionals and are specialists in the management of physiological pregnancy and birth ${ }^{4}$.

When a woman is considered to be at increased risk or her pregnancy/birth is complicated by pathology, she will be referred to the hospital (secondary care) setting, or, in the case of extreme complications (e.g. very early prematurity or complex comorbidity) to tertiary, University level hospital care 5 . In the past, referral to secondary care meant referral to an obstetrician who would provide care, but today a woman who is referred to an obstetrician will often be attended by a hospital midwife ${ }^{6}$.

In order to understand the significance of this change and to provide context for midwifery service provision in the Netherlands today, it is useful to briefly sketch the series of events that have led to this point.

\section{A short history of midwifery in the Netherlands.}

There is a long tradition of midwifery in the Netherlands. Evidence of organised, independent midwifery care extends back to 1530 A.D ${ }^{7}$. Over the years since then, the independence of the profession has been affirmed, and 
the sphere of practice given to midwives has been defined, by various acts of parliament (M edical Act 1865 (updated 1932 and 1951), the Ordinance for M idwives (1941), and the WET BIG (2001). It is important to note that the focus of all these regulations has been primary care midwifery.

The current midwifery profile owes much to Gerrit-Jan Kloosterman, a professor of obstetrics and the head of the midwifery training school in Amsterdam from 1957 until 1982. A strong proponent of primary care midwifery, Professor Kloosterman was influential in shaping the maternity care system in the Netherlands ${ }^{8}$ by structuring the management of maternity care based on a "list" that used level of risk to assign responsibilities to different types of care providers ${ }^{9}$. This list has evolved over the years. It was introduced in $1958^{10}$ and revised in 1966, 1973, 1987 (at this point it was known as the "obstetric indication list" [or, in Dutch, the VIL], and 1992). In 2003, it was

officially renamed the Verloskundige Vademecum (maternity care manual). The logic of the list, contrary to the logic in most modern maternity care systems, is that the process of birth is 'normal' until proven otherwise ${ }^{4,11}$. To this day, the midwives' sphere of practice - the boundaries and circumstances under which a midwife can practice and when she should refer to specialist care - is defined by the VIL. Like the regulations mentioned above, the VIL was created to define the scope of practice of a primary care midwife.

\section{The short history of hospital midwives in the Netherlands.}

The advent of the hospital midwife in the Netherlands is not well documented. M idwifery in post-war Holland was not for the faint of heart. Primary care midwives - most working in solo practices - were expected to be on-call 24 hours per day, 7 days per week. They were poorly paid and had no provision for pensions. These conditions made it difficult to combine the practice of midwifery with family life ${ }^{12}$. During this time, there is sporadic mention in the literature of midwives ${ }^{13}$ (typically married, with children) in the service of a hospital. However, there is no suggestion of systematic employment of midwives as a matter of policy.

It appears that a policy of employing hospital midwives began sometime between 1950-1960. First mention of midwives as hospital employees appears in the minutes of a meeting of the national midwifery service committee in $1950^{14}$. This idea found favour with Prof. Kloosterman who, at that time, was also responsible for the education of obstetric residents. Kloosterman reasoned that residents would benefit from exposure to the management of 'normal' (physiological) birth attended by midwives. Furthermore, he also reasoned that a woman with a complicated pregnancy who had been referred to an 
obstetrician had more chance of achieving a normal birth with the presence of a midwife ${ }^{8}$. Accordingly, for the first time in the Netherlands, there is evidence of midwives being employed in the hospital setting to 'teach' obstetric residents and promote normal birth ${ }^{15}$.

It was this idea that gave birth to the hospital midwife. By 1960, national records show that 17 midwives were in hospital employment in the Netherlands ${ }^{16}$. At this time, there was no suggestion that hospital midwives should do anything other than manage (and teach) normal physiological birth. The advent of the hospital midwife did not give rise to an amended sphere of practice for midwives.

It is important to note that the practice of employing midwives in the hospital setting is separate and distinct from the custom of low risk hospital births being supervised by primary care midwives. Beginning in the 1970 s primary care midwives were allowed to attend to birthing women in their care- where the birth is physiological and is progressing normally - in the hospital setting. Known as "policlinic" births, this practice is considered 'a home-birth in another setting' and falls under the responsibility of the primary care midwife. In this scenario, even though they are assisting birthing women in hospitals, primary care midwives retain their independence and are not employees of the hospital ${ }^{17}$.

Beginning in the 1960s, there was a gradual, but small increase in the number of hospital midwives. By the late 1980s hospital midwives made up approximately ten percent of the total of practicing midwives in the Netherlands ${ }^{18}$. This number remained fairly constant until the late $1990 \mathrm{~s}^{19}$.

During this time, there is growing acknowledgement of the existence of hospital midwives in the literature ${ }^{20}$, but there was little documentation of their efficacy. This began to change in 1995 with the publication of the OBINT study. This study examined intervention rates for women in labour in Dutch hospitals and - in keeping with Kloosterman's idea that midwives would promote physiological birth in the clinic - found that rates of intervention were lower in hospitals where midwives were employed ${ }^{21}$. Since then, this effect has been seen in other studies ${ }^{22}$, and it has been confirmed by the findings of the systematic review by Hattam et a ${ }^{23}$, and more recently by the Lancet Midwifery series ${ }^{24}$.

By the early 1990s, and for the first time in the Netherlands, hospital midwives appeared in the salary scales agreed to within the collective bargaining framework for hospitals ${ }^{25}$, a formal indication of the integration of hospital midwifery in the Dutch maternity care system. 
The number of hospital midwives in the Netherlands continued to grow in the second half of the 1990s. The reasons for this growth are not immediately clear. It has been variously suggested that the decline of birth at home (with a concomitant rise in hospital births), together with the desire of midwives for fixed hours and a secure salary, increased both the demand for, and supply of, hospital midwives, making hospital practice an attractive option ${ }^{26,27}$. As the number of hospital midwives increased, their role changed and expanded ${ }^{28}$. Initially, as noted above, midwives were brought into the hospital to teach 'normal' (physiology), but over the years, the care entrusted to midwives has become more complex ${ }^{29}$. Through substitution of care, hospital midwives have come to manage more (complex) cases $^{30}$, leading to today's situation where hospital midwives routinely attend women with complex care needs, often working without direct medical supervision ${ }^{31}$.

The evolution of the role and responsibilities of the hospital midwife has not been matched by changes to the legal framework of practice. Current midwifery practice law covers only (the performance of) midwifery acts in the presence of normal (physiological) pregnancy and birth in the primary care setting ${ }^{32}$. Lack of clarity surrounding the regulations governing hospital midwives - about what she can and cannot do - creates uncertainty over the midwives' role and the extent of their capabilities. In addition, current midwifery training does not equip midwives for the skill-set required for hospital practice, including caring for women with complex needs ${ }^{33}$. This confusion leads to discrepancies in the competencies and skills demanded of hospital midwives and can lead to misperceptions about their role on the part of other practitioners and patients/ clients $^{34}$.

Key stakeholders, such as the professional organisations of midwives and gynaecologists (KNOV \& NVOG), are aware of this situation ${ }^{35}$. To date however, there have been no suggestions for the regulation of the practice of hospital midwives that all parties can agree upon ${ }^{36}$.

Over the last decade, various attempts have been made to formally ratify the position of the hospital midwife. In 2007, the KNOV and NVOG attempted to formalise the position of the hospital midwife within the maternity care system. However, due to differences of opinion over the position of the hospital midwife within the maternity care system (primarily related to who was responsible for what), they were unable to come to an agreement ${ }^{37}$. A second attempt was made in $2010^{37}$ when a joint (KNOV/NVOG) work group was given a mandate for change. After several months of deliberation, the work group recommended: 
i. That a change to the existing Law regarding midwives' practice was required in order to reflect the broadened role of the hospital midwife;

ii. That a new category of 'clinical (hospital) midwife' be added to the Health Practitioners Law ${ }^{32}$;

iii. That profiles be agreed upon, specifying content and criteria for the training programmes and the job description of clinical (hospital) midwives.

In the 2010s, two education programmes for hospital midwives were created $^{38,39}$. However, the KNOV declared that neither programme fully matched the criteria for training a 'Clinical Midwife' as specified in the final report of the work group (KNOV/NVOG). Indeed, the work group suggested that a new course, designed specifically to prepare hospital midwives for the work they are asked to do, was needed if the new category of 'Clinical M idwife' is to be formally recognised ${ }^{40}$.

A further attempt to strengthen the position of the hospital midwife was made in 2014 when the KNOV, in conjunction with the NVOG, published a joint position paper titled: "Blueprint for the Positioning of the Clinical M idwife". This document was intended to support hospital midwives in establishing their position within the local organisational structure of hospitals ${ }^{41}$. However, this too, has produced mixed results as the blueprint is advisory in nature and carries no mandate or obligation for its introduction or use.

In spite of these well-intentioned efforts, the regulatory status and responsibilities of the hospital midwife remain unclear. The four-year baccalaureate-level training for Dutch midwives still focuses on the normal physiological processes of pregnancy and childbirth, with insufficient preparation for managing births in secondary or tertiary care. And although agreement has been reached over an education profile for the hospital midwife ${ }^{42}$, there is no formal requirement for additional training for midwives choosing to work in hospitals.

The ideal profile of the hospital midwife has also been described ${ }^{43}$, but the place of the hospital midwife within the midwifery model of care has not yet been formalized. The future of hospital midwifery remains uncertain, and there is a great deal of diversity in the way hospital midwives practice.

\section{From independent practice to employee.}

The fact that nearly one in three of Dutch midwives works as an employee of a hospital ${ }^{44}$ represents a significant change in the profession of midwifery and the working lives of midwives. Hospital midwives are subject to a different, 
more hierarchical organisational structure and are part of a larger, more complex organisational culture. This work environment is likely to affect their job satisfaction and changes the meaning of autonomous practice.

In spite of this significant change in the content and process of midwifery work, we know very little about how the structure and culture of the hospital is altering midwifery in the Netherlands. There is, for example, growing disquiet from some within the profession regarding the possibility of the creation of a new category (clinical midwife) within the register. There is concern that the introduction of a new category of midwife may, in effect, introduce a twotiered system within the profession, altering the practice of the primary care midwife and her place in the maternity care system ${ }^{46}$.

This concern may lead to greater challenges in collaboration between hospital and primary care midwives and underscores the need to better understand and respect the similarities and differences between the two groups of midwives. Uncertainty over the contribution of hospital midwives - in terms of the cost of, and client satisfaction with, maternity care - adds to the need to establish a baseline in our understanding of their role in Dutch maternity care. This need has been made more acute by the move toward integrated maternity care ${ }^{47}$ the introduction of which - without first having a clear understanding of the contribution of the parties involved - will make it more difficult to measure the impact of new models of service provision.

\section{The future of midwifery in the Netherlands.}

The current model of service provision has been the subject of inquiry in the last few years ${ }^{48}$. A government report in $2009^{49}$ suggested - with little evidence - that improvement in perinatal mortality and morbidity in the Netherlands may be achieved by greater collaboration between the professionals involved in maternity services. The report went on to propose that integrated models of care - changing the current system with its strict delineation of physiology in primary care and pathology in secondary care - would lead to better collaboration and hence better outcomes. At present, however, there is no consensus about what integrated care looks like or how it can be facilitated, introduced, or managed ${ }^{50}$. And yet, integrated models are being introduced ${ }^{51}$.

Although the position and role of hospital midwives is still not well defined, it is likely that the move toward new models of integrated care will also change and expand their scope of practice.

\section{The need to understand the place and practise of hospital midwifery.}


In summary, there are several lacunae in our knowledge about hospital midwives.

1. We know how many midwives are practicing in hospitals, and we know that they form the fastest growing group of midwives in the Netherlands. However, we do not know to what extent, or exactly how many, have received additional training, nor do we know if they are practicing in every maternity hospital.

2. We know that there is an agreed upon profile for the hospital midwife $e^{43}$. However, we do not know to what extent, if any, this actually reflects the work of hospital midwives in their daily practice.

3. We know that high-level evidence exists to support the value of the practice of hospital midwives. However, we do not know to what extent, if any, this evidence is available to hospital midwives.

4. We know that the Dutch midwifery model of care is undergoing a period of substantial change. However, we do not know how hospital midwives view these changes and, in particular, how they view their autonomy, job satisfaction, and the collaboration within a multi-disciplinary healthcare team.

5. We know that all hospital midwives are employees, and that in primary care, the majority of midwives are self-employed. However, we do not know whether there are significant differences between the composition of these groups or whether (and where) their views of midwifery practice differ.

6. Lastly, we know that there has been progress made towards establishing a new category of 'Clinical (hospital) M idwife' in the Netherlands. However, we do not know whether this is will come to fruition or if there is a desire, or a mandate, for this change among midwives in the Netherlands.

The net result of this knowledge deficit is that it is difficult to measure, and hence to understand, the contribution of hospital midwives to contemporary midwifery practice. This information is critical if we are to assess how hospital midwifery can best be supported and developed to provide the best care for women and their babies.

In this thesis, we explore some of these questions. Importantly, the research we have done serves as a baseline in our understanding of the contribution of Dutch hospital midwives.

\section{Aims of this thesis:}

By mapping and critically reviewing the practise of hospital midwives, this thesis explores the contribution of hospital midwives to contemporary 
midwifery practice within the context of the Dutch maternity care system. In addition, this thesis clarifies the position of hospital midwives within the current organisation of maternity service provision in the Netherlands.

The objectives of our research are:

1. To describe the existing diversity in the scope and practice of hospital midwives in the Netherlands (chapter 2).

2. To examine the content and quality of the protocols for hospital midwives used in maternity hospitals in the Netherlands (chapter 3).

3. To compare hospital midwives and primary care midwives with regard to job satisfaction and attitudes towards their work (chapter 4).

4. To examine how maternity care professionals in the Netherlands perceive their job autonomy and whether their expectations about job autonomy will change in a system of integrated maternity care (chapter 5).

5. To examine the quality of collaboration between multi-disciplinary teams of maternity service providers in the Netherlands (chapter 6 ).

In chapter 7,the general discussion, we bring together the aim and objectives of the thesis, examining the results and findings of our research in light of contemporary midwifery service provision in the Netherlands. The general discussion concludes with an analysis of the implications of our research for practice and consideration of avenues for future research in view of our findings. 


\section{References.}

1). Harmsen J, Kingstman L. Cijfers uit de Registratie van Verloskunde (Numbers from the Registration of Midwives) 1995, NIVEL, Utrecht, the Netherlands.

2). Kenens R, Batenburg R, Kasteleijn A. Cijfers uit de Registratie van Verloskundigen (Numbers from the Registration of M idwives) 2017, NIVEL, Utrecht, the Netherlands.

3). Cellissen E, Engeltjes B, Rijke R, Steegers E, Scheele F. De physician assistant klinisch verloskundige in Nederland (The physician assistant clinical midwife in the Netherlands). Nederlands Tijdschrift voor Obstetrie \& Gynaecologie (Dutch Journal for obstetrics and Gynaecology) vol. 131, juni 2018 www.ntog.nl.

4). Amelink-Verburg M , Buitendijk S. De Verloskundige Indicatie Lijst: wat is normaal? De rolverdeling tussen verloskundigen en gynaecologen in het Nederlandse verloskundig systeem (The midwifery indication list: what is normal? The role division between midwives and gynaecologists in the Dutch midwifery system) TvV November 2010, KNOV.

5). van der Lee N. Tailoring CanM eds for training in Obstetrics and Gynaecology in the Netherlands. 2014. Thesis, Vu Amsterdam, the Netherlands.

6). Betlem J, Droog J, Hakkenberg R, ledema R, van Loon A, Oei S, Rijninks G. De klinische verloskundige: de verbindende factor Leidraad voor Protocol positie klinisch verloskundigen (The clinical midwife: the connecting factor Guideline for Protocol for the position clinical midwives). TvV 4/2014. KNOV, Utrecht, the Netherlands.

7). van Lieburg M. M emoryboeck van de vrouwens. Het notitieboek van een Friese vroedvrouw (M emory book of women. The notebook of a Frisian midwife) 1693-1745(1984)-Catharina Schrader, 1984, Dokkum, the Netherlands.

8). Kloosterman GJ. De voortplanting van de mens. Leerboek voor obstetrie en gynaecologie (Human reproduction. Textbook for obstetrics and Gynaecology). Bussum: Uitgeversmaatschappij Centen, 1973.

9). Goodarzi B, Holten L, van El C, et al. (2018) Risk and the politics of boundary work: preserving autonomous midwifery in the Netherlands, Health, Risk \& Society, 20:7-8, 379-407, DOI: 10.1080/13698575.2018.1558182.

10). de Bruin A. Verloskunde in Nederland (Midwifery in the Netherlands). Medisch Contact, No 22 - 1 juni 1973, Utrecht, the Netherlands. 
11). Commissie Verloskunde Zorg (CVZ). Eind Rapport van de Commissie Verloskunde van het College voor zorg Verzekering: Verloskundige Vademecum (Final Report from the Obstetrics Committee of the Healthcare Insurance Board: Midwives Handbook) 2003. Diemen, the Netherlands.

12). Hilfman, M.M. Jaarverslag Rijkskweekschool voor vroedvrouwen te Rotterdam 1957 (Annual report State School for midwives in Rotterdam) Ned. Tijdschr Geneeskd. 1958;102:2193.

13). Schultz E. Nederlandse verloskundigen hun historie en verloskundig erfgoed: een veronachtzaamd gebied (Dutch midwives, their history and midwifery heritage: a neglected area) M aster Scriptie Cultuurgeschiedenis Universiteit Utrecht (M asters thesis, University of Utrecht), 2013. https://dspace.library.uu.nl/bitstream/handle/ 1874/281660/Gs\%202013\%20M asterUU\%20scriptie\%20Erfgoed\%20veronachtzaamd\%20versie\%20lgitur.pdf?s equence=1\&isAllowed $=y$. Accessed Jan 2019.

14). Schaap M . Verslag Jaarlijkse Algemene Vergadering te Nijmegen, juli 1950 (Report of the Annual General M eeting in Nijmegen, July 1950). KV(23) 1050 181-186.

15). van Daalen R. De groei van de ziekenhuisbevalling in Nederland en het buitenland (The growth of hospital birth in the Netherlands and abroad). Amsterdams Sociologisch Tijdschrift, jrg. 15, nr. 3, december 1988.

16). Drenth P. 1898-1998 100 jaar vroedvrouwen verenigt (100 years of united midwifery). Nederlandse Organisatie Van Verloskundigen, 1998, Bilthoven, the Netherlands.

17). De Vries R, Wiegers T, Smulders B, van Teijlingen E. The Dutch Obstetrical System Vanguard of the Future in M aternity Care. California University Press. 2009. DOI:10.1525/california/9780520248632.003.0002. Accessed November 2018.

18). Abraham-van der Mark E. Dutch Midwifery, past and present: An overview. In: Successful Home Birth and Midwifery. Bergin \& Garvey, 1993. Connecticut, USA.

19). Hingstman L. Cijfers uit de Registratie van Verloskundigen (Numbers from the registration of midwives), 2000. NIVEL. Utrecht, the Netherlands.

20). de Graaf J, Merkus J, Bonsel G, and Steegers E. Nederlandse geboortezorg in een historisch perspectief (Dutch pregnancy and birth care in a historical 
perspective); wonderbaby en zorgkind. Bilage 1 p. 80-100. Rotterdam: Erasmus MC, 2017.

21). Pel M, Heres M HB. OBINT. A study of obstetric intervention. Thesis. Amsterdam: Universiteit van Amsterdam, 1995.

22). Hodnett ED, Downe S, Edwards N, Walsh D. Home-like versus conventional institutional settings for birth. Cochrane Database Syst Rev 2005;(1):CD000012.

23). Hatem M, Sandall J, Devane D, Soltani H, Gates S. M idwife-led versus other models of care for childbearing women. Cochrane Database Syst Rev 2008;(4):CD004667.

24). Renfrew, Prof $M, M$ cFadden $A$, Bastos $M$, et al. Midwifery and quality care: findings from a new evidence-informed framework for maternal and newborn care. M idwifery| Volume 384, ISSUE 9948, P1129-1145, September 20, 2014. Published: June 22, 2014 •DOI:https://doi.org/10.1016/S0140-6736 (14)607893.

25). Cerbas A. Beroepsomschrijving verloskundigen ( $\mathrm{J}$ ob description of midwives), Nederlandse Organisatie van Verloskundigen, 1990, Bilthoven, the Netherlands.

26). Wiegers T and Hukkelhoven $C$. The role of hospital midwives in the Netherlands. BM C Pregnancy Childbirth. 2010; 10: 80. Published online 2010 Dec 9. doi: [10.1186/1471-2393-10-80] PM CID: PM C3016258. PMID: 21143883.

27). de Vries R, Nieuwenhuijze M , Buitendijk S. What does it take to have a strong and independent profession of midwifery? Lessons from the Netherlands. M idwifery 29(2013)1122-1128.

28). Nederlandse Vereniging van Obstetrie en Gynaecologie (NVOG). Nota Klinisch Verloskundigen (Note: clinical midwives), 2008. NVOG, Utrecht, the Netherlands.

29). Perdok H. Challenges of integrating maternity care. 2017. Thesis, Vu Amsterdam, the Netherlands.

30). Koninklijke Nederlandse Organisatie van Verloskundigen (KNOV). Takenpakket verloskunde Onderzoek naar taken, tijdsbesteding en productie van verloskundigen (Task package obstetrics Onderzoek into tasks, time use and production of midwives) 2015, Significant, Barnaveld, The Netherlands. 
31). ledema-Kuiper H. Leidraad voor een protocol voor de positie van klinisch verloskundigen (Guideline for a protocol for the position of clinical midwives). Ned. Tijdschrift voor Obstetrie en Gynaecologie 7/2014, Utrecht, the Netherlands.

32). Nederlandse Overheid. Wet op de beroepen in de individuele gezondheidszorg, hoofdstuk 2, artikel 3-17 (Law for the individual Professions within Healthcare, [WET BIG] chapter 2, article 3-17) https://wetten.overheid.nl/BWBR0006251/2015-01-01/1\#0pschrift, Accessed dec 2018.

33). Academie Verloskunde Amsterdam Groningen (2019). Study Guide. Curriculum Bachelor in Midwifery. 2017. Amsterdam. https://studiegids.verloskunde-academie.nl/de-opleiding-totverloskundige/schema-curriculum-2014/ Accessed Feb 2019.

34). Betlem J. Oei G. De klinisch verloskundige. Van nu en de nabije toekomst! Samen werken aan de positie van de klinisch verloskundige (The clinical midwife. From now and the near future! Working together on the position of the clinical midwife), 2017, KNOV, Utrecht, the Netherlands.

35). Cellissen E, Engeltjes B, Rijke R. Klinische verloskundige werkt zonder wettelijke dekking (The clinical midwife works without legal protection). M edisch Contact, 12/2014. Utrecht, the Netherlands.

36). Croonen H. Ruzie binnen de perinatale zorg (Argument within perinatal care). Medisch Contact 2/2014, Utrecht the Netherlands.

37). Koninklijke Nederlandse Organisatie van Verloskundigen (KNOV) / Nederlandse Vereniging voor Obstetrie en Gynaecologie (NVOG). Eindrapport KNOV- NVOG Werkgroep Klinisch Verloskundigen (Final report KNOV-NVOG working party clinical midwives). April, 2010. Utrecht, The Netherlands.

38). Hogeschool Rotterdam. Physician Assistant (Klinisch Verloskundige) (clinical midwife) duaal.

https://www.hogeschoolrotterdam.nl/opleidingen/master/physician-assistantklinisch-verloskundige/duaal/. Accessed November 2018.

39). University M edical Centre Academie Utrecht. Klinisch Verloskundige Opleiding (Clinical Midwife Course).

https://www.umcutrecht.nl/nl/Opleidingen/Opleidingen-voorzorgprofessionals/Ons-aanbod/Klinisch-verloskundige. Accessed November 2018. 
40). Koninklijke Nederlandse Organisatie van Verloskundigen (KNOV). M emo Klinisch Verloskundigen (memo clinical midwives), 2017. KNOV. Utrecht, the Netherlands. va-r.nl/wp-content/uploads/M emo-M KV-18-9-2017.pdf. Accessed November 2018.

41). Werkgroep Leidraad Stuurgroep Klinisch Verloskundige. Leidraad voor Protocol positie klinisch verloskundigen (Working Group Guideline Clinical M idwives Steering Group. Guideline for the position of clinical midwives), 2014, KNOV/NVOG, Utrecht, the Netherlands.

42). Koninklijke Nederlandse Organisatie van Verloskundigen (KNOV)/Nederlandse Vereniging voor Obstetrie en Gynaecologie (NVOG). Landelijk opleidingsprofiel Klinisch Verloskundige HBO master (National education profile clinical midwife Masters programme). 2015, Utrecht, the Netherlands.

43). Koninklijke Nederlandse Organisatie van Verloskundigen (KNOV). KNOV. Beroepsprofiel Klinisch Verloskundige (J ob description Clinical Midwife), 2013, KNOV, Utrecht, the Netherlands.

44). van Hassel D, Wiegers T. Aandeel verloskundigen met een klinische vervolgopleiding neemt toe Een analyse gebaseerd op de NIVEL-registratie van verloskundigen (Share of midwives with continuing clinical training is increasing An analysis based on the NIVEL registration of midwives). TVV 6, 2014. KNOV, Utrecht, the Netherlands.

45). Visser R. De nieuwe kleren van de keizer (The emperor's new clothes)? TvV 2/2014. KNOV, Utrecht, the Netherlands.

46). Jans S. Afscheid van Eileen Hutton als hoogleraar M idwifery Science (Farewell to Eileen Hutton as professor of M idwifery Science). TVV, 2015; 06, Utrecht, The Netherlands.

47). Zorginstituut Nederland. Zorgvraag zwangere centraal in Zorgstandaard Integrale Geboortezorg Nieuwsbericht (Care demand for pregnant women at the heart of Integrated Care Standard Care Standard News item) 01-07-2016 11:29.

https://www.zorginstituutnederland.nl/actueel/nieuws/2016/07/01/zorgvraag -zwangere-centraal-in-zorgstandaard-integrale-geboortezorg. Accessed November 2018.

48). M ohangoo A, Buitendijk S, Hukkelhoven C, Ravelli A, Rijninks-van Driel, Tamminga G, Nijhuis J. Hoge perinatale sterfte in Nederland vergeleken met andere Europese landen (High perinatal mortality in the Netherlands compared 
to other European countries): de Peristat-II-studie. Ned Tijdschr Geneeskd. 2008; 152:2718-27.

49). van der Velden J. A good beginning: safe care around pregnancy and birth. Advice of the steering group pregnancy and birth. Rijks Overheid. 2009. http://www.rijksoverheid.nl/enzwangerschap-en/x-cz-2978049b.pdf/ . Accessed June 2018.

50). Perdok H, Jans S, Verhoeven $C$, Henneman, L et al. Opinions of maternity care professionals and other stakeholders about integration of maternity care: a qualitative study in the Netherlands. BM C pregnancy and childbirth, (2016) 16(1), pp. 188-016-0975-z.

51). Inspectie voor Gezondheidszorg (Dutch Inspectorate for Healthcare). M ogelijkheden voor verbetering geboortezorg nog onvolledig benut (Report into the Incomplete use of the Possibilities for the improvement in healthcare) Accessed dec 2018. 


\section{2}

Diversity in the Scope and Practice of

Hospital-Based

Midwives in the

Netherlands

Doug Cronie, M A, RM, RN, M arlies Rijnders, PhD, RM, Simone Buitendijk, MD, PhD, MPH

J Midwifery Women's Health 2012, 57 (5): 469-475 
Abstract

Introduction: Not all midwives in the Netherlands are independent practitioners. One in four midwives registered to practice is employed in the hospital setting, where $70 \%$ of all births occur. There has not yet been an indepth examination of hospital-based midwives' practice in the Netherlands, in the context of care in a higher-risk environment. The primary aims of this study were to describe the diversity and scope of practice of hospital-based midwives in the Netherlands.

M ethods: This was an online survey of all hospitals throughout the Netherlands with labor/ birthing rooms and employing hospital-based midwives. The survey covered five topic areas: demographic/organizational details, duties, responsibilities, experience/additional qualifications and how the midwife functioned within the multi-disciplinary hospital team. Descriptive statistics are provided.

Results: 59 secondary and tertiary level hospitals from a possible total of 98 were included for analysis ( $60 \%$ national response rate). Forty per cent of all births occurring during study period were managed solely by a hospital midwife. The provision of midwifery care in the hospital setting was not universal and where present, the presence of a hospital-based midwife was not necessarily 24 hours a day or seven days per week. Hospital-based midwives reported a high level of autonomy.

Discussion: Currently there is no universal provision of midwifery care in the hospital setting in the Netherlands. Where there are hospital-based midwives, they appear to manage the majority of births. However, there are no nationally agreed standards for midwifery practice in the hospital setting and no agreement exists over minimum requirements relating to additional education for midwives in these settings. A national evaluation and setting of minimum standards is needed.

Key words: Clinical-midwife, diversity/scope of practice, midwives role, midwives autonomy, survey. 


\section{Introduction}

The Netherlands enjoys a high standard of healthcare with universal health care coverage funded via a hybrid system, partly funded by central government (with the cost deferred through taxation) and partly funded by health insurance. Outside of the Netherlands, the Dutch midwifery model of care is known for its relatively high home-birth rate, $30 \%$ of the total births, currently unprecedented in any other western world country. ${ }^{1-3}$

Pregnancy care in the Netherlands is facilitated according to an assessment of risk. This assessment is based on risk profiling from a comprehensive list of conditions contained within 'the midwifery indication list' (as listed in the midwifery handbook) ${ }^{4}$ and forms an essential component of the midwifery care system. The midwife is acknowledged as the lead caregiver for normal pregnancy and is usually the first point of call for all pregnant women. When an increased element of risk is identified, then the pregnant women is referred to an obstetrician and to hospital-based care. In the presence of increased risk, the cost of hospital care is provided for within basic insurance programmes.

The majority (75\%) of the 1763 registered midwives in the Netherlands are independent practitioners (known as 'primary-care midwives') who work in the community setting, are usually self-employed and commonly work in small group practices. ${ }^{5}$ Under certain conditions (for example: uncomplicated pregnancy/labor, women not requiring continuous monitoring/pain relief), primary care midwives have rights to practice in their local hospitals but will only look after their own clients with uncomplicated labours. However, should a pregnant woman whose pregnancy has been assessed as low-risk choose to deliver in hospital, rather than at home, she must either have extra (more than the basic level of coverage) insurance, or pay a surcharge for the hospital birth. Primary-care midwives follow their clients in the community for postnatal care. In this system obstetricians may choose to either work for a hospital or be selfemployed but commonly only work in hospital settings.

Pregnancy care is usually with a primary-care midwife in the community, when risk is assessed to be low, or at a secondary or tertiary level hospital (nominally under the care of an obstetrician) in the presence of increased risk. Care is provided either in a level two hospital when risk is classified as 'medium risk', or in a level three, university-teaching hospital upon the identification of high risk. Care pathways are non-linear in nature and care episodes can be shared, 
or switch between professionals depending on the individual circumstances involved.

Not all midwives in the Netherlands are independent practitioners. One in four midwives registered to practice is employed in the hospital setting, where $70 \%$ of all births occur. ${ }^{6} \mathrm{M}$ idwives employed to work in secondary or tertiary hospital settings are known as clinical-midwives. According to a position statement from the Dutch Obstetrician's professional body (NVOG) clinicalmidwives bridge the gap between primary-care midwives and obstetricians and should be seen as having the same level of autonomy/skill as junior residentsin-training. ${ }^{7}$ The role of the clinical-midwife is distinct from that of primary-care midwives in that clinical-midwives function semi-autonomously within the hospital setting, routinely caring for women in labor who are at increased risk, such as women requiring pain relief in labor, labours complicated by meconium staining of the amniotic fluid, or post-term pregnancy. Clinical-midwives currently only work in the secondary and tertiary hospital environment.

As a percentage of all midwives registered to practice in the Netherlands, the total of clinical-midwives has risen by $10 \%$ in the last ten years. ${ }^{5}$ Twenty-five percent of all Dutch midwives now work as clinical-midwives. While little evidence for this rise exists and no in-depth examination of their working practices to date has been published, factors that have been suggested include a shortage of obstetricians and a desire [by midwives] for more regular hours. ${ }^{8}$

Despite their growing number, there is no universal provision of clinicalmidwives in hospitals. ${ }^{9}$ Where there are clinical-midwives, their presence and provision of care may not be 24 hours a day or seven days a week. Large hospitals (>2000 births per year) are not common in the Netherlands and it is acceptable for doctors to be on-call from home providing they can be available within 30 minutes; however, clinical midwives must be on-site.

The right to practice and call oneself a midwife in the Netherlands is regulated by the central government. ${ }^{10}$ However, there is no national agreement on the scope of the clinical-midwives' practice in hospitals. ${ }^{11}$ In addition, there is no provision for the clinical-midwife to be named the responsible caregiver at a hospital birth in the national perinatal classification statistics. Rather, the obstetrician (who may or may not have seen the women giving birth) is considered to have responsibility. Consequently, there is no official record (and therefore no assessment of efficacy) of births managed by clinical-midwives. 
In addition, midwifery education in the Netherlands is not presently at a graduate level. ${ }^{12}$ Education focuses on the normalcy of birth and the importance of good risk assessment. Following the initial training of four years to become a primary-care midwife there is no requirement for additional training or further education in order to work as a clinical-midwife with a higher risk population in hospital. Despite this, the current reality is that a clinical-midwife may be the professional in attendance and indeed, the sole caregiver at higher-risk hospital-based births. While this is seen as controversial ${ }^{13}$ there is as yet no consensus on whether or how to change this situation.

Previous studies have shown that the provision of midwifery care in the hospital setting can positively influence selected outcome measures, such as reducing the instrumental birth rate and the need for pharmacological analgesia. ${ }^{14,15}$ However, an in-depth examination of the practice of clinicalmidwives in the Netherlands, in the context of care in high-risk environment has not previously been described. The primary aims of this study were to investigate the contribution of Dutch clinical-midwives practice by establishing what they are actually doing, to catalogue clinical-midwives presence and provision of care in the secondary and tertiary settings and to clarify the working patterns and practices of midwives so employed.

\section{Methods}

An electronic survey was sent to all hospitals in the Netherlands that provide obstetric care $(n=98)$. A paper/postal version was available on request. Questionnaire/ survey studies are exempt from ethics committee approval in the Netherlands. ${ }^{16}$ The survey instrument was designed by the research team for the purpose of this study, as there was no existing, validated questionnaires addressing the subject matter. The survey contained 31 questions in five sections: demographics, duties, responsibilities, experience/additional qualifications and the place of the clinical-midwife within the obstetric team. The timeline for completion was two months; one reminder letter was sent.

Respondents were asked to provide their postal code, which was crossreferenced with their Internet provider address to ensure responses were analyzed as those of differing organizations. Where multiple responses were received from the same organization, sub analysis was carried out until a single response remained. The profession of respondents was categorized into three groups: 1) Clinical-midwife, 2) Manager (with clinical background), and 3) Other. 
Perinatal data regarding number of births/reasons for transfer were obtained from the Dutch national perinatal database. ${ }^{6} \mathrm{~A}$ definition of small/medium/large hospitals was calculated by using the mean number of births per hospital, per year ( $n=1442$; range $450-3000$ ) plus and minus one standard deviation (calculated as 650). Therefore, we defined small hospitals as those having 792 births per year or fewer. M edium hospitals were defined as those with 793-2092 births per year. Large hospitals were defined as those with 2093 births per year or more. We were aware of one other study, ${ }^{3}$ which categorized hospitals with 6 separate levels of size. However, due to the small number of responses in our study, we felt three levels would be more representative.

Respondents were asked to consider the involvement of clinical-midwives in the care of birthing women over the last two shifts worked. The total number of births was quantified. The clinical-midwife's involvement in the management of birth was classified as follows: Category A included births totally managed by a clinical-midwife, without any involvement of the obstetrician. Category $B$ included births managed by clinical-midwife but having one (or more) consultation(s) with obstetrician during labour/birth; in this case the consult could be by telephone or face to face but the obstetrician did not actually see the woman during the labour/birth. Category $C$ included births managed by clinical-midwife but where the obstetrician was actually in attendance for all or part of the labour/birth. Finally, Category $D$ included those births where the management of birth was either in part or completely taken over by the obstetrician.

In order to assess the clinical-midwife's autonomy in the hospital setting, a series of ten statements regarding actual practice in a range of duties was provided with a five-point, Likert-type scale for responses. The clinicalmidwives' practice was classified as autonomous where respondents answered: Regularly/Often/Always and as non-autonomous where respondents answered: Never/Sometimes.

Clinical-midwives were considered 'experienced' when they had been working for more than five years since qualification as midwives (i.e., after their original education), 'moderately experienced' with two to five years since qualification, of 'limited experience' with one to two years and 'inexperienced' when they had worked less than 1 year since qualification.

For the purposes of our study we defined 'original education' to be the nationally approved four year training programme for midwives. The terms 
'further training'/ 'further education'/'additional training' were categorized as interchangeable. When asked to give more information regarding 'further training'/'further education' respondents could choose from the following three accredited options: one year diploma level clinical-midwives course/M aster's degree Physician Assistant programme / M aster of Science midwifery.

Survey results were analyzed using SPSS software for Windows, version 17. Descriptive statistics were presented as means and proportions. Statistical significance was assessed by Chi square and Fisher's exact tests for categorical variables and by ANOVA for nominal variables. We considered a $P$ value of $\varangle 0.05$ as statistically significant.

\section{Results}

From the 98 possible hospital sites, a total of 106 responses were received. Thirty-four respondents did not complete the survey and were therefore not included in the final analysis. Sub analysis between complete and incomplete questionnaires did not suggest that any particular category of hospital was under or over represented in the final analysis. Comparison of the postal codes from completed questionnaires demonstrated responses from all provinces. Further comparison of the annual number of births revealed that there was a representative spread of small, medium and large hospitals in the data analyzed. A further 13 responses were found to be multiple responses (more than one response from the same organization) and were evaluated to collapse them into a single response. Ultimately, 59 completed responses from separate sites were included for final analysis, giving an overall (national) response rate of $60 \%$.

Sixty-eight percent $(n=40)$ of our respondents were themselves clinicalmidwives and a further $25 \%(n=15)$ were managers with a clinical background. The remaining $7 \%(n=4)$ classified themselves as 'other' (two were obstetricians, one administrator and one manager with a non-clinical background).

\section{Demographics}

Table 1 details clinical-midwives' employment in hospitals. Ninety-two percent $(n=54)$ of hospitals employed clinical-midwives at least some of the time. However, one in three units surveyed $(29 \%, n=17)$ did not provide clinicalmidwives 24 hours per day, seven days per week (24/7). No significant correlation existed between clinical-midwives being employed and hospital 
size. However, large hospitals were more likely to employ more clinicalmidwives $(P=0.01)$ and had a longer history of having employed them. Of the responding units who at the time of the survey did not employ clinicalmidwives, half $(n=3)$ stated their intention to do so within the coming 12 months.

Table 1: Employment of clinical-midwives ${ }^{\mathrm{a}}$ in 59 hospital units in the Netherlands.

\begin{tabular}{|c|c|c|c|c|c|}
\hline & $\begin{array}{l}\text { Total } \\
n=59\end{array}$ & $\begin{array}{l}\text { Small }{ }^{\text {b. }} \\
n=7\end{array}$ & $\begin{array}{l}\text { Medium }^{b .} \\
n=41\end{array}$ & $\begin{array}{l}\text { Large }^{b .} \\
n=11\end{array}$ & P value \\
\hline $\begin{array}{l}\text { Number of } \\
\text { units where } \\
\text { clinical- } \\
\text { midwives } \\
\text { employed, } \\
\mathrm{n}(\%)\end{array}$ & $54(92)$ & $6(11)$ & $37(69)$ & $11(20)$ & 0.49 \\
\hline $\begin{array}{l}\text { Number of } \\
\text { clinical- } \\
\text { midwives } \\
\text { employed, } \\
\text { mean [SD] }\end{array}$ & & $5.29[3.9]$ & $7.76[4.0]$ & $11.45[5.5]$ & 0.01 \\
\hline $\begin{array}{l}\text { Length of time } \\
\text { clinical- } \\
\text { midwives have } \\
\text { been } \\
\text { employed, } \\
\text { mean [SD] }\end{array}$ & & $5.7[4.4]$ & $15.5[13.4]$ & 14.8 [15.3] & 0.25 \\
\hline $\begin{array}{l}\text { Number of } \\
\text { units where } \\
\text { clinical- } \\
\text { midwives are } \\
\text { employed 24/7, } \\
\mathrm{n}(\%)\end{array}$ & $42(71)$ & $4(10)$ & $30(71)$ & $8(19)$ & 0.68 \\
\hline $\begin{array}{l}\text { Number of } \\
\text { units where } \\
\text { obstetricians } \\
\text { are employed } \\
24 / 7, n(\%)\end{array}$ & $11(19)$ & $0(0)$ & $5(45)$ & $6(55)$ & 0.02 \\
\hline
\end{tabular}

\section{Duties}

Using the classification of involvement described in the methods section, Table 2 details the level of clinical-midwives' autonomy reported by respondents. Analysis reveals that these midwives were partially responsible for the management of care during $77 \%$ of all births (the A, B and C categories) during 
the period analysed and were the sole caregiver (the A category) responsible for management of the birth in $40 \%$ of births analyzed.

Table 2: Responsibility for management of birth among [54] hospitals in the Netherlands employing clinical-midwives ${ }^{a}$

\begin{tabular}{|l|l|l|l|l|}
\hline $\begin{array}{l}\text { Responsibility for } \\
\text { birth }\end{array}$ & $\begin{array}{l}\text { Number (\%) of } \\
\text { births }^{\text {b }}\end{array}$ & $\begin{array}{l}\text { Mean (SD) births } \\
\text { per unit where } \\
\text { obstetrician not } \\
\text { in house 24/7 }\end{array}$ & $\begin{array}{l}\text { Mean (SD) births } \\
\text { per unit where } \\
\text { obstetrician is in } \\
\text { house 24/7 }\end{array}$ & P value \\
\hline $\begin{array}{l}\text { Clinical-midwife } \\
\text { only }\end{array}$ & $114(40)$ & $2.4(2.0)$ & $2.1(2.0)$ & 0.75 \\
\hline $\begin{array}{l}\text { Clinical-midwife } \\
\text { with telephone } \\
\text { consultation to } \\
\text { obstetrician }\end{array}$ & $84(30)$ & $1.5(1.3)$ & $2.8(1.5)$ & 0.02 \\
\hline $\begin{array}{l}\text { Clinical-midwife: } \\
\text { with consultation } \\
\text { obstetrician where } \\
\text { obstetrician } \\
\text { actually saw } \\
\text { woman }\end{array}$ & $19(7)$ & $0.3(0.6)$ & $1.0(1.4)$ & 0.02 \\
\hline $\begin{array}{l}\text { Obstetrician/obstet } \\
\text { rician in training }\end{array}$ & $66(23)$ & $1.3(2.0)$ & $1.6(2.0)$ & 0.66 \\
\hline \multicolumn{2}{|c|}{ a. Midwives employed to work in secondary, or tertiary hospital settings. b. Total births in the two time periods analyzed were 283. } \\
\hline
\end{tabular}

The mean number of births led by a clinical-midwife where there had been consultation with an obstetrician (the B category) and where the obstetrician was in attendance (the $C$ category) was significantly greater where there was an obstetrician in house $(\mathrm{P}=0.02)$.

\section{Responsibilities}

Table 3 gives additional detail regarding elements of autonomous practice. Where clinical-midwives were employed, $98 \%$ of respondents stated that these midwives had supervisory responsibilities for at least one other group of staff, such as nurses or junior residents. Where clinical-midwives were working, almost two-thirds of respondents $(59 \%, n=32)$ stated that these midwives cared for labouring women and had additional simultaneous responsibility for other clinical areas, such as antenatal and postnatal wards and other duties, such as teaching and assessing students and seeing urgent consults. Fifty-four percent $(n=27)$ of respondents stated clinical-midwives autonomously prescribed medications, including night sedation, although this is not within the official scope of practice of midwives in the Netherlands. 


\section{Table 3: Autonomous practice reported by clinical-midwives ${ }^{\mathrm{a}}$ employed in [54] hospital units in the Netherlands}

\begin{tabular}{|c|c|c|}
\hline $\begin{array}{l}\text { Clinical-midwives' duties and responsibilities } \\
\text { (number of hospitals responding to this question) }\end{array}$ & $\begin{array}{l}\text { Clinical-midwives practice } \\
\text { autonomously for these } \\
\text { tasks in the hospital } \\
\mathrm{n}(\%)\end{array}$ & $\begin{array}{l}\text { Clinical-midwives do not } \\
\text { practice autonomously } \\
\text { for these tasks in the } \\
\text { hospital } \\
\text { n (\%) }\end{array}$ \\
\hline $\begin{array}{l}\text { Other than clients in labor, clinical-midwives [may] see/make } \\
\text { a treatment plan for women admitted to antenatal/postnatal } \\
\text { wards, }(n=52)\end{array}$ & $39(75)$ & $13(25)$ \\
\hline Clinical-midwives may see antenatal clients $(n=51)$ & $39(76)$ & $12(24)$ \\
\hline $\begin{array}{l}\text { Clinical-midwives may prescribe medicines such as night } \\
\text { sedation }(n=50)\end{array}$ & $27(54)$ & $23(46)$ \\
\hline $\begin{array}{l}\text { Clinical-midwives may order testing such as ultrasound } \\
\text { scans/laboratory work }(n=51)\end{array}$ & 48 (94) & $3(6)$ \\
\hline Clinical-midwives may interpret testing results $(n=52)$ & $47(90)$ & $5(10)$ \\
\hline Clinical-midwives may discharge clients $(n=52)$ & $45(87)$ & $7(13)$ \\
\hline $\begin{array}{l}\text { Clinical-midwives may alter an existing treatment plan such } \\
\text { as deciding to change vital signs observations from } 4 \text { to } 2 \\
\text { times per day }(n=50)\end{array}$ & $25(50)$ & $25(50)$ \\
\hline $\begin{array}{l}\text { Clinical-midwives may undertake other care-related activities } \\
\text { autonomously (for example, perform fetal blood sampling, } \\
\text { vacuum births, or ultrasound scan for cervix length; assist } \\
\text { with cesareans, decide method of induction, perform } \\
\text { external cephalic version; start/coordinate treatment in } \\
\text { presence of emergency; manage interdisciplinary } \\
\text { consultation) }(n=40)\end{array}$ & $30(75)$ & $10(25)$ \\
\hline $\begin{array}{l}\text { Clinical-midwives have responsibility for other clinical areas } \\
\text { (as well as labor ward) while working (for example: } \\
\text { antenatal/ postnatal areas, triage, antenatal clinic or } \\
\text { ultrasound scanning) }(n=54)\end{array}$ & $32(59)$ & $22(41)$ \\
\hline $\begin{array}{l}\text { Clinical-midwives have supervisory responsibility for at least } \\
\text { one other group of staff (for example: medical students, } \\
\text { residents, interns, nurses, student midwives \& maternity } \\
\text { assistants) ( } n=54)\end{array}$ & $53(98)$ & $1(2)$ \\
\hline
\end{tabular}

\section{Experience \& additional qualifications}

Forty-one percent $(n=24)$ of respondents stated that their hospital employed more than five experienced clinical-midwives, as defined in our survey. Conversely, 34\% $(n=20)$ stated that at least one inexperienced clinical-midwife was employed. In relation to further education, $31 \%(n=18)$ of respondents indicated that a requirement for employment at their hospital was that clinicalmidwives must have had or must agree to undertake some form of additional training. Seventeen percent of respondents $(n=10)$ had at least one clinicalmidwife with a Master's degree. Two respondents reported an entire workforce of clinical-midwives with M aster's level qualifications. However, 15\% 
$(n=9)$ of respondents reported a workforce of clinical-midwives with no additional training beyond their initial qualification.

\section{Teamwork}

Irrespective of size of the hospital, $71 \%(n=42)$ of respondents reported the presence of clinical-midwives 24 hours a day, 7 days a week. The clinicalmidwife was most likely to be alone when working ( $70 \%$ average across all shifts) although $10 \%(n=6)$ of respondents stated there was a second clinicalmidwife on duty, M onday through Friday, between 8am and 6pm. Only 19\% $(n=11)$ of respondents stated that there was an obstetrician on-site 24 hours per day, 7 days per week. This was more likely to be in larger hospitals $(P=0.02)$.

When asked how caregivers of varying disciplines made decisions and how the responsibility was divided, almost all $92 \%(n=54)$ of respondents stated that they always (or frequently) worked according to protocols in which duties and responsibilities were explicit. However (as protocols tend to be institutionspecific) when questioned regarding the likelihood that protocols were up-todate and were systematically selected and reviewed, respondents agreement dropped to $78 \%(n=46)$ and $79 \%(n=47)$ respectively.

\section{Discussion}

In this first assessment of hospital-based midwifery in the Netherlands we found that there is a national inequity of service provision by clinical-midwives across the country. According to data from the national perinatal database ${ }^{6}$ $70 \%$ ( $n=121391$ ) of births annually occur in a hospital setting within the context of increased perinatal risk. However, in our study $29 \%(n=17)$ of the hospitals did not provide clinical-midwifery care twenty-four hours per day, seven days per week. Previous large-scale studies ${ }^{15}$ have shown that the provision of midwifery care can lead to an improvement in selected outcome measures. In addition, within the context of the Dutch model of care, employment of midwives in the hospital setting has led to less intervention. ${ }^{14} \mathrm{As}$ a result, where there are no clinical-midwives in the hospital setting, or where they are not available 24 hours a day, 7 days a week, this does not best serve the needs of the pregnant woman.

According to the data gathered during the survey period, the reality of practice was that the majority of (hospital) births $(77 \%)$, were in fact conducted by clinical-midwives and that almost half (40\%) were managed solely from start to finish by clinical-midwives (see also table 2). Given the type of exempt study being conducted and confidentiality concerns, we could not ask specific details 
regarding the level of care that laboring women actually required. However, reasons for transfer from primary-care midwifery in the community to a hospital facility, as obtained from the national perinatal statistics, ${ }^{6}$ shows the most common causes to be meconium staining of the amniotic fluid (28\%), failure to progress in second-stage of labor $(23 \%)$ and maternal request for analgesia (15\%). This then, gives some insight to the type and risk profile of the women cared for by clinical-midwives in the hospital.

Currently, national statistics in the Netherlands only assess provider contribution to perinatal outcomes by these specific categories of providers; primary-care midwife, obstetrician or general practitioner, and by location of birth (home/hospital). No category exists in the national perinatal database for the hospital-based clinical-midwife as responsible caregiver at birth and therefore no assessment can be made about the effectiveness of care or contribution of the Dutch clinical-midwife to perinatal outcomes. Our findings related to caregiver at birth make a compelling argument for creating a classification in the national perinatal database of 'clinical-midwife' as responsible caregiver during birth.

We found a wide diversity in the scope of practice of clinical-midwives. In addition, little conformity in working patterns seemed to exist. There was little correlation between the number of clinical-midwives and the number of births or working patterns. To our knowledge, no nationally agreed staffing formula for clinical-midwives exists. However, substantive work regarding the number of midwives required to provide quality of care, such as the UK derived Birthrate Plus ${ }^{8}{ }^{7}$ is available. Further research into staffing requirements, from the perspective of the Dutch midwifery model, could assist service providers in the Netherlands when considering service specifications.

In the Netherlands, a 2008 report ${ }^{18}$ considered the issues surrounding birth. One of the conclusions ${ }^{13}$ is that some change to current policy with regard to on-site obstetrician presence out of office hours is needed. Respondents in our survey commented that there was a perception of additional responsibility being more likely out of office hours (where there was no on-site obstetrician). Comments such as "only at night" and "mainly in the evening, weekend and at night" were made in relation to clinical-midwives having additional responsibility.

In addition, our survey showed that clinical-midwives were substantially more likely to consult with an obstetrician if the obstetrician was in-house. Although we had no data regarding the specific level of care required in consult 
situations, nevertheless one hypothesis is that clinical-midwives show some reluctance to call an obstetrician at home. Delay in instituting appropriate care has been shown to increase risk ${ }^{19}$ while there is also evidence from a Dutch ${ }^{20}$ and international perspective ${ }^{21}$ of an increase in adverse outcomes in the evening, weekend and at night. Our survey augments existing knowledge regarding the presence of obstetricians in hospital and adds weight to the current discussion for change.

Currently, there is no national clearinghouse for guidelines or protocols for inhospital midwifery care. The nationally agreed midwifery standards that do exist relate, on the whole, to care given by primary-care midwives in the community. Protocols (or local agreements) that contain clear guidance on matters such as how/ when to summon help have the potential to minimize this risk and are therefore desirable. ${ }^{22}$

Another theory for reducing risk and conflict within the labor ward (and indeed across the healthcare sector as a whole), which has steadily gained credence over the last few years is that of collaborative working. ${ }^{23-25}$ The basic premise of collaborative working is good communication. The underlying philosophy is that there should be no hierarchy within the team and that the team is entirely co-reliant. Downe et $\mathrm{al}^{23}$ suggest that introducing strategies for collaborative working in the maternity care setting is key to improving outcomes in care. Based on the diversity of practice arrangements demonstrated in our findings, we suggest further research in the Dutch ward-ward setting in order to assess the potential impact of collaborative working strategies in the Netherlands.

Published evidence all but overlooks any potential contribution of Dutch clinical-midwives to contemporary practice. Clearly, our research demonstrates that the role of the clinical-midwife in the Netherlands is complex. Our survey shows that clinical-midwives are required, by the nature of their employment conditions to have advanced diagnostic, interpretive, managerial and teaching skills. However, the additional dynamic of these skills as they are related to care for women with a perceived higher risk highlights the desirability of national standards relating minimum experience, scope of practice and additional training.

The Netherlands accepts the International Confederation of M idwives definition of a midwife ${ }^{26}$ as a legal statement of meaning. Yet contemporary clinical-midwives' practice in the Netherlands is not in line with the existing legislation relating to Dutch midwives' scope of practice, which is largely related to primary care midwifery in the community. ${ }^{10}$ We found that hospital- 
based clinical-midwives displayed a high level of autonomy and that they were frequently required by nature of their employment conditions to assess, plan, implement and treat laboring women at increased risk in a stand-alone capacity. Nonetheless, we found that one third of hospitals surveyed employed at least one inexperienced clinical-midwife while two thirds had no requirement that clinical-midwives undergo additional training. Therefore, the hospital-based clinical-midwife is neither protected by law ${ }^{27}$ nor by agreement regarding the scope of her practice (we note that a job profile has been suggested by the Dutch society of obstetricians, but this is not binding). ${ }^{28}$ The resultant dichotomy between practice and mandate as a result of the current legal scope of midwifery practice is of concern.

Although the higher education systems of the United States and the United Kingdom are not directly comparable to that of the Netherlands, midwifery education in the Netherlands is nevertheless not yet at university-level. ${ }^{29}$ Although student midwives have compulsory modules covering abnormality, arguably this does not prepare them adequately for current conditions of practice in the hospital setting. Various options for additional education exist. M asters programmes ${ }^{30,31}$ as well as diploma-level, non-accreditable courses ${ }^{32}$ are available but they are not [yet] mandatory. In addition, although dialogue over academisation is ongoing from within the midwifery profession ${ }^{33}$ there is no absolute timeframe for it's' establishment. The current situation creates potential for confusion among clinical-midwives over what/how professional development should best be addressed.

In addition to debates about the level of additional education required for hospital-based practice, discussion from within the profession regarding recognition of the clinical-midwives' actual sphere of practice is also the subject of ongoing debate. ${ }^{34}$ Various international studies have examined the potential contribution of some elements of practice, such as midwife ventouse practitioners (midwives trained in the use of the vacuum), midwife ultrasonagraphers and midwives' prescribing authority. ${ }^{35-37}$ These studies could perhaps be used to inform Dutch national policy.

Lastly, our survey also highlights the need for debate regarding the issue of midwife prescribing. Where midwives are regularly called on to dispense medications that they are not authorized to prescribe, this can be problematic, not only for the client but also in potentially exposing clinical-midwives (or their employers) to disciplinary or even punitive action. While current Dutch legislation ${ }^{10}$ allows for limited local devolution to midwives of certain practices regarding prescription privileges, in our view this is a sub-optimal use of the 
Health Practioner's Law. International comparison provides a potentially better way forward, such as including pharmacologic management within the midwives education curriculum and/or simplifying what requires prescription. ${ }^{38,39}$ Should such amendments be made, prescriptive privileges could then conceivably be broadened in the clinical-midwives' scope of practice.

\section{Limitations}

The response rate of this study may limit its generalizability. The rationale for using web-based methodology was that it can better contain cost and is hypothesized to improve traditionally low response rates. ${ }^{40} \mathrm{~W}$ ith initial contact and one reminder, our survey achieved a national response rate of $60 \%$. However, small studies have an acknowledged limited ability to provide statistically significant outcomes. ${ }^{41}$ In addition, self reporting of data has been shown to increase bias in surveys. ${ }^{42}$ Thus, the reliability and validity of small surveys is sometimes questioned. However, our data analysis showed that small, medium and large hospitals were proportionally represented in our results and that responses were received from all provinces in the Netherlands. From the pattern of received responses and further consideration of incomplete responses we are confident that our survey is representative.

\section{Conclusion}

The primary aim of this study was to describe the current situation with regard to the spread and working practices of the Dutch clinical-midwife. Our survey is unique in that it presents the first national assessment of service provision of clinical-midwives in the Netherlands. This paper adds to the body of evidence regarding the clinical-midwives' autonomous practice in caring for pregnant women in the presence of increased risk.

Currently there is no universal or continuous presence of clinical-midwives in the hospital setting in the Netherlands. Where there are clinical-midwives, they appear to manage the majority of births. However, there are no nationally agreed standards for practice and no agreement exists over minimum requirements relating to additional education. The current situation is not in the best interests of pregnant women desiring a hospital birth.

In order to begin qualify the efficacy of clinical-midwives and to inform the ongoing debate regarding clinical-midwives' sphere of practice a new category of 'clinical-midwife' as responsible caregiver in the Dutch national perinatal database is desirable. 


\section{References:}

1. Dahlen H. Undone by fear? Deluded by trust? Midwifery. 2010; 10.1016/j.midw.11.008.

2. de Jonge $A$, Goes BY, Ravelli AC, et al. Perinatal mortality and morbidity in a nationwide cohort of 529688 low risk, planned home and hospital births. BJOG. 2009; 116(9):1177-1184.

3. Ravelli AC, Tromp M, van Huis M, et al. Decreasing perinatal mortality in The Netherlands, 2000-2006: a record linkage study. J Epidemiol Community Health. 2009; Sep; 63(9):761-5.

4. M idwifery Handbook: final report from the Midwifery Committee of the College of Health Insurers.

http://www.knov.nl/docs/uploads/Verloskundig_Vademecum 2003.pdf. Accessed June 26th, 2011.

5. Hingstman L, Kenens RJ. Numbers from the registration of M idwives 2008. Utrecht: NIVEL; 2009.

6. Foundation for Registration of Dutch perinatal data: SPRN. Care by M idwives and Gynaecologists. Utrecht: SPRN; 2007.

7. Dutch Society of Obstetricians and Gynaecologists: NVOG. Annotation of clinical midwives, Version 1. Utrecht: NVOG; 2008.

8. Wiegers $T$, and Hukkelhoven $C$. The role of hospital midwives in the Netherlands. BM C Pregnancy and Childbirth. 2010; 10:80.

9. Royal Dutch Organisation of Midwives: KNOV. Vision document: the clinical midwife: Medical professional in the hospital. Utrecht: KNOV; 2007.

10. The Individual Professional Practice in Healthcare Law (wet BIG):

Rijksoverheid web site. http://www.rijksoverheid.nl/kwaliteitvanzorg/. Accessed June $26^{\text {th }}, 2011$.

11. Everhardt E. NVOG/KNOV re: Clinical Midwives: Rijksoverheid web site. http:// www.rijksoverheid.nl/verloskundige/meva-2916273b.pdf/. Accessed June $26^{\text {th }}, 2011$.

12. Royal Dutch Organisation of M idwives: KNOV. For those almost pregnant. KNOV website. http:// www.knov.nl/voor-zwangeren/. Accessed June $26^{\text {th }}$, 2011.

13. van der Velden J. A good beginning: safe care around pregnancy and birth. Advice of the steering group pregnancy and birth. Rijksoverheid web site. http://www.rijksoverheid.nl/enzwangerschap-en/x-cz-2978049b.pdf/. Accessed 26 $6^{\text {th }}$ June 2011.

14. Pel M, Heres M HB. OBINT a study of obstetric intervention. Amsterdam. University of Amsterdam; 1995. 
15. Hatem M, Sandall J, Devane, D, Soltani H, Gates S. Midwife-led versus other models of care for childbearing women (Review). The Cochrane Collaboration. 2009. http://www.thecochranelibrary.com/. Accessed $26^{\text {th }}$ June 2011.

16. Dutch Central Committee for Research Involving Human Subjects (English Version) web site. http://www.ccmo-online.nl/main.asp/English/FAQ/WM O/. Accessed $26^{\text {th }}$ June 2011.

17. Ratios for midwifery workforce planning at national SHA and local level. Birthrate plus web site. http:// www. birthrateplus.co.uk/. Accessed June26th, 2011.

18. Essential care for pregnancy and birth. Rijksoverheid web site. http:// www.rijksoverheid.nl/documenten-en-publicaties/. Accessed $26^{\text {th }}$ June 2011.

19. Schutte JM, Schuitemaker NW, van Roosmalen J, Steegers EA. Dutch $M$ aternal M ortality Committee. Substandard care in maternal mortality due to hypertensive disease in pregnancy in the Netherlands. BJOG, 2008; 115(6):7326.

20. Kramer J, Smit M, Simons R, Rijnders M. Factors that influence patient safety in the evening, night and weekend: a literature study. Leiden: TNO; 2009. 21. de Graaf J, Ravelli A, Visser G. et al. Increased adverse perinatal outcome of hospital delivery at night. BJOG. 2010; 117: 1098-1107.

22. National Institute for Clinical Effectiveness. Intra-partum Care Clinical Guideline. London. RCOG; 2007.

23. Downe $S$, Finlayson $K$, Fleming A. Creating a collaborative culture in maternity care. J of American college of Nurse-M idwives. 2010; Vol 55(3) p250254.

24. Lemieux-Charles L, M cGuire WL. What do we know about health care team effectiveness? A review of the literature. Med Care Res Rev. 2006; 63:263-300. 25. Simpson K, James D, Knox G. Nurse-physician communication during labor and birth: Implications for patient safety. J Obstet Gynecol Neonatal Nurs.

2006; 35: 246-249.

26. Definition of a midwife. International Confederation of Midwives web site. http:// www.internationalmidwives.org/ICM/DefinitionoftheM idwife2005.pdf Accessed 26 $6^{\text {th }}$ June 2011.

27. Droog J. Results from the KNOV/NVOG work group clinical midwives at National study day for clinical midwives 2010. M idwives Journal. April 2010. 28. Dutch Society of Obstetricians and Gynaecologists: NVOG. Practical standards: Clinical midwives. Utrecht: NVOG; 2009.

29. HBO M idwifery: The M idwives Academy Amsterdam \& Groningen: AVAG web site: http://www.verloskunde- 
academie.nl/VerloskundeStuderen/detail/HBO-Bachelor-verloskunde/ . Accessed $26^{\text {th }}$ June, 2011.

30. M aster of Science Midwifery: Academic Medical Centre University of Amsterdam: AMC, UvA. Web site. http://www.amc.nl/masterverloskunde/. Accessed 26th June 2011.

31. Physician Assistant Clinical Midwfery: Hogeschool Rotterdam web site. http://www.hogeschool-rotterdam.nl/eCache/DEF/1/14/650.html/ . Accessed 26th June 2011.

32. Clinical M idwife Course: course content. UM C Utrecht web site. http://www.umcutrecht.nl/onderwijs/opleiding/K/ klinisch-verloskundige-/. Accessed 26th June.

33. Royal Dutch Organization of M idwives: KNOV Scientific Committee. Academisation of midwifery training. Utrecht: KNOV; 2011.

34. Royal Dutch Organisation of M idwives: KNOV. Annual general meeting: final report KNOV/NVOG Workgroup Clinical Midwives, Utrecht: KNOV; 2010. 35. M ulholland L. M idwife ventouse practitioners. British Journal of M idwifery. 1997: 5(5): 255.

36. Andrews S. Midwives as obstetric ultrasonagraphers. RCM M idwives J 2002 Jul; 5(7):216-8.

37. Latter S, M aben J, M yall M, Young A. Evaluating the clinical appropriateness of nurses' prescribing practice: method development and findings from an expert panel analysis. Qual Saf Health Care. 2007 Dec; 16(6):415-21.

38. Griffith R. Restrictions on the supply and administration of medications British Journal of M idwifery. 2009:17(8):530.

39. Spence $D$, Anderson $M$. Implementing a prescribing practicum within a M aster's degree in advanced nursing practice. Nurs Prax N Z. 2007 Nov; 23(2):27-42.

40. Cobanoglu C, Warde B, and M oreo P. A Comparison of Mail, Fax, and Web Survey M ethods. International Journal of M arket Research. 2001. 43:441-52. 41. Polit D, Hungler B. Inferential statistics. In: Nursing Research. 4th ed. Philadelphia, PA: J.P. Lippincott, 1991: 430-439.

42. Salvucci S, Walter E, Conley V, Fink S, Saba M, and Kaufman S. NCES measurement error programs. Washington, DC: U.S. Department of Education, NCES; 1997: 97-464. 


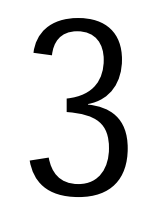

\section{Making Evidence Available for} Hospital-Based Midwives: A Systematic Examination of the Content and M ethodological Quality of

\section{Three Protocols Used in} $M$ aternity Hospitals in

\section{the Netherlands}

Doug J. Cronie, M arlies Rijnders, Raymond de Vries, and Simone Buitendijk International Journal of Childbirth 2014, 4 (4): 208-218. 
Abstract

Introduction: In recent years the Dutch have begun to question the safety and efficacy of their maternity care system. Particular concerns have been raised about the quality of care in hospital settings. One way to address concerns regarding quality and efficacy of care is by the introduction and use of evidence-based protocols for practice. The primary aims of this study are to 1) describe the availability and diffusion of protocols in Dutch maternity hospitals, 2 ) to systematically assess the methodological quality of these protocols, and 3) to consider the content of the protocols in relation to the best evidence for practice.

Methods: A mailed and Internet questionnaire to all hospitals with maternity facilities in the Netherlands inquiring about the availability, content, and methodological quality of protocols for three situations: hypertensive conditions of pregnancy, fetal surveillance, and post-partum haemorrhage. All protocols were systematically assessed twice. We first assessed the methodological quality of the protocol using the AGREE framework and we then evaluated protocol content using a framework we developed for this purpose. Protocols were scored using a Likert-type scale.

Results: Fifty-three percent $(n=48)$ of all maternity hospitals in the Netherlands responded. The methodological quality of protocols we evaluated was poor. Using the AGREE framework, seventy percent of fetal surveillance protocols could not be recommended. Only one protocol from one hospital scored "strongly recommend". Confusion regarding the definition of a protocol and what it should contain were common problems. There was a general paucity of evidence in the protocols assessed.

Discussion: Protocols may not be not widely available in Dutch maternity hospitals. Where they are available, the quality is poor. There is no national strategy for coordination, implementation, and dissemination of evidencebased protocols. Because centralization, uniformity, and interprofessional collaboration are known to improve adherence, it would be prudent for maternity care professions to develop and disseminate protocols based on best evidence.

Keywords: Midwife, hospital-midwife, protocol, survey, evidence-based medicine, EBM , evidence-based practice, teaching hospital, non-teaching hospital, Dutch maternity care, Netherlands. 
Introduction

The maternity care system of the Netherlands has become the subject of national debate. The rates of perinatal death, as well as sub-standard care as a factor in maternal death, are particular concerns (Euro-Peristat 2008, Schutte 2010). While much of the debate concerns place of birth (de Jonge et al. 2009, Amelink-Verburg 2011) discussion is increasingly focusing on hospital births (Smeenk \& ten Have 2006, Weigers 2009, Kooy et al. 2011). Studies have been critical of the level of cooperation and collaboration in the hospital maternity setting (Schutte et al. 2008, Visser \& Steegers 2008, Evers et al. 2010) particularly after reports of an increase in adverse incidents in the evening, at weekends and at night (de Graaf et al. 2010, Kramer et al. 2010, IGZ2011).

A recently published government-backed strategic review of maternity care in the Netherlands suggested that stakeholders in maternity-service provision should place a higher priority on the coordination, production, and use of evidence-based, inter-professional guidelines (van der Velden 2010). Evidence suggests that the use of standardized, evidence-based care plans in the form of guidelines or protocols can substantially improve health outcomes (AHCPR 1990, Enkin et al. 2000, Sackett et al. 2000, AGREE 2001, Grimshaw et al. 2002). Conversely, there is evidence to suggest that where professionals rely on poor protocols, there is a significant risk of harm from inappropriate care (Woolf et al. 1999, Grol 2001) with the attendant effect on costs (Hogg 2005).

Widespread gold-standard collaboration in protocol development - as in the UK with the National Institute for Clinical Effectiveness (NICE) or the United States National Guideline Clearing House (ARHQ) - is not common in the Netherlands ( $v$ Loon 2012). Although there is a stronger tradition of protocol use in midwifery in the primary care sector (KNOV 2003, KNM P 2012) the current system of guideline development rarely leads to national, interprofessional agreements in hospital care (NVOG 2010, NVOG 2012).

While a comprehensive description of the Dutch maternity healthcare system is outside the scope of this article, it is important to note that midwives are the predominant professional group caring for pregnant women in the current system. Dutch women with low-risk pregnancies are cared for in the primary care sector; those with medium risk in the secondary care sector and those with high-risk pregnancies are managed in tertiary referral centers. Risk selection forms the basis for allocation of women to a particular care level (Cronie et al. 2012).

Sixty-three percent of midwives in the Netherlands work in primary care, caring for women with low-risk pregnancies. They tend to be self-employed and work 
individually or in group practices. The remaining twenty-seven percent of midwives work in a secondary or tertiary hospital setting (Hingstman \& Kenens 2011).

In secondary care, there are two types of hospitals: non-teaching and teaching. Furthermore, there are eight university teaching hospitals spread throughout the Netherlands, which function as tertiary referral centers for high-risk pregnant women. M idwives commonly work autonomously in all three types of hospitals, caring for women with an increased risk profile. In the evening, on weekends and at night there is a significant chance that there will be only one midwife on duty and no in-house obstetrician. While in addition it was recently shown that up to forty percent of all hospital births, previously assumed to be managed by obstetricians, were solely managed by hospital midwives (Cronie et al. 2012).

In relation to midwifery education, the national curriculum for the four-year midwifery-training course in the Netherlands focuses on the normal physiology of childbirth, with an emphasis on home birth. There is currently no statutory requirement for additional training targeting midwife care in hospitals for women with higher-risk pregnancies.

Consequently, little is known regarding protocol use and how this affects midwives' ability to deliver evidence-based care in Dutch maternity hospitals. We divided our basic research question - "Do hospital-based midwives deliver evidence-based care?" - into three sub questions: 1. To what extent are protocols available in Dutch maternity hospitals?; 2 . What is the methodological quality of the protocols that are being used?; 3 . Is the content of the protocols based on the best evidence for practice? In addition, we explored the correlation between scores for methodological quality and the content scores of the protocols.

To our knowledge, this is the first assessment of the methodological quality and/ or content of guidelines in use by midwives in Dutch maternity hospitals.

Methods

Our data set was obtained from an on-going examination by the Dutch Healthcare Inspectorate (IGZ) of the current levels of efficacy in care associated with pregnancy and birth (IGZ2011). As a part of this project all Dutch maternity hospitals ( $n=91$ ) were asked in 2010 to provide documentation (protocols) relating to the following three aspects of clinical midwifery care: hypertensive conditions of pregnancy, post-partum haemorrhage and fetal surveillance. Hypertensive conditions of pregnancy and haemorrhage are the 
top two causes of maternal mortality, while unexplained stillbirth is the leading cause of fetal demise (Khan et al. 2006).

Initial contact was by letter from the IGZ to the hospital-management secretarial department. The project aims were stated and contact (e-mail) details were requested for the senior consultant in each obstetric department. A dedicated website was developed for the purpose of data collection. Login codes were e-mailed to all consultants, allowing them access to the website. A timeline of six weeks was set for completing data registration; two e-mail reminders were sent to the individual consultants who had not responded. One week before the closing date a letter was sent to the hospital-management secretarial departments of the hospital's from whom no response had yet been received, requesting compliance with the initial request to send the relevant protocols. It was estimated that there could be a maximum of three protocols from each of the ninety-one hospitals providing maternity services in the Netherlands ( $n=273$ protocols).

The data were received digitally and sorted by organization and subject headings: hypertensive conditions of pregnancy, post-partum haemorrhage (pph) and fetal surveillance. Data were analyzed using the SPSS 17 software package. After calculating descriptive statistics, we examined differences between the types of hospitals - non-teaching, teaching and academic tertiary - using Chi-square tests, Fisher's exact tests and analyses of means. Because we received only one response from an academic tertiary hospital, we dichotomized "type of hospital" grouping the academic hospital with teaching hospitals. We considered a P value of 0.05 to be statistically significant.

We began our research with a Pub M ed literature search for articles available in English in full text using the search terms 'Guidelines and appraisal and instrument' to identify guideline appraisal instruments. The majority $(n=6)$ of the full-text articles reviewed $(n=11)$ identified the internationally validated AGREE framework (AGREE 2001) as a reliable tool for guideline assessment. Accordingly, the protocols in our study were first subjected to an analysis of methodological quality, i.e., the quality of methods used to determine the protocol, using the AGREE instrument for the appraisal of guidelines for research and evaluation.

The AGREE appraisal criteria consist of twenty-three items in the following six domains:

Scope and purpose ( 3 items)

Stakeholder involvement (4 items) 
Rigor of development ( 7 items)

Clarity of presentation ( 4 items)

Applicability (3 items)

Editorial independence ( 2 items)

Each of the items is rated on a 4-point, Likert scale in which 4 is 'strongly agree' and 1 'strongly disagree'.

After the methodological assessment we analyzed protocol content. Given our focus on protocols that are primarily related to intra-partum practices, we wanted to evaluate the documents in light of best practice in the management of the three conditions. Because we could not find a validated appraisal framework that assessed content from this perspective, we developed a tool for measuring the degree to which a protocol was based on the best available evidence.

Four steps were involved in the development of this tool. First, in order to create a benchmark for the Dutch protocols, we searched for protocols based on high-quality evidence. We used the US National guidelines clearing house database (AHRQ 2012) \{HYPERLINK

"http:// www.guideline.gov"www.guideline.gov to find protocols containing high-quality evidence relating to the three subject areas studied. Second, we evaluated the evidence used in the protocols found in the NGC according to the National Institute for Health and Clinical Excellence's hierarchy of evidence table (NICE 2005) \{Figure 1\}. Level 1 is the highest and level 4 is the lowest level of evidence. For our study, we considered evidence at level 2 or higher to be high quality. In this step we located five protocols that used high quality evidence (RCOG 2001, NICE 2007, WHO 2007, NICE 2010). From the five protocols we found nine recommendations with high quality evidence matching our criteria - three in each of the subject areas.

For protocols relating to hypertensive conditions of pregnancy the three recommendations based on high-quality evidence were:

Induction of labor with gestational hypertension or mild pre-eclampsia from 37 completed weeks of pregnancy onwards; evidence level 1+

Labetalol (antihypertensive) for the treatment of moderate hypertension; evidence level 1-

Magnesium sulphate for treatment of severe hypertension or severe preeclampsia; evidence level $1+$ 
In the case of post-partum haemorrhage, the three recommendations with high-quality evidence were:

Risk assessment of antenatal factors, with care plan covering third-stage management; evidence level 2

Uterotonics for all women after delivery of baby; evidence level 1-

Active management of the third stage of labor for all women; evidence level 1+ (uterotonics + cord clamping after cessation of pulsing + controlled cord traction)

In the case of fetal surveillance, the three recommendations with high-quality evidence were:

Continuous fetal monitoring in increased-risk pregnancies; evidence level 1+

Fetal blood sampling in the presence of pathological cardiotocograph (CTG); evidence level 2

Where fetal hypoxia is suspected, umbilical artery acid-base status should be assessed; evidence level 2

Third, we used a scoring system to assess systematically the Dutch protocols we had received. Based on whether or not best evidence was included, we assigned a clinical practice content score to each (yes $=2 /$ unclear $=1 /$ no $=0$ ). The maximum possible score for each protocol was 6 - assigned to a protocol that contained all three recommendations for that subject area.

Fourth, we used these scores for a simplified assessment of efficacy as suggested by the AGREE framework (AGREE 2001) \{strongly recommend/recommend with provisos/would not recommend \}we adopted a threshold for "strongly recommend" of $>4$ (66-100\%), The threshold for "recommend with provisos" was a score of 3-4 (33-65\%), and the threshold for "would not recommend" was a score of $<3(0-32 \%)$.

Studies using data of this type are not subject to ethics committee approval in the Netherlands (CCM 0 2012). http:// www.ccmoonline.nl/main.asp/English/FAQ/WMO.

Results

Table 1 shows the response rate by type of hospital. Forty-eight of the 91 Dutch maternity hospitals replied (response rate: $53 \%$ ). All thirteen provinces and all 
of the four largest cities in the Netherlands were represented. Academic teaching hospitals were under-represented $(n=1$ of 8$)$.

$M$ any different forms of documentation were received. For the purpose of this study, we classified and analyzed all the documents received as protocols. All the responding hospitals had protocols for the management of hypertensive conditions of pregnancy ( $n=48$ ). One hospital (a teaching hospital) had no postpartum haemorrhage protocol. Twenty-five percent $(n=12)$ of hospitals supplied no fetal surveillance protocol. Non-teaching hospitals were significantly less likely to have a fetal surveillance protocol $(p \leq 0.05)$.

Methodological quality

Table 2 shows the methodological quality of the protocols, according to the AGREE criteria. The possible maximum total score for the methodological analysis for each of the protocols was 92 . The maximum scores achieved were: 52 for protocols relating to hypertensive conditions of pregnancy (1 of the 48 received), 46 for protocols relating to fetal surveillance ( 1 of 37 received), and 44 for protocols relating to post-partum haemorrhage (1 of 47 received).

Although the protocols for all three conditions at teaching hospitals generally scored higher than non-teaching hospitals, these differences were not significant.

\section{Content analysis}

The results of our content analysis are shown in Table 3. Only one of 48 hospitals scored a 6 - the maximum score - for its protocol relating to hypertensive conditions of pregnancy; two of 36 hospitals scored a 6 for their protocols relating to fetal surveillance; and the highest score for protocols relating to post-partum haemorrhage, achieved by five of 47 hospitals, was a 5 .

Only one hospital had a combined content score of 17 out of 18 possible points. Six (13\%) of the protocols relating to hypertensive conditions of pregnancy scored a 0 , as did seven (19\%) of the protocols relating to fetal surveillance.

The protocols for post-partum haemorrhage protocols scored better than the protocols for the other two conditions. The mean scores for protocols relating to post-partum haemorrhage and fetal surveillance were $30 \%$ of the maximum score. Teaching hospitals scored higher than non-teaching hospitals for the protocols relating to all three conditions, although the difference was not significant. 
Protocols commonly used vague language in relation to content when describing actions or noting who had responsibility. In all three types of protocols it was often difficult to ascertain the authorship of the protocol or the organization responsible and, even when this was stated, the date of origin was commonly more than three years ago.

Table 4 shows the level of recommendation by type of protocol according to both the methodological assessment and content assessment. During methodological analysis very few protocols could be classified in the "strongly recommend" category $(n=1)$. While protocols for fetal surveillance showed the lowest level of recommendation during both analyses. On occasion however, conflicting scores were noted: a few protocols with a low score for methodological quality scored higher for content analysis. However, we found no distinct pattern here. We noted that this was most likely to be a feature of protocols dealing with post-partum haemorrhage. However, the small numbers involved precluded finding significant differences in the relationships. In addition, we found that teaching hospitals scored consistently better than nonteaching hospitals in both analyses. However, once again, the difference was not large enough to be significant.

\section{Discussion}

To our knowledge, this study is the first national comparison of the protocols in use in Dutch maternity hospitals. We divided our research question into three sub-questions. The first of these is: are protocols sufficiently available in Dutch maternity hospitals? Our survey suggests that this may not be the case. Although the overall response rate of $53 \%$ was lower than expected, this is still considered to be an acceptable response rate (Salvucci et al. 1997). However, previous studies have demonstrated a positive association between the organization conducting the study (and therefore soliciting a response) and the response rate itself. The importance of the requesting body as perceived by the recipient is likely to influence the response rate (Jacoby 1990, Edwards et al. 2002). In view of the fact that the questionnaire was sent via the Dutch Healthcare Inspectorate, a governmental organization with authority over healthcare institutions, the relatively low response rate leads us to conclude that the development and use of protocols in Dutch maternity hospitals is not a high priority. In addition, academic tertiary hospitals were under-represented in our study. We are therefore unable to comment on, or draw conclusions about, protocol use in tertiary referral hospitals in the Netherlands.

Turning to the second sub-question: what is the methodological quality of the protocols used in Dutch maternity hospitals? The answer is moderate to low. 
We found few examples of good practice from the sample of protocols in use in Dutch maternity hospitals. This was most notable during analysis of methodological quality where ninety-eight percent of protocols in the "management of hypertension" category could not be rated "strongly recommend" while none of the fetal surveillance or management of post partum haemorrhage protocols were rated "strongly recommend".

A lack of standardization, and apparent confusion as to what constitutes a protocol (as well as to what it should contain), are troublesome. A variety of documents described as protocols was received. Included were: protocols, guidelines, policy documents, work agreements and procedures. This difficulty is acknowledged internationally (Kramer et al. 2010, IOM 2011, AHRQ 2012). Adopting a standard definition of a protocol in the Netherlands may reduce confusion and improve care.

It is particularly noteworthy that, in the AGREE analysis of methodological quality, some domains scored lower than others, most notably stakeholder involvement, applicability and editorial independence. No single protocol we analyzed included confirmation that patients' views were obtained during protocol development. Similarly, turning to the domain of applicability, none of the protocols gave sufficient detail with respect to the potential cost implications of implementing the protocol. Editorial independence scored equally low. None of the protocols analyzed gave any information to suggest that the guideline was editorially independent from the funding body. This suggests a systematic failure in Dutch maternity hospitals with regard to these three areas of protocol development and suggests a priority area to be addressed by stakeholders.

Poor protocols are not unique to the Netherlands (Sudlow \& Thompson 1997, Graham et al. 2001, Grilli et al. 2001, Goergen et al. 2010, Leach \& Segal 2010, M cNair \& Hegarty 2010). Nor is the AGREE instrument exempt from criticism (Vlayen et al. 2005) since it does not allow for an assessment of protocol content. This led us to the third sub-question: does the content of protocols used in Dutch maternity hospitals match best evidence for practice?

The answer to this question is also "no". Although more protocols scored "strongly recommend" after content analysis than after methodological analysis, overall the scores for content were poor. For example, seventy per cent of all fetal surveillance protocols rated "would not recommend" while $21 \%$ of them scored zero for content analysis because the did not include any of the three high quality evidence recommendations for practice. 
In general, we found a paucity of evidence-based protocols in use in Dutch maternity hospitals. Protocols were often old (in one case, the date of the last review was more than twelve years previously). We found guidance that was frequently confusing or vague, a recurrent theme being the use of terms such as "as necessary" and "when needed". In addition, we found potentially harmful advice such as the recommendation of the use of ergometrine as firstline management in the event of post-partum haemorrhage. One study suggests that this is also a widespread issue, finding that $20-25 \%$ of care provided is not needed or potentially harmful (Grol \& Grimshaw 2003).

A barrier that prevents individual hospitals from producing high-quality, evidence-based protocols is the lack of resources required to produce, update and disseminate them (Yamill et al. 2003, Grimshaw et al. 2004). Removing the burden from individual hospitals by centralizing protocol production in a centrally funded body (NICE 2007) would be a good step forward in this respect. Both the KNOV (Royal Dutch Organization of Midwives) and the NVOG (Dutch Association of Obstetricians and Gynaecologists) agree that more attention to cooperative working practices (in the form of national protocols) is desirable (NVOG 2011, KNOV 2012). However, this way of working has not yet been formalized.

There are some national examples of good practice in the Netherlands, such as the $\mathrm{CBO}$ (National institute for healthcare quality) guideline for pain management options in labor (CBO 2008) \{the only guideline from this organization which could be identified at the time of writing or the NVOG Guideline for fetal monitoring (NVOG 2003). However, few hospitals stated that they used them.

Despite this, we suggest that adopting an inclusive, inter-professional strategy for protocol development using a standardised format on the lines of the SIGN guideline developer's handbook (SIGN 2008) "http:// www.sign.ac.uk" with dissemination through a central, accredited body such as those in place in other developed nations is the approach most likely to improve the quality of protocols available and to assist midwives in Dutch maternity hospitals to make judgments based on the best available evidence. However, in so suggesting, we are mindful of the comment by Oxman et al. "that there are no magic bullets" in terms of implementation strategies and protocol adherence (Oxman et al. 1995, p1431).

\section{Limitations}

While we are confident that our analysis represents an accurate picture of the hospitals surveyed nevertheless, the relatively low response rate of 53\% may 
mean that our results are not generalizable to all maternity hospitals in the Country. However, the fact that our survey contains results from maternity hospitals in all provinces $(n=13)$ and from the four major cities of the Netherlands suggests a consistent pattern throughout the Country. Because of financial constraints only one researcher analyzed the protocols. Although this is a limitation, the format for assessment was clear and specific, therefore is less likely to generate errors in coding.

\section{Conclusion}

Our survey demonstrates that protocols may not be widely available in Dutch maternity hospitals and that the methodological quality of the available protocols is poor. In addition, examination of the content of protocols used revealed inconsistency and minimal use of quality evidence. This leads us to conclude that in current practice conditions, using the protocols analyzed it is likely that hospital midwives in the Netherlands will be hampered rather than assisted in their quest to deliver evidence-based care.

Hospital midwives are the backbone of maternity service provision in the Netherlands. They manage almost half of all the births occurring in hospitals, often work alone and care for women with higher-risk pregnancies (Cronie et al. 2012). Not having access to high quality, up-to-date, evidence-based protocols further complicates the work of hospital midwives and could have a potentially detrimental effect on the health of women in their care.

\section{FIGURES AND TABLES}

Figure 1: Grading for levels of evidence ${ }^{32}$

\begin{tabular}{|l|l|}
\hline Evidence Level & Source of evidence \\
\hline $1+$ & $\begin{array}{l}\text { High quality meta-analyses, systematic reviews of randomized } \\
\text { Controlled trials (RCTs) or RCTs with a very low risk of bias }\end{array}$ \\
\hline $1+$ & $\begin{array}{l}\text { Well conducted meta-analyses, systematic reviews of RCTs or } \\
\text { RCTs with a low risk of bias }\end{array}$ \\
\hline $1-$ & $\begin{array}{l}\text { Meta-analyses, systematic reviews or RCTs or RCTs with a high } \\
\text { risk of bias }\end{array}$ \\
\hline $2+$ & $\begin{array}{l}\text { High-quality systematic reviews of case-control or cohort } \\
\text { studies; high-quality case-control or cohort studies with a very } \\
\text { low risk of confounding, bias or chance and a high probability } \\
\text { that the relationship is causal }\end{array}$ \\
\hline $2+$ & $\begin{array}{l}\text { Well conducted case-control or cohort studies with a low risk } \\
\text { of confounding, bias or chance and a moderate probability } \\
\text { that the relationship is causal }\end{array}$ \\
\hline $2-$ & $\begin{array}{l}\text { Case-control or cohort studies with a high risk of confounding, } \\
\text { bias or chance and a significant risk that the relationship is not } \\
\text { causal }\end{array}$ \\
\hline
\end{tabular}




\begin{tabular}{|l|l|}
\hline 3 & Non-analytical studies (e.g. case reports, case series) \\
\hline 4 & Expert opinion, formal consensus \\
\hline Hierarchy of evidence table, NICE. &
\end{tabular}

Table 1: Number of protocols per type of hospital in the Netherlands $(n=48)$

\begin{tabular}{|l|l|l|l|l|}
\hline Type of protocols & $\begin{array}{l}\text { Teaching hospitals } \mathbf{n} \\
\text { (\%) }\end{array}$ & $\begin{array}{l}\text { non-teaching } \\
\mathbf{n}(\%)\end{array}$ & $\begin{array}{l}\text { Tertiary academic } \\
\text { hospitals n(\%) }\end{array}$ & $\begin{array}{l}\text { Number of hospitals } \\
\text { with protocols for this } \\
\text { situation } \\
\mathbf{n}(\%)\end{array}$ \\
\hline $\begin{array}{l}\text { Hypertensive conditions } \\
\text { of pregnancy protocols }\end{array}$ & $18(38)$ & $29(60)$ & $1(2)$ & $48(100)$ \\
\hline $\begin{array}{l}\text { Post-partum } \\
\text { haemorrhage protocols }\end{array}$ & $17(35)$ & $29(60)$ & $1(2)$ & $47(97)$ \\
\hline $\begin{array}{l}\text { Fetal surveillance } \\
\text { protocols }\end{array}$ & $15(31)$ & $21(44)$ & $1(2)$ & $37(77)$ \\
\hline
\end{tabular}

Table 2: AGREE ${ }^{19}$ scores $^{\S}$ for methodological quality of protocols

\begin{tabular}{|c|c|c|c|c|c|}
\hline $\begin{array}{l}\text { Domain (possible } \\
\max \text { score)* }\end{array}$ & type of protocol & $\begin{array}{l}\text { Modal score }\{\text { mean }\} \\
\text { (standard deviation) }\end{array}$ & $\begin{array}{l}\text { Range } \\
\text { of actual scores }\end{array}$ & $\begin{array}{l}\% \text { of hospitals with } \\
\text { actual maximum score }\end{array}$ & $\begin{array}{l}\% \text { of hospitals with } \\
\text { minimum score }\end{array}$ \\
\hline $\begin{array}{l}\text { Scope and purpose } \\
\text { (12) }\end{array}$ & $\begin{array}{l}\text { Hypertensive } \\
\text { conditions } \\
\text { Post-partum } \\
\text { haemorrhage } \\
\text { Fetal surveillance }\end{array}$ & $\begin{array}{l}5\{6.94\}(2.85) \\
3\{4.98\}(1.97) \\
3\{3.13\}(2.32)\end{array}$ & $\begin{array}{l}3-12 \\
3-9\end{array}$ & $\begin{array}{l}10 \% \\
6 \% \\
4 \%\end{array}$ & $\begin{array}{l}27 \% \\
44 \%\end{array}$ \\
\hline $\begin{array}{l}\text { Stakeholder } \\
\text { Involvement (16) }\end{array}$ & $\begin{array}{l}\text { Hypertensive } \\
\text { conditions } \\
\text { Post-partum } \\
\text { haemorrhage } \\
\text { Fetal surveillance }\end{array}$ & $\begin{array}{l}4\{4.63\}(0.94) \\
4\{4.65\}(1.26) \\
4\{3.63\}(2.16)\end{array}$ & $\begin{array}{l}4-7 \\
4-7 \\
4-7\end{array}$ & $\begin{array}{l}2 \% \\
6 \% \\
2 \% \\
\end{array}$ & $\begin{array}{l}67 \% \\
65 \% \\
46 \% \\
\end{array}$ \\
\hline $\begin{array}{l}\text { Rigor of } \\
\text { development (28) }\end{array}$ & $\begin{array}{l}\text { Hypertensive } \\
\text { conditions } \\
\text { Post-partum } \\
\text { haemorrhage } \\
\text { Fetal surveillance }\end{array}$ & $\begin{array}{l}8\{9.48\}(2.41) \\
7\{8.35\}(2.07) \\
7\{6.33\}(3.94)\end{array}$ & $\begin{array}{l}7-19 \\
7-13 \\
7-16\end{array}$ & $\begin{array}{l}4 \% \\
2 \%\end{array}$ & $\begin{array}{l}15 \% \\
33 \% \\
35 \%\end{array}$ \\
\hline $\begin{array}{l}\text { Clarity of } \\
\text { presentation (16) }\end{array}$ & $\begin{array}{l}\text { Hypertensive } \\
\text { conditions } \\
\text { Post-partum } \\
\text { haemorrhage } \\
\text { Fetal surveillance }\end{array}$ & $\begin{array}{l}8\{7.81\}(2.46) \\
5\{7.10\}(2.86) \\
4\{4.15\}(2.77)\end{array}$ & $\begin{array}{l}4-12 \\
4-13\end{array}$ & $\begin{array}{l}8 \% \\
4 \% \\
4 \% \\
\end{array}$ & $\begin{array}{l}13 \% \\
15 \% \\
38 \%\end{array}$ \\
\hline Applicability (12) & $\begin{array}{l}\text { Hypertensive } \\
\text { conditions } \\
\text { Post-partum }\end{array}$ & $\begin{array}{l}3\{3.08\}(0.40) \\
3\{2.98\}(0.48)\end{array}$ & $3-5$ & $4 \%$ & $94 \%$ \\
\hline
\end{tabular}




\begin{tabular}{|c|c|c|c|c|c|}
\hline & $\begin{array}{l}\text { haemorrhage } \\
\text { Fetal surveillance }\end{array}$ & $3\{2.42\}(1.36)$ & $3-4$ & $10 \%$ & $67 \%$ \\
\hline $\begin{array}{l}\text { Editorial } \\
\text { Independence (8) }\end{array}$ & $\begin{array}{l}\text { Hypertensive } \\
\text { conditions } \\
\text { Post-partum } \\
\text { haemorrhage } \\
\text { Fetal surveillance }\end{array}$ & $\begin{array}{l}2\{2.00\}(0) \\
2\{2.00\}(0) \\
2\{2.00\}(0)\end{array}$ & $\begin{array}{l}0-2 \\
0-2 \\
0-2\end{array}$ & $\begin{array}{l}* * \\
* * \\
* *\end{array}$ & $\begin{array}{l}100 \% \\
100 \% \\
100 \%\end{array}$ \\
\hline Total score (92) & $\begin{array}{l}\text { Hypertensive } \\
\text { conditions } \\
\text { Post-partum } \\
\text { haemorrhage } \\
\text { Fetal surveillance }\end{array}$ & $\begin{array}{l}30\{5.00\}(2.53) \\
24\{4.00\}(1.78) \\
23\{3.8\}(1.72)\end{array}$ & $\begin{array}{l}24-52 \\
23-44 \\
23-46\end{array}$ & $\begin{array}{l}2 \% \\
2 \% \\
2 \%\end{array}$ & $\begin{array}{l}6 \% \\
2 \% \\
25 \%\end{array}$ \\
\hline
\end{tabular}

$\S$ The AGREE appraisal criteria consist of twenty-three key items in the following six domains.

Scope and purpose ( 3 items), Stakeholder involvement ( 4 items), Rigor of development ( 7 items), Clarity of presentation (4 items), Applicability ( 3 items), Editorial independence ( 2 items)

Each of the items is then scored on a 4-point, Likert-like scale in which 4 is "strongly agree" and 1 "strongly disagree".

*possible maximum total score: 92 **no difference: $100 \%$ of respondents scored 2

Table 3: Scores for content analysis

\begin{tabular}{|l|l|l|l|l|l|}
\hline $\begin{array}{l}\text { Element of } \\
\text { evidence assessed } \\
\text { (possible max } \\
\text { score) }\end{array}$ & Type of protocol & $\begin{array}{l}\text { Modal score } \\
\text { \{mean\}standard } \\
\text { deviation) }\end{array}$ & Range & $\begin{array}{l}\text { \% of hospitals } \\
\text { with maximum } \\
\text { score }\end{array}$ & $\begin{array}{l}\text { \% of hospitals } \\
\text { with minimum } \\
\text { score }\end{array}$ \\
\hline $\begin{array}{l}\text { Induction of labor } \\
\text { (IOL) advised from } \\
\text { 37 complete weeks } \\
\text { of pregnancy } \\
\text { onwards (2) }\end{array}$ & $\begin{array}{l}\text { Hypertensive } \\
\text { conditions of } \\
\text { pregnancy }\end{array}$ & $\mathbf{0 \{ 0 . 6 9 \} . 8 3 )}$ & $\mathbf{0 - 2}$ & $\mathbf{2 3 \%}$ & $\mathbf{5 4 \%}$ \\
\hline $\begin{array}{l}\text { Labetalol 1st drug } \\
\text { of choice for } \\
\text { treatment of } \\
\text { moderate } \\
\text { hypertension (2) }\end{array}$ & $\begin{array}{l}\text { Hypertensive } \\
\text { conditions of } \\
\text { pregnancy }\end{array}$ & $\mathbf{1 \{ 0 . 9 0 \} . 6 6 )}$ & $\mathbf{0 - 2}$ & $\mathbf{1 7 \%}$ & $\mathbf{2 7 \%}$ \\
\hline $\begin{array}{l}\text { Magnesium } \\
\text { sulphate drug of } \\
\text { choice for } \\
\text { treatment of severe } \\
\text { hypertension/pre- } \\
\text { eclampsia (2) }\end{array}$ & $\begin{array}{l}\text { Hypertensive } \\
\text { conditions of } \\
\text { pregnancy }\end{array}$ & $\mathbf{2 \{ 1 . 3 5 \} . 7 3 )}$ & $\mathbf{0 - 2}$ & $\mathbf{5 0 \%}$ & $\mathbf{1 5 \%}$ \\
\hline $\begin{array}{l}\text { Risk assessment of } \\
\text { Post-partum }\end{array}$ & $\mathbf{1 \{ 0 . 5 1 \} . 5 0 )}$ & $\mathbf{0 - 2}$ & $\mathbf{0 \%}$ & $\mathbf{5 1 \%}$ \\
\hline
\end{tabular}




\begin{tabular}{|c|c|c|c|c|c|}
\hline $\begin{array}{l}\text { antenatal factors } \\
\text { with care plan } \\
\text { covering third stage } \\
\text { management }\end{array}$ & haemorrhage & & & & \\
\hline $\begin{array}{l}\text { Uterotonics for all } \\
\text { women after } \\
\text { delivery of baby }\end{array}$ & $\begin{array}{l}\text { Post-partum } \\
\text { haemorrhage }\end{array}$ & $2\{1.87\}(.40)$ & $0-2$ & $89 \%$ & $51 \%$ \\
\hline $\begin{array}{l}\text { Active management } \\
\text { of the third stage } \\
\text { for all women }\end{array}$ & $\begin{array}{l}\text { Post-partum } \\
\text { haemorrhage }\end{array}$ & $0\{0.60\}(.88)$ & $0-2$ & $26 \%$ & $66 \%$ \\
\hline $\begin{array}{l}\text { Continuous fetal } \\
\text { monitoring during } \\
\text { labor for increased- } \\
\text { risk pregnancies }\end{array}$ & Fetal surveillance & $2\{1.24\}(.88)$ & $0-2$ & $54 \%$ & $19 \%$ \\
\hline $\begin{array}{l}\text { Fetal blood } \\
\text { sampling advised in } \\
\text { the presence of } \\
\text { pathological } \\
\text { cardiotocograph }\end{array}$ & Fetal surveillance & $0\{0.74\}(.98)$ & $0-2$ & $38 \%$ & $62 \%$ \\
\hline $\begin{array}{l}\text { Where fetal hypoxia } \\
\text { is suspected } \\
\text { umbilical artery } \\
\text { acid-base status } \\
\text { should be assessed } \\
\text { post-partum }\end{array}$ & Fetal surveillance & $0\{0.16\}(.55)$ & $0-2$ & $8 \%$ & $92 \%$ \\
\hline $\begin{array}{l}\text { Total score per } \\
\text { protocol (6) }\end{array}$ & $\begin{array}{l}\text { Hypertensive } \\
\text { conditions of } \\
\text { pregnancy } \\
\text { Post-partum } \\
\text { haemorrhage } \\
\text { Fetal surveillance }\end{array}$ & $\begin{array}{l}4\{2.96\} 1.72) \\
2\{2.94\} 1.24) \\
0\{1.69\} 1.74)\end{array}$ & $\begin{array}{l}0-6 \\
0-6 \\
0-6\end{array}$ & $\begin{array}{l}2 \% \\
11 \% \\
5 \%\end{array}$ & $4 \%$ \\
\hline $\begin{array}{l}\text { Total scores for all } \\
\text { three protocols (18) }\end{array}$ & & $5\{7.56\} 2.88)$ & $0-16$ & $2 \%$ & $4 \%$ \\
\hline
\end{tabular}

Table 4 Level of recommendation* by type of protocol according to the methodological assessment and content assessment - N (percent)

\begin{tabular}{|l|l|l|l|l|l|}
\hline Type of protocol & Method of assessment & Strongly recommend & Recommend with & $\begin{array}{l}\text { Would not } \\
\text { provisos } \\
\text { recommend }\end{array}$ & \\
\hline Hypertensive conditions & methodological 48 & $1(2)$ & $36(75)$ & $11(23)$ \\
\hline
\end{tabular}




\begin{tabular}{|l|l|l|l|l|}
\hline of pregnancy & $\begin{array}{l}(100 \%) \\
\text { content 48 (100\%) }\end{array}$ & $11(23)$ & $19(39)$ & $18(38)$ \\
\hline $\begin{array}{l}\text { Post-partum } \\
\text { haemorrhage }\end{array}$ & $\begin{array}{l}\text { methodological } 47 \\
(100 \%)\end{array}$ & 0 & $18(38)$ & $29(62)$ \\
\hline Fetal surveillance & $\begin{array}{l}\text { methodological 37 } \\
(100 \%)\end{array}$ & 0 & $19(40)$ & $21(46)$ \\
\hline & $\begin{array}{l}\text { content } 47(100 \%) \\
\text { content 37 (100\%) }\end{array}$ & $3(8)$ & $12(32)$ & $25(68)$ \\
\hline
\end{tabular}

* Using a simplified assessment of efficacy as suggested by the AGREE framework19 (strongly recommend/recommend with provisos/would not recommend), we assigned a level of recommendation to each protocol. 


\section{References}

The AGREE Collaboration (2001) Appraisal of Guidelines for Research and Evaluation (AGREE) Instrument. 2001.

"http:// www.agreecollaboration.org"www.agreecollaboration.org accessed Jan 2011.

AHCPR (Agency for Health Care Policy and Research) (1990) Program Note. M edical Treatment Effectiveness Research. Rockville, M d.: U.S. Department of Health and Human Services, Agency for Health Care Policy and Research, March.

Amelink-Verburg M (2011) The role of primary care midwives in the Netherlands: Evaluation of midwifery care in the Dutch maternity care system: a descriptive study. Thesis, University of Amsterdam, the Netherlands, 2011.

Cronie D, Rijnders M \& Buitendijk S (2012) Diversity in the Scope and Practice of Hospital-Based M idwives in the Netherlands. Journal of M idwifery \& Women's Health, 57, 469-475.

Dutch Central Committee for Research (CCM 0) Involving Human Subjects, English Version (2012) web site. "http:// www.ccmoonline.nl/main.asp/English/FAQ/WM O/. Accessed Feb 2012.

Dutch Inspectorate for Healthcare (IGZ) (2011) Risks in hospital care in the evening, night and in the weekend must be better covered (in Dutch) IGZ, Utrecht, the Netherlands.

Dutch Institute for Healthcare Quality (CBO) (2008) pain management in labor, $\mathrm{CBO}$, Utrecht, the Netherlands.

Dutch Society for Obstetricians (NVOG) (2003) Fetal monitoring protocol, NVOG, Utrecht, the Netherlands.

Dutch Society for Obstetricians (NVOG) (2010) Guideline for Diabetes and pregnancy, NVOG, Utrecht, The Netherlands, 2010.

Dutch Society for Obstetricians (NVOG) (2011) Vision document; integrated midwifery care in the Netherlands; a step further, NVOG, Utrecht, The Netherlands.

Dutch Society for Obstetricians (NVOG) (2012) Guideline for SSRI use in pregnancy and breastfeeding, NVOG, Utrecht, The Netherlands. 
Edwards P, Roberts I, Clarke M , DiGuiseppi C, Pratap S, Wentz R, Kwan I \& Cooper $R$ (2002) Increasing response to postal questionnaires: a systematic review. British M edical Journal 324(7347): 1183.

Enkin M, Keirse M, Neilson J, Crowther C, Duley D, Hodnett E \& Hofmeyr J (2000) A Guide to Effective Care in Pregnancy and Childbirth 3rd ed. Oxford: Oxford University Press.

EURO-PERISTAT (2008) European Perinatal Health Report at "http:// www.europeristat.com. Accessed Feb 2012

Evers A, Brouwers $H$, Hukkelhoven C, Nikkels $P$, Boon J, van Egmond-Linden A, Hillegersberg J, Snuif Y, Sterken-Hooisma, Bruinse H \& Kwee J (2010) Perinatal mortality and severe morbidity in low and high risk term pregnancies in the Netherlands: prospective cohort study. British Medical Journal 341:c5639.

Goergen S, Rumbold G, Compton G \& Harris C. Systematic review of current guidelines, and their evidence base on the risk of lactic acidosis after administration of contrast medium for patients receiving metformin. Radiology Jan; 254 (1):

de Graaf J, Ravelli A, Visser G, Hukkelhoven C, Tong W, Bonsel G. \& Steegers E (2010) Increased adverse perinatal outcome of hospital delivery at night. British Journal of Obstetrics \& Gynecology, 117: 1098-1107. doi: 10.1111/j.14710528.2010.02611.

Graham I, Beardall S, Carter A, Glennie J, Herbert P, Tetroe J, M cAllister F, Visentin S, \& Anderson G (2001)I What is the quality of drug therapy in Canada? Canadian Medical Association Journal. 165: 157-163.

Grilli R, Magrin N, Penna A, M ura G \& Liberati A. (2000) Practice guidelines developed by specialty societies: the need for a critical appraisal. Lancet. 335: 103-106.

Grimshaw J, Eccles M , Walker A \& Thomas R (2002) Changing physician's behaviour: what works and thoughts on getting more things to work. Journal of Continuing Education in the health professions. 22: 237-43.

Grimshaw J, Thomas R, M acLennan G, Fraser C \& Ramsay C, Vale L, Whitty P, Eccles M, M atowe M, Shirran L, Wensing M , Dijkstra R \& Donaldson C (2004) Effectiveness and efficiency of guideline dissemination and implementation strategies. Health Technology Assessment 8(6):iii-iv, 1-72.

Grol R (2001) Successes and failures in the implementation of evidence-based guidelines for clinical practice. M edical Care. 39: 46-54. 
Grol R \& Grimshaw , J (2003) From best evidence to best practice: effective implementation of change in patients' care. Lancet 362:1225-30.

Hingstman L \& Kenens R (2011) Numbers from the registration of midwives. NIVEL, Utrecht, the Netherlands.

Hogg W, Baskerville N \& Lemlin J (2005) Cost savings associated with improving appropriate and reducing inappropriate preventative care: cost consequences analysis. Bio M edical Central Health Service Research; 5-20.

Institute of M edicine, IOM (2011) Clinical Guidelines we can trust. Standards for Developing Trustworthy Clinical Practice Guidelines (CPGs).

"www.iom/edu/Reports/2011/Clinicalpracticeguidelines accessed Feb 2012.

Jacoby A (1990) Possible factors affecting response to postal questionnaires: findings from a study of general practitioner services Journal of Public Health 12(2): 131-135.

de Jonge A, van der Goes B, Ravelli A, Amelink-Verburg M, M ol B, Nijhuis J, Bennebroek-Gravenhorst J, \& Buitendijk S (2009) Perinatal mortality and morbidity in a nationwide cohort of 529,688 low-risk planned home and hospital births. British Journal of Obstetrics \& Gynaecology 116(9):1177-84.

Khan K, Wojdyla D, Say L, Gülmezoglu \& van Look P (2006) WHO analysis of causes of maternal death: a systematic review. Lancet; 367:1066-1074.

Kramer J, Smit M, Simmons R, Rijnders M . \& van der Beek D. (2010) Literature study into factures influencing patient safety in the evening, weekend and night. Dutch Organization Applied Scientific Research (TNO) Leiden, the Netherlands.

vd Kooy J, Poeran J, de Graaf J, Birnie E, Denktas S, Steegers E \& Gouke J (2011) Planned home compared with planned hospital births in the Netherlands. Obstetrics \& Gynecology; 118:1037-46.

Leach M \& Segal L (2010) Are clinical practice guidelines (CPG's) useful for health services and workforce planning? A critique of diabetes CPG's. Diabetic Medicine; 27(5): 570-7.23.

v Loon, A (2012) The role of the clinical midwife within the hospital organization, legal position and training, an interactive discussion. Paper presented to: The clinical midwife, a new profession? NVOG conference, Amersfoort, The Netherlands, 14-12-2012.

M cNair R \& Hegarty K (2010) Guidelines for the primary care of lesbian, gay and 
bisexual people: a systematic review. Annuls of Family M edicine; Nov-Dec; 8(6): 533-41.

National Institute for Health and Clinical Excellence (NICE) (2005) Guideline Development M ethods: Information for National Collaborating Centers and Guideline Developers. NICE, London. UK.

National Institute for Clinical Effectiveness (NICE) (2007) Intrapartum care guideline; care of healthy women and their babies during childbirth. NICE, London, UK.

National Institute for Clinical Effectiveness (NICE) (2010) Hypertension in pregnancy; the management of hypertensive disorders during pregnancy. NICE, London, UK.

Netherlands Inspectorate of healthcare (IGZ) (2011) Risks hospital in evening, night and weekend should be better covered (in Dutch). Utrecht, the Netherlands.

Oxman A, Thomson M, Davis D \& Haynes R (1995) No magic bullets: a systematic review of 102 trials of interventions to improve professional practice. Canadian M edical Association Journal. November 15; 153(10): 14231431.

Royal College of Obstetricians and Gynaecologists (RCOG) (2001) The use of Electronic Fetal M onitoring, evidence-based clinical guideline No 8. RCOG, London, UK.

Royal College of Obstetricians and Gynaecologists (RCOG) (2010. Hypertension in pregnancy. RCOG, London, UK.

Royal Dutch M idwives Organization (KNOV) (2003) M idwifery Handbook: final report from the Midwifery Committee of the College of Health Insurers. "http://www.knov.nl/docs/uploads/Verloskundig_Vademecum_2003.pdf. Accessed Nov. 2012.

Royal Dutch Midwives Organization (KNOV) (2012) Position statement; integrated care model: New balance in midwifery care. KNOV, Utrecht, the Netherlands.

Royal Dutch Pharmacist's Society (KNM P) (2012) National Primary Care Agreements (LESA's) http://www.knmp.nl Accessed Nov. 2012. 
Sackett D, Strauss S, Richardson W, Rosenburg W, Haynes R. (2000) Evidencebased medicine How to practice and teach EBM . 2nd ed. Churchill Livingstone, Edinburgh, UK.

Salvucci S, Walter E, Conley V, Fink S, Saba M, and Kaufman S. (1997) NCES measurement error programs. Washington, DC: U.S. Department of Education, NCES; 97-464.

Schuttte J, Schuitemaker N, van Roosmalen J, Steegers E (2008) Substandard care and maternal mortality due to hypertensive disease in pregnancy in the Netherlands. British Journal of Obstetrics \& Gynaecology; 115:732-6.

Schutte J (2010) Safe motherhood, confidential enquires into maternal deaths in the Netherlands 1993-2005. Thesis, free university, Amsterdam, The Netherlands.

Scottish Intercollegiate Guidelines Network (SIGN) (2008) SIGN 50: A guideline developer's handbook. www.sign.ac.uk NHS QIS, Edinburgh, UK.

Smeenk A \& ten Have H (2006) Medicalization and obstetric care: An analysis of developments in Dutch midwifery. Medicine, Health Care and Philosophy.

Volume 6, Number 2, 153-165.

Sudlow M \& Thompson R (1997) Clinical guidelines: quantity without quality. Quality Health Care; 6:60-61.46-54.

U.S. Dept. of Health and Human Services. Agency for Healthcare Research and Quality (AHRQ) (2012) National Guidelines Clearinghouse http://www.guideline.gov Accessed Feb 2012.

van der Velden J (2010) A good beginning: safe care around pregnancy and birth. Advice of the steering group pregnancy and birth.

http://www.rijksoverheid.nl/enzwangerschap-en/x-cz-2978049b.pdf/. Accessed Feb 2012.

Visser G \& Steegers E (2012) Better birthing (in Dutch). M edisch Contact; 63:969.

Vlayen J, Aertgeerts B, Hannes K, Sermeus W \& Ramaekers, D (2005) A systematic review of appraisal tools for clinical practice guidelines: multiple similarities and one common deficit. International Journal for Quality in Health Care;17(3): 235-2421. 
Weigers T (2009) The quality of maternity care services as experienced by women in the Netherlands. Bio Medical Central Pregnancy and Childbirth, http://www.biomedcentral.com/1471-2393/9/18. Accessed Feb 2012

Woolf S, Grol R, Hutchinson A, Eccles M \& Grimshaw, J (1999) Potential benefits, limitations and harms of clinical guidelines. British M edical Journal; 318: 527-30.

World Health Organization (WHO) (2007) WHO recommendations for the prevention of postpartum haemorrhage. WHO, Geneva, Switzerland.

Yamill K, Pollak K, Ostbye T, Krause K, M ichener J (2003) Primary care: is there enough time for prevention? American Journal of Public Health; 93:635-41. 


\section{4}

\section{Are midwives in the Netherlands satisfied with their jobs?}

A systematic examination of satisfaction levels among hospital and primary-care midwives in the Netherlands.

Doug Cronie, M A, BSc, RM , RN, Hilde Perdok M Sc RM

Corine J. Verhoeven PhD RM, Suze Jans PhD RM

M arieke Hermus M AA, RM, MSc, Prof. Dr. Raymond de Vries PhD

Dr M arlies Rijnders RM PhD

Accepted: BM C Health Services Research, M ay 2019. 


\section{Abstract.}

Background: Job satisfaction is generally considered to be an important element of work quality and workplace relations. Little is known about levels of job satisfaction among hospital and primary-care midwives in the Netherlands. Proposed changes to the maternity care system in the Netherlands should consider how the working conditions of midwives affect their job satisfaction.

Aim: We aimed to measure and compare job satisfaction among hospital and primary-care midwives in the Netherlands.

M ethods: Online survey of all practising midwives in the Netherlands using a validated measure of job satisfaction (the Leiden Quality of Work Questionnaire) to analyze the attitudes of hospital and primary-care midwives about their work. Descriptive and inferential statistics were used to assess differences between the two groups.

Results: Approximately one in six of all practising midwives in the Netherlands responded to our survey (hospital midwives $n=103$, primarycare midwives $n=405$ ). All midwives in our survey were satisfied with their work $(n=508)$. However, significant differences emerged between hospital and primary-care midwives in terms of what was most important to them in relation to their job satisfaction. For hospital midwives, the most significant domains were: working hours per week, workplace agreements, and total years of experience. For primary-care midwives, social support at work, work demands, job autonomy, and the influence of work on their private life were most significant.

Conclusion: Although midwives were generally satisfied, differences emerged in the key predictors of job satisfaction between hospital and primary-care midwives. These differences could be of importance when planning workforce needs and should be taken into consideration by policymakers in the Netherlands and elsewhere when planning new models of care.

Key words: Job satisfaction, Survey, Hospital Midwife, Primary-care Midwife, Integrated-care. 


\section{Background.}

In the Netherlands, maternity care has been traditionally organized around primary-care (where midwives are the lead-professional). The role, remit and autonomy of primary-care midwives to provide low-risk pregnancyrelated care is protected by law ${ }^{1}$. Approximately $28 \%$ of all midwives in the Netherlands are registered to practise as hospital midwives of which, $100 \%$ are employed. The remaining $72 \%$ of midwives are registered as primarycare midwives. Of these, $45 \%$ are self employed practice owners (practices are further divided into $16 \%$ solo practice, $24 \%$ duo practice and $60 \%$ are part of a group practice). Of the group practices, $40 \%$ have 3 or 4 primarycare midwives and $60 \%$ consist of group practices with 5 or more primarycare midwives. Of the remaining primary-care midwives, $17 \%$ are selfemployed agency midwives working only in primary-care, $6 \%$ are employed by a midwifery practice (but are not practice owners) and 3\% are employed by health or birth centres².

Being in employment as part of a large (hospital) organisation means that hospital midwives are part of a different organisational structure and are subject to a different organisational culture than midwives in primary-care. This is can be seen throughout the Dutch midwifery model of care, perhaps most obviously relating to the position of the midwife within the multidisciplinary team; primary-care midwives are autonomous practitioners, recognised as the lead-carer for women with low-risk, physiological pregnancies. Their status is confirmed within the multi-disciplinary team, whereas, for the hospital midwife this is often not the case. Hospital midwives are frequently the only obstetric professional (in the context of the Dutch maternity care system, the phrase 'obstetric-professional' is understood to be limited to: an obstetrician, an obstetrician in training or a hospital midwife) at any one time on shift and commonly look after more than one women in labour at a time. Women birthing in hospitals usually have an increased risk, or known pathology. Hospital midwives usually work fixed periods, typically 8 or 12 hour shifts with minimal or no on-call. Whereas primary-care midwives (particularly those in solo, or duo practices routinely work longer hours with greater on-call commitments (24 or even 48 hours on-call during weekends are not uncommon). Primary-care midwives, who are paid a per-client fee by insurance companies, will have a caseload of upwards of 100 women per midwife, per year (the recommended maximum norm is 105 women, per midwife, per year ${ }^{3}$ ). For a fuller explanation of the Dutch maternity care system see: Amelink-Verburg \& Buitendijk 4 . 
In recent years, there has been an increase in the number of midwives working in secondary (hospital) care?

Under the present system of care pregnant women who are healthy, as defined by a list of indications ${ }^{5}$, are cared for by midwives in the primary care sector. If during pregnancy, a woman develops a condition considered to be "medium or high risk", she will be transferred to hospital-based care under the care of an obstetrician; in practice however, maternity care in the hospital setting is commonly provided by a hospital-based midwife ${ }^{6}$. This means that care by the primary-care midwife stops at the point of referral to secondary care. This delineation of care has traditionally meant that low risk pregnancy is managed by primary-care midwives and those with increased risk are managed by secondary (hospital) care. Although back and forth referral between primary and secondary care does occur, formal agreements relating to integrated care - where this strict delineation between the primary and secondary care sectors is blurred - are rare. In practice, there is little-to-no continuity of care when a woman is referred from primary to secondary care.

Following the publication of a report detailing perinatal mortality statistics across European nations, where it appeared that perinatal mortality in the Netherlands was higher than that of comparable countries, a strategic review of maternity services was commissioned ${ }^{7}$. The review panel was of the opinion that strict delineation of care may affect collaboration between maternity service providers. As a direct result, changes to the midwifery service provision in the Netherlands are being considered, with the emphasis shifting toward a so-called model of integrated care ${ }^{8}$ where the separation between primary and secondary care will become less rigid.

New integrated models of care are likely to result in changes in the working patterns of midwives and may affect their job satisfaction. It is important, therefore, to benchmark current levels of job satisfaction and to more fully explore the drivers of job satisfaction among midwives prior to changes in the system of care.

The concept of job satisfaction is generally accepted to consist of many aspects such as: job autonomy, potential for development and financial reward, working relationships, work demands, social support at work, workplace agreements, organization, and the influence of work on private life ${ }^{9}$.

Furthermore, job satisfaction is also seen as an important element of work quality and workplace relations ${ }^{10}$. Studies show a correlation between job 
satisfaction and efficiency ${ }^{11}$, productivity ${ }^{12}$, wellbeing ${ }^{13}$, as well as the working atmosphere ${ }^{14}$. In the nursing, midwifery and medical professions, ways of working which lead to increased job satisfaction have been shown to improve patient safety, reduce costs, and increase the quality of patient/client experience ${ }^{15,16,17,18}$.

Existing, small-scale (qualitative) studies considering the views of midwives show that direct client contact, continuity of care, positive support, teamwork, and the ability to work independently and autonomously lead to higher levels of satisfaction ${ }^{19,20}$. In this study, we have measured Dutch midwives' job satisfaction. Furthermore, we compare satisfaction levels between hospital and primary-care midwives and examine the factors associated with job satisfaction. Our study of job satisfaction offers a comprehensive view of the opinion of midwives under the current system of care and identifies the drivers of job satisfaction, important knowledge for policymakers, in the Netherlands and elsewhere, who are considering changes in the provision of maternity care.

\section{Methods.}

Design: This is a quantitative study using a cross sectional, selfadministered, online questionnaire.

Sample: The study population is all practising midwives in the Netherlands ( $\mathrm{N}=3150$ ). Our sample includes 103 hospital midwives and 405 primarycare midwives.

Data collection: Invitations were sent by email to 452 (out of a total of $532^{2}$ ) midwifery practices that included an e-mail address on their website. During the first week of $M$ arch 2015, these practices received a personal email containing information about the study and a link to the survey. In this email, we asked that an link to the survey was forwarded to all midwives in the practice inviting their participation in the study The survey was open to all and accessible via Survey M onkey from February 2015 until April 2015.

An email was also sent to the head-of-department in all hospitals in the Netherlands with maternity-care facilities ( $n=91$ ) asking them to forward the email invitation to participate to all colleagues (including hospital midwives).

In addition to this direct approach, we also used snowball sampling. The Royal Dutch Organization of M idwives (KNOV) placed a notification on their website, asking all members to participate in this study. Each midwife was 
asked to distribute the recruiting email among other colleagues after completion of the survey. A first reminder email was sent to all hospitals and midwifery practices after four weeks and further reminders were placed on the KNOV website and forums, such as the hospital midwives' group within the KNOV. Following this, no further reminders were sent.

There was no restriction on the number of participants per hospital or practice. Data were stored electronically in an encrypted database.

M easures: The Leiden quality of work questionnaire ${ }^{9}$ (LQWLQ), was used to measure job satisfaction. The formulation of the questions was adjusted for maternity-care professionals in consultation with the author of the questionnaire (see additional files 1 and 2 for Dutch and English versions of questionnaire). In total, the questionnaire consists of ten domains, each containing several factor-statements. Nine of the domains explore various elements related to job satisfaction and one domain is specifically focused on job satisfaction. This 'job satisfaction scale' $(\alpha=0.805)$ consists of the following six factor-statements: "If I had to choose, I'd choose this job again"| "I would like to change my job"|"I'm satisfied with my job"| "I would recommend this job to a friend"/ "When I applied, this was the job that I wanted"| "I often have to do work that I'd rather not do".

Respondents were asked to answer each statement using a four-point scale (ranging from 1: totally disagree to 4 : totally agree). The domain "job satisfaction" was defined as the mean of the six statements. A higher mean score indicated a higher level of job satisfaction. Negatively formulated questions were reversed for analysis.

In addition, we collected information about respondents' demographic characteristics such as gender, age, years of experience in profession and current organisation, as well as employment status and average working hours per week.

We defined two categories of midwife in the Netherlands. They were: 'hospital midwife' (midwife was employed in a hospital in the secondary or tertiary-care sector) or 'primary-care midwife' (midwife was self-employed or employed by a primary care midwifery practice). In addition, respondents were offered the option of 'other' if their occupation did not fit these categories.

The questionnaire was piloted prior to the survey by five midwives from the primary and secondary care sectors. This resulted in the simplification of 
two questions and the deletion of one that had been included twice in the draft questionnaire.

Statistical methods: We compared hospital midwives with primary-care midwives. A mean score for each of the domains for each group was calculated. We used t-tests and linear regression to assess the differences in job satisfaction between the two groups. We then used a bivariate analysis (Pearson's correlation coefficient) to examine the strength of the withingroup relationship between each of the domains and mean job satisfaction. Lastly, we used multiple linear regression to examine the effect of several independent variables (personnel and organisation, work demands and tasks, social support at work, working relationships, workplace agreements and referrals, autonomy, potential for development, financial reward, and the influence of work on private life) on job satisfaction. A p-value of 0.05 or lower was considered statistically significant.

IBM SPSS version 22.0 (SPSS, Inc., Chicago, IL, USA) was used for data analysis. Descriptive statistics, chi-square, bivariate and multi-variable regression analyses were performed and normality of the outcome measures was examined. In calculating means, we excluded those with more than one missing item on that scale.

Ethical considerations: This study forms part of larger study ${ }^{21}$ that was submitted to the medical ethics committee of VU University M edical Center (reference number 2014/030). As the research did not involve patient contact, the committee found the study to be exempt from ethical approval under existing Dutch legislation ${ }^{22}$. The authors have no conflicts of interest.

\section{Results.}

Given the method of recruitment (i.e. invitations to midwifery practices and hospital departmental heads and via the KNOV notification on their noticeboards), we are unable to determine the precise response rate. However, given that there are 3150 practising midwives in the Netherlands at the time of the study and that we had 508 midwife respondents, we estimate that our sample includes almost $17 \%$ of all practicing midwives in the country.

Fifty-eight of the 566 questionnaires we received were excluded because they were incomplete. Analysis of the incomplete responses showed that these data were missing completely at random (M CAR). No further analysis was performed on these M CAR data. Data were found to be sufficiently normally distributed to allow parametric testing. None of the midwife 
respondents used 'other' to describe their practice area. Hospital midwives make up $28 \%$ of all midwives in the Netherlands; our sample included $11 \%$ of hospital midwives and $18 \%$ of primary-care midwives.

The majority of respondents were female ( $>98 \%$ ). In addition, although the numbers were small, men were over represented in the hospital-midwife category: the national average is $<2 \%$ and in our survey it was $4 \%$.

The distribution of postcodes showed that all twelve provinces in the Netherlands were represented. We received responses from $97 \%$ of all maternity-hospitals ( $n=89$ ) in the Netherlands.

Table 1. Demographic characteristics of our sample

\begin{tabular}{|c|c|c|c|}
\hline & $\begin{array}{l}\text { Hospital } \\
\text { Midwives* } \\
\text { n (\%) }\end{array}$ & $\begin{array}{l}\text { Primary- } \\
\text { care } \\
\text { Midwives** } \\
\text { n (\%) }\end{array}$ & $\begin{array}{l}P \\
\text { value }\end{array}$ \\
\hline total & $103(100)$ & $405(100)$ & \\
\hline $\begin{array}{l}\text { Gender: } \\
\text { Male }\end{array}$ & $4(4)$ & $4(1)$ & 0.05 \\
\hline Female & $99(96)$ & 401 (99) & \\
\hline $\begin{array}{l}\text { M ean Age } \\
( \pm S D)\end{array}$ & $42(9.8)$ & $38(10.5)$ & 0.001 \\
\hline Employed & $103(100)$ & 77 (19) & 0.001 \\
\hline $\begin{array}{l}\text { Self } \\
\text { employed }\end{array}$ & $0(0)$ & $313(77)$ & 0.001 \\
\hline $\begin{array}{l}\text { Total years } \\
\text { of work } \\
\text { experience } \\
\text { M ean (SD) }\end{array}$ & $16(9.0)$ & $13(8.9)$ & 0.002 \\
\hline $\begin{array}{l}\text { Years of } \\
\text { experience } \\
\text { at current }\end{array}$ & $9.3(7.0)$ & $9.7(7.9)$ & 0.59 \\
\hline
\end{tabular}




\begin{tabular}{|l|l|l|l|}
\hline $\begin{array}{l}\text { work place } \\
\text { M ean (SD) }\end{array}$ & & & \\
\hline $\begin{array}{l}\text { Working } \\
\text { hours per } \\
\text { week (SD) }\end{array}$ & $29(5.6)$ & $44(14.9)$ & 0.001 \\
\hline
\end{tabular}

* Total number of hospital midwives registered in the Netherlands: N =919

** Total number of primary care midwives registered in the Netherlands: $\mathrm{N}=2231$

Table 1 shows the demographics of our sample population. The mean age of all respondents was 40 years. Hospital midwives were slightly older than primary-care midwives ( $42 \mathrm{yrs}$. vs. $38 \mathrm{yrs} ., p=\varangle 0.001$ ). Hospital midwives were significantly more likely to work fewer hours ( $n=29,95 \% \mathrm{Cl} 27-30, p=<$ 0.001 ) compared to primary-care midwives ( $n=44,95 \%$ Confidence Interval $[\mathrm{Cl}] 42-45, p=\varangle 0.001$ ). In addition, the range of working hours per week was significantly smaller for hospital midwives than primary-care midwives (28 vs. 142 respectively, $p=\varangle 0.001$ ). Hospital midwives had slightly more experience compared to primary-care midwives (16 yrs., 95\% Cl 14.2-17.8 vs. 13 yrs., $95 \% \mathrm{Cl} 11.9-13.74$ respectively, $p=<0.002)$. All hospital midwives were salaried employees (100\%). The majority $(77 \%)$ of primary-care midwives were self-employed.

Table 2. Mean scores^ [standard deviation] for hospital and primary-care midwives for questions in 'job satisfaction' domain

\begin{tabular}{|l|l|l|l|l|}
\hline $\begin{array}{l}\text { Individual factor } \\
\text { statements for } \\
\text { 'job-satisfaction' } \\
\text { domain }\end{array}$ & $\begin{array}{l}\text { Overall mean } \\
\text { for both } \\
\text { professional } \\
\text { groups. } \\
\text { mean [SD] }\end{array}$ & $\begin{array}{l}\text { Hospital } \\
\text { Midwives* }\end{array}$ & $\begin{array}{l}\text { Primary Care } \\
\text { Midwives** }\end{array}$ & P value \\
mean [SD] & \\
\hline $\begin{array}{l}\text { If I had to } \\
\text { choose again, I'd } \\
\text { choose this job }\end{array}$ & $3.12[0.68]$ & $3.15[0.64]$ & $3.02[0.74]$ & 0.54 \\
\hline $\begin{array}{l}\text { I would like to } \\
\text { change jobs }\end{array}$ & $3.18[0.71]$ & $3.02[0.72]$ & $3.03[0.76]$ & 0.28 \\
\hline I'm satisfied & $3.21[0.59]$ & $3.06[0.59]$ & $3.13[0.63]$ & 0.31 \\
\hline
\end{tabular}




\begin{tabular}{|l|l|l|l|l|}
\hline with my job & & & \\
\hline $\begin{array}{l}\text { I would } \\
\text { recommend a } \\
\text { friend to take } \\
\text { this job }\end{array}$ & $2.87[0.67]$ & $2.90[0.64]$ & $2.62[0.72]$ & 0.001 \\
\hline $\begin{array}{l}\text { When I applied } \\
\text { this is the job } \\
\text { that I wanted }\end{array}$ & $3.36[0.55]$ & $3.25[0.52]$ & $3.27[0.59]$ & 0.70 \\
\hline $\begin{array}{l}\text { I often have to } \\
\text { do work that I } \\
\text { would rather } \\
\text { not do }\end{array}$ & $3.03[0.57]$ & $3.04[0.53]$ & $2.86[0.64]$ & 0.11 \\
\hline $\begin{array}{l}\text { Domain score } \\
\text { per profession } \\
\text { (mean) SD }\end{array}$ & $3.13[0.47]$ & $3.07[0.48]$ & $3.02[0.48]$ & 0.45 \\
\hline \multirow{2}{*}{$\begin{array}{l} \\
\end{array}$} & & & \\
\hline
\end{tabular}

$* n=103 * * n=405$

Table 2 shows the difference in means between hospital and primary-care midwives on the individual statements from the domain of 'job satisfaction'. Overall, both groups of midwives were either satisfied or very satisfied with their jobs (mean satisfaction level was: satisfied for combined groups: 3.13, $95 \% \mathrm{Cl}$ 2.9-3.16).

Mean job satisfaction between the two groups of midwives did not differ significantly. Hospital midwives showed a mean satisfaction of $3.07(95 \% \mathrm{Cl}$ 2.97-3.17) compared to $3.02(95 \% \mathrm{Cl} 2.98-3.08)$ for primary-care midwives.

When the mean scores for the factor-statements of the domain 'job satisfaction' were analyzed individually, no differences emerged with the exception of hospital midwives, who were significantly more likely to recommend their job to a friend $(p=0.001)$.

Table 3. M ean scores [standard deviations] for hospital and primary-care midwives for other domains

\begin{tabular}{|l|l|l|l|l|}
\hline Domain & $\begin{array}{l}\text { Overall } \\
\text { mean }\end{array}$ & $\begin{array}{l}\text { Mean } \\
\text { score } \\
\text { hospital }\end{array}$ & $\begin{array}{l}\text { Mean score } \\
\text { primary-care }\end{array}$ & P value \\
\hline
\end{tabular}




\begin{tabular}{|c|c|c|c|c|}
\hline & $\begin{array}{l}\text { both } \\
\text { groups } \\
\text { (SD) }\end{array}$ & $\begin{array}{l}\text { midwives* } \\
\text { (SD) }\end{array}$ & midwives**(SD) & \\
\hline $\begin{array}{l}\text { Personnel \& } \\
\text { organization }\end{array}$ & $\begin{array}{l}3.17 \\
{[0.37]}\end{array}$ & $3.00[0.30]$ & $3.21[0.38]$ & 0.001 \\
\hline $\begin{array}{l}\text { Work } \\
\text { demands \& } \\
\text { tasks }\end{array}$ & $\begin{array}{l}2.60 \\
{[0.25]}\end{array}$ & $2.49[0.24]$ & $2.63[0.25]$ & 0.001 \\
\hline $\begin{array}{l}\text { Social } \\
\text { support at } \\
\text { work }\end{array}$ & $\begin{array}{l}3.03 \\
{[0.30]}\end{array}$ & $2.93[0.22]$ & $3.06[0.31]$ & 0.001 \\
\hline $\begin{array}{l}\text { Working } \\
\text { relationships }\end{array}$ & $\begin{array}{l}2.74 \\
{[0.28]}\end{array}$ & $2.78[0.23]$ & $2.74[0.29]$ & 0.190 \\
\hline $\begin{array}{l}\text { Workplace } \\
\text { agreements } \\
\& \text { referrals }\end{array}$ & $\begin{array}{l}2.19 \\
{[0.31]}\end{array}$ & $2.20[0.30]$ & 2.19 [0.32] & 0.759 \\
\hline Autonomy & $\begin{array}{l}2.70 \\
{[0.33]}\end{array}$ & $2.52[0.28]$ & $2.74[0.33]$ & 0.001 \\
\hline $\begin{array}{l}\text { Potential for } \\
\text { development }\end{array}$ & $\begin{array}{l}2.98 \\
{[0.39]}\end{array}$ & $2.91[0.40]$ & $2.99[0.39]$ & 0.080 \\
\hline $\begin{array}{l}\text { Financial } \\
\text { reward }\end{array}$ & $\begin{array}{l}2.58 \\
{[0.60]}\end{array}$ & $2.70[0.56]$ & $2.55[0.61]$ & 0.024 \\
\hline $\begin{array}{l}\text { Influence of } \\
\text { work on } \\
\text { private life }\end{array}$ & $\begin{array}{l}2.60 \\
{[0.63]}\end{array}$ & $2.13[0.47]$ & $2.72[0.60]$ & 0.001 \\
\hline
\end{tabular}

$* n=103 * * n=405$

Table 3 shows the mean scores for hospital and primary-care midwives for all other domains. For both groups of midwives, the three domains with the highest overall scores were 'personnel and organization', 'social support at work' and 'potential for development'. There were differences between groups in these scores with primary-care midwives generally scoring higher. These differences were statistically significant for the following domains: 'personnel and organization' ( $p=0.001)$, 'social support at work' $(p=0.001)$, 
'work demands and tasks' $(p=0.001)$, 'autonomy' $(p=0.001)$ and 'influence of work on private life' $(p=0.001)$.

Table 4. Within-group correlation $\left(P_{r}\right)$ between job satisfaction and each of the other domains for hospital and primary-care midwives

\begin{tabular}{|c|c|c|}
\hline Domain & $\begin{array}{l}\text { Correlation } \\
\text { coefficient } \\
\text { hospital- } \\
\text { care } \\
\text { midwives* } \\
\text { (p value) }\end{array}$ & $\begin{array}{l}\text { Correlation } \\
\text { coefficient } \\
\text { primary-care } \\
\text { midwives** } \\
\text { (p value) }\end{array}$ \\
\hline $\begin{array}{l}\text { Personnel \& } \\
\text { organisation }\end{array}$ & $\begin{array}{l}0.404 \\
(0.001)\end{array}$ & $0.297(0.001)$ \\
\hline $\begin{array}{l}\text { Work } \\
\text { demands \& } \\
\text { tasks }\end{array}$ & $\begin{array}{l}0.314 \\
(0.002)\end{array}$ & $0.380(0.001)$ \\
\hline $\begin{array}{l}\text { Social } \\
\text { support at } \\
\text { work }\end{array}$ & $\begin{array}{l}0.526 \\
(0.001)\end{array}$ & $0.410(0.001)$ \\
\hline $\begin{array}{l}\text { Working } \\
\text { relationships }\end{array}$ & $\begin{array}{l}0.356 \\
(0.001)\end{array}$ & $0.264(0.001)$ \\
\hline $\begin{array}{l}\text { Workplace } \\
\text { agreements } \\
\& \text { referrals }\end{array}$ & $\begin{array}{l}0.448 \\
(0.001)\end{array}$ & $0.251(0.001)$ \\
\hline Autonomy & $\begin{array}{l}0.522 \\
(0.001)\end{array}$ & $0.370(0.001)$ \\
\hline $\begin{array}{l}\text { Potential for } \\
\text { development }\end{array}$ & $\begin{array}{l}0.514 \\
(0.001)\end{array}$ & $0.499(0.001)$ \\
\hline $\begin{array}{l}\text { Financial } \\
\text { reward }\end{array}$ & $\begin{array}{l}0.316 \\
(0.002)\end{array}$ & $0.271(0.001)$ \\
\hline $\begin{array}{l}\text { Influence of } \\
\text { work on } \\
\text { private life }\end{array}$ & $\begin{array}{l}-0.025 \\
(0.811)\end{array}$ & $0.256(0.001)$ \\
\hline
\end{tabular}

$$
* n=93 * * n=382
$$


Table 4 shows the differences between hospital and primary-care midwives in the within-group correlation of the means of all the other domains to the mean of 'job satisfaction' using Pearson's correlation coefficient.

Overall, the correlations for each of the domains with job satisfaction were higher for hospital midwives. For hospital midwives, strong correlations were observed in three domains: 'social support at work' ( $r=0.526)$, 'autonomy' ( $r=0.522)$, and 'potential for development' ( $r=0.514)$. For primary-care midwives, the strongest correlations were in the domains: 'potential for development' ( $r=0.514)$, 'social support at work' $(r=0.410)$, and 'work demands and tasks' ( $r=0.380)$.

For each group, we looked more closely at the factor-statements within each domain that contributed most strongly to the relation between that domain and job satisfaction. For hospital midwives, the domain with the strongest correlation was 'social support at work'. This domain has eight factor-statements. Of these, the factor-statement "I experience the other partners in the care-chain more like colleagues than competitors" (data not shown) revealed the strongest correlation to job satisfaction. For primarycare midwives the strongest correlation to job satisfaction was 'potential for development'. This domain has five factor-statements. The factor-statement with the strongest correlation to job satisfaction was "In my work, I can develop sufficiently".

Table 5. Regression model predicting job satisfaction for hospital and primary-care midwives

\begin{tabular}{|c|c|c|c|c|}
\hline & \multicolumn{2}{|c|}{ Hospital midwives* } & \multicolumn{2}{|c|}{$\begin{array}{l}\text { Primary-care } \\
\text { midwives** }\end{array}$} \\
\hline $\begin{array}{l}\frac{\text { Model }}{\text { variable }} \\
\mathrm{s}\end{array}$ & Beta & $\begin{array}{l}95 \% \text { C.I.lower/ up } \\
\text { per }\end{array}$ & $\begin{array}{l}\text { Bet } \\
\text { a }\end{array}$ & $\begin{array}{l}\text { 95\%C.I.lower/ } \\
\text { upper }\end{array}$ \\
\hline Age & 0.089 & $-0.017 / 0.008$ & $\begin{array}{l}0.0 \\
31\end{array}$ & $-0.006 / 0.009$ \\
\hline $\begin{array}{l}\text { Total } \\
\text { years of } \\
\text { experie } \\
\text { nce in } \\
\text { professi }\end{array}$ & 0.259 & $-0.026 /-0.001$ & $\begin{array}{l}0.1 \\
57\end{array}$ & $-0.019 / 0.002$ \\
\hline
\end{tabular}




\begin{tabular}{|c|c|c|c|c|}
\hline on & & & & \\
\hline $\begin{array}{l}\text { Total } \\
\text { years of } \\
\text { experie } \\
\text { nce in } \\
\text { current } \\
\text { job }\end{array}$ & 0.146 & $0.003 / 0.022$ & $\begin{array}{l}0.0 \\
50\end{array}$ & $-0.005 / 0.12$ \\
\hline $\begin{array}{l}\text { Workin } \\
\text { g Hours } \\
\text { per } \\
\text { week }\end{array}$ & 0.170 & $0.002 / 0.027$ & $\begin{array}{l}0.0 \\
16\end{array}$ & $-0.002 / 0.003$ \\
\hline $\begin{array}{l}\text { Personn } \\
\text { el } \& \\
\text { Organiz } \\
\text { ation }\end{array}$ & 0.042 & $-0.227 / 0.361$ & $\begin{array}{l}0.0 \\
68\end{array}$ & $-0.029 / 0.203$ \\
\hline $\begin{array}{l}\text { Work } \\
\text { demand } \\
\text { s \& } \\
\text { tasks }\end{array}$ & 0.171 & $--0.020 / 0.627$ & $\begin{array}{l}0.1 \\
86\end{array}$ & $0.116 / 0.376$ \\
\hline $\begin{array}{l}\text { Social } \\
\text { support } \\
\text { at work }\end{array}$ & 0.185 & $-0.028 / 0.851$ & $\begin{array}{l}0.1 \\
99\end{array}$ & $0.168 / 0.451$ \\
\hline $\begin{array}{l}\text { Work } \\
\text { relation } \\
\text { ships }\end{array}$ & 0.001 & $-0.359 / 0.364$ & $\begin{array}{l}0.0 \\
34\end{array}$ & $-0.094 / 0.208$ \\
\hline $\begin{array}{l}\text { Workpl } \\
\text { ace } \\
\text { agreem } \\
\text { ents \& } \\
\text { referral } \\
\text { s }\end{array}$ & 0.220 & $0.077 / 0.543$ & $\begin{array}{l}- \\
0.0 \\
04\end{array}$ & $-0.130 / 0.119$ \\
\hline $\begin{array}{l}\text { Autono } \\
\text { my }\end{array}$ & 0.066 & $-0.188 / 0.418$ & $\begin{array}{l}0.1 \\
08\end{array}$ & $0.024 / 0.299$ \\
\hline $\begin{array}{l}\text { Potenti } \\
\text { al for }\end{array}$ & & $0.112 / 0.516$ & 0.3 & $0.278 / 0.511$ \\
\hline
\end{tabular}




\begin{tabular}{|l|l|l|l|l|}
\hline $\begin{array}{l}\text { develop } \\
\text { ment }\end{array}$ & & & 15 & \\
\hline $\begin{array}{l}\text { Financia } \\
\text { I reward }\end{array}$ & 0.094 & $-0.056 / 0.216$ & 0.0 & $-0.023 / 0.123$ \\
\hline Influenc & - & & 63 & \\
e of & .0 .14 & $-0.485 / 0.12$ & 0.9 & $0.005 / 0.236$ \\
work on & 3 & & 1 & \\
private & & & & \\
life & & & & \\
\hline R & $\mathrm{R}^{2}$ & & & \\
Model & $=$ & & $\mathrm{R}^{2}$ & \\
& 0.5 & & $=$ & \\
& 67 & & 4 & \\
& & & 2 & \\
& & & & \\
& & & & \\
\hline
\end{tabular}

Model multiple regression analysis: outcome $=$ mean job satisfaction. Predictor(s) demographic characteristics $=$ age $/$ total years of experience in profession / total years in current job/hours per week worked plus work-related elements of job satisfaction = personnel \& organization/ work demands and tasks/, social support at work/ working relationships/ workplace agreements \& referrals/autonomy/potential for development/financial reward/influence of work on private life.

$* n=103 * * n=405$

Table 5 shows the results of a linear regression analysis that used demographic characteristics (age, years of work experience, years at current workplace and working hours-per week) plus the nine domains associated with job satisfaction (personnel and organization, work demands and tasks, social support at work, working relationships, workplace agreements and referrals, autonomy, potential for development, financial reward and the influence of work on private life) to predict job satisfaction for each group.

Our model shows that for hospital midwives, the domains 'working hours per week' ( $p=0.022)$, 'potential for development' $(p=0.003)$ 'workplace agreements and referrals' $(p=0.010)$ and 'total years in the profession' $(p=0.034)$ were all significant predictors for job satisfaction.

For primary-care midwives, the domains 'potential for development' $(p=0.001)$, 'social support at work' $(p=0.001)$, 'work demands and tasks' 
$(p=0.001)$, 'autonomy' $(p=0.022)$ and 'influence of work on private life' $(p=$ 0.041 ) were all found to be significant predictors for job satisfaction.

The $\mathrm{R}^{2}$ for hospital midwives was .57 and for primary care midwives it was .41 .

\section{Discussion.}

Our study is the first national study to compare job satisfaction between hospital and primary-care midwives. Based on the total number of midwives practising in the Netherlands ( $n=3150$ ) our survey has a collective response rate of $17 \%$ of all midwives. Our study showed that all midwives in our survey were satisfied with their jobs and that there was no significant difference between hospital midwives and primary-care midwives in terms of overall satisfaction. While this is broadly in line with other, smaller-scale studies on the subject ${ }^{17,18}$ there are some important differences.

We found that the strongest predictor for job satisfaction for both groups of midwives was the domain 'potential for development'. This suggests that the facilitation of ways in which midwives can develop should be of primary concern to policy-makers. This is especially important in the context of midwifery service provision and changing models of care both in the Netherlands and internationally.

Midwives' professional organizations are becoming increasingly aware of the importance of the components of job satisfaction. Within the Netherlands the KNOV has campaigned for the reduction in the caseloads of primary-care midwives and for an increase in the potential for development of the midwives' scope of practice. In the UK, in response to a Government white paper on healthcare reform, the Royal College of Midwives (RCM) stated that almost half of all midwives surveyed wanted further training and development ${ }^{23}$.

Other healthcare professionals have also commented on the importance of the potential for development within their role. For example, Bjorka et $\mathrm{al}^{24}$ found that the introduction of career ladders significantly improved job satisfaction in Norwegian nurses. Clearly, an understanding of the importance of the potential for development to midwives can be advantageous when considering the strategic planning of maternity services.

Potential for development can also be seen in terms of the ongoing need to develop professionally, such as a commitment to life-long learning. 
Professional development will of course, have cost implications for employers and midwives themselves ${ }^{25}$. For Dutch midwives, who have different terms of remuneration according to the type and place of their practice (which, in turn, may be affected by new models of care), this is a particularly important fact for policymakers to consider ${ }^{8,26}$.

Insufficient opportunity for development was also associated with higher rates of burnout among Australian hospital midwives ${ }^{27}$. In addition, Yoshida and Sandall ${ }^{28}$ found that rates of occupational burnout are not only higher among midwives than those in comparable professions, but also that the incidence of 'midwife burnout' is on the rise. Like 'potential for development', burnout is linked to other aspects of job satisfaction ${ }^{29}$.

The domain 'workplace agreements' (which contains factor-statements relating to workplace protocols) was also a significant predictor for job satisfaction for hospital midwives. Over the last twenty years, as evidencebased practice has become more common, widespread reliance on protocols has become the norm ${ }^{30}$. However, it is important to note that these protocols need to be of sufficient quality and up-to-date in order to ensure that they are fit-for-purpose. A recent national survey of the proliferation of labour-ward protocols in the Netherlands found that those protocols were of variable quality and often out of date ${ }^{31}$. Over reliance on poor protocols may lead to a false sense of security and may harm patient care $^{32}$.

For hospital midwives in our survey, the domain 'working hours-per-week' was also a significant predictor of job satisfaction. Work/life balance is an oft-cited issue in the promotion of job satisfaction ${ }^{33,34}$. Internationally, the introduction of flexible work schedules has been suggested as a way to mitigate work constraints ${ }^{35}$. Among midwives in the Netherlands it has been hypothesized that having more regular hours may be the reason for the shift to hospital practice ${ }^{36}$. Two out of three Dutch midwives work part-time and most new graduates indicate a desire to work part-time by the time they reach the age of thirty ${ }^{37}$.

There is evidence that shows that older workers contribute more value in the workplace than their younger counterparts ${ }^{38}$. Studies of nurses indicate that keeping staff in-post, especially those with more experience is also linked to job satisfaction ${ }^{39}$. Our survey certainly demonstrates that for hospital midwives in the Netherlands, having more experience led to higher levels of satisfaction. 
The domain 'work demands and tasks' was a significant predictor of job satisfaction for primary-care midwives in our survey. For midwives and other healthcare providers, the pressure of work is cited as one of the main contributing factors leading to reduced motivation, increased levels of sickness, and ultimately, to leaving the profession $40,41,42,43$. This situation is mirrored in the Netherlands where Dutch primary-care midwives receive payment according to how many clients they care for during pregnancy and birth. This payment schedule is set nationally and means that Dutch primary-care midwives must accept a high caseload in order to meet the nationally agreed salary for full-time employment. Although in recent years the norm of the number of clients in the average primary-care midwife's caseload has been reduced (from 112 to 105 per year ${ }^{3}$ ), there are calls to reduce it even further ${ }^{44}$. Our survey suggests that this is a matter of importance for primary-care midwives in terms of their job satisfaction.

The domain 'social support at work' is also identified as a significant predictor of job satisfaction for primary-care midwives. This is important in the context of continuity-of-care models (COCM) characteristic of midwifery service provision in the Netherlands. While some studies report lower rates of burnout for primary-care midwives ${ }^{45}$, others report higher levels of occupational stress and burnout among primary-care midwives ${ }^{46}$.

Nevertheless, in the Netherlands where the caseload norm of primary-care midwives are high (105 per year) the pressure of work can lead to a sense of isolation, stress and burnout among midwives ${ }^{43}$. Research has confirmed the need to 'care for the carer', with reports of organizational or systematic stress, and even post-traumatic stress disorder, in healthcare professionals who feel isolated and lack good support networks at work ${ }^{47}$. The recent initiative by the UK RCM 48: 'Caring for You Charter' is a good example of midwives' professional organizations encouraging key stakeholders to commit to improving support networks in the workplace. A system of formal mentoring and support among Dutch midwives (particularly in the context of new models of care) is likely to contribute to increased satisfaction levels. Formal arrangements for mentoring in midwifery settings have been shown to have merit ${ }^{49}$.

Studies consistently confirm that elements which allow for a 'sense of control' are important to job satisfaction ${ }^{50,51,52}$. We also found this to be true in our study. The ability to work autonomously and the influence of work on private life (being able to "leave work at work") were significant predictors of job satisfaction for primary-care midwives in our study. This has been reported in other studies of midwives ${ }^{53,54}$, general practitioners ${ }^{55}$, 
and nurses ${ }^{56}$. Primary-care midwives in the Netherlands are autonomous practitioners and they see this as an important facet of their work. Any changes to working practices of midwives should protect or improve their level of autonomy.

Primary-care midwives indicated that their level of job satisfaction was higher when their work least impinged on their private life. This is however, made difficult by the fact that primary-care midwives in the Netherlands often work long periods on-call. The European Working Time-Directive ${ }^{57}$ dictates maximum working hours and minimal rest periods, but exempts self-employed persons. The Dutch Healthcare Inspectorate has said that self-employed primary-care midwives fall under the guidance issued for doctors ${ }^{58}$, which states that there should be "a maximum of five on-call shifts per week". Because 24 or even 48 hour shifts are not unknown in the Netherlands ${ }^{6}$, there is a clear need to establish what constitutes a safe maximum working period for primary-care midwives and to balance this with service needs.

\section{Strengths and limitations.}

Our survey has explored the views of Dutch midwives related to their job satisfaction. It provides a deeper understanding of the underlying differences in the factors that contribute to the job satisfaction of Dutch midwives and how those factors relate to their working practices.

Our respondents came from most areas of the Netherlands and they mirror the population of Dutch midwives. We used a validated questionnaire and piloted our survey with hospital and primary-care midwives.

Our study is limited by the fact that our sample was self-selected and was dependent on willingness to share our survey on the part of the person responsible for the email in the practice setting (primary-care or hospital). We attempted to compensate for this by placing notices encouraging all midwives to complete the survey on the midwives' professional organization' website. However, more primary-care midwives than hospital midwives are members of the midwives' professional organization ( $94 \%$ vs $52 \%{ }^{2}$ ), a factor that may have contributed to the lower proportion of hospital midwives accessing the questionnaire via the KNOV route. Nevertheless, since we received replies from $97 \%$ of all hospitals in the Netherlands, we are confident that the number and geographic distribution of responders was high enough to provide valid insights.

\section{Relevance}


Midwifery in the Netherlands is changing; nationally, there is a trend toward hospital employment for midwives ${ }^{2}$ and new models of care are being introduced. These changes have the potential to alter the way midwives work. A deeper understanding of what midwives themselves see as important contributors to their job satisfaction, before the introduction of substantial change, is necessary and prudent.

Our study offers a better understanding of what midwives say is important to them; its message is also relevant internationally, where it has been stated that the midwifery profession has the opportunity to learn from changes to practice in the Netherlands ${ }^{59}$.

\section{Conclusion.}

Overall, Dutch midwives are satisfied with their jobs. Significant differences in predictors for job satisfaction between hospital and primary-care midwives in the Netherlands exist. Given job satisfaction affects the quality of care (and satisfaction with that care), these differences are important to consider when planning workforce needs and should be used by policymakers in the Netherlands and elsewhere when planning new models of care.

\section{List of abbreviations.}

KNOV: Koninklijke Nederlandse Organisatie van Verloskundigen (Royal Dutch Organisation of Midwives)

NVOG: Nederlandse Vereniging van Obstetrie en Gynaecologie (Dutch Society of Obstetricians and Gynaecologists)

LQWLQ: The Leiden Quality of Work Life Questionnaire

MCAR: M issing Completely at Random

RCM : The Royal College of Midwives of the UK

COCM : Continuity of Care Model

\section{Declarations.}

Ethics and consent to participate.

This study is part of a larger study ${ }^{21}$ that was submitted to the medical ethics committee of VU University M edical Centre (reference number 2014/030). The study was approved. Ethical approval was not considered necessary according to Dutch legislation ${ }^{22}$. 
Consent. Not Applicable

Availability of data and materials.

Data were stored electronically in an encrypted database. Copies of datasets used for this study may be available from the corresponding author on reasonable request.

Competing interests.

The authors declare no competing interests.

Funding.

No funding was obtained for this study.

Authors 'contributions.

$D C, H P, C V \& M R$ designed the study DC, HP, MH \& M R undertook the analysis, DC wrote the article with substantial assistance and contributions from HP, CV , SJ, M H RdV \& M R. All authors have read and approved the manuscript

Acknowledgements.

The authors would like to thank Dr. v.d. Doef for the permission to adapt and use the Leiden Quality of Work Questionnaire.

\section{References.}

1) Rijks Overheid, Wet op de beroepen in de individuele gezondheidszorg (Laws for the Professions in Healthcare). 2016, http:// wetten.overheid.nl/BWBR0006251/2016-08-01.html accessed 23/2/2017.

2) Hingstman, L., \& Kenens, R. Numbers from the registration of midwives. (Nederlandse instituut voor onderzoek van de gezondheidszorg). 2015. Utrecht, The Netherlands. Nederlandse Zorg Autoriteit (Dutch Healthcare Authority). - BR / REG-19135. Beleidsregel verloskunde (Policy rule on obstetrics). Basis verloskundige zorgprestaties (Basic obstetric care performance) 2018. https://puc.overheid.nl/nza/doc/PUC_236323_22/1/

3) Amelink-Verburg M, Buitendijk S. Pregnancy and labour in the Dutch maternity care system: what is normal? The role division between 
midwives and obstetricians. J M idwifery and Women's Health. 2010 M ay-June; 55(3):216-25. doi: 10.1016/j.jmwh.2010.01.001.

4) Royal Dutch organization of midwives (KNOV). Dutch organization for obstetrics and gynecology (NVOG). Verloskundige Indicatielijst. 2014. Utrecht, the Netherlands. www.knov.nl/vakkennis-enwetenschap/tekstpagina/.../verloskundige-indicatie-lijst.

5) Cronie D, Rijnders M, Buitendijk S. Diversity in the Scope and Practice of Hospital-Based Midwives in the Netherlands. Journal of Midwifery \& Women's Health, 2012; 1526-9523.

6) van der Velden J. A good beginning: safe care around pregnancy and birth. Advice of the steering group pregnancy and birth. Rijks Overheid. 2009. http:// www.rijksoverheid.nl/enzwangerschap-en/x-cz2978049b.pdf/. Accessed 26th June 2016.

7) College Perinatale Zorg. Zorgstandaard 'Integrale geboortezorg' Versie 1.0 (care standard 'integrated birth care' version 1.0). College Perinatale Zorg, 2015. Utrecht, the Netherlands.

https:// www.kennisnetgeboortezorg.nl/kennisbank/college-perinatalezorg/documenten/9088-zorgstandaard-integrale-geboortezorg. Accessed 5 Nov 2018.

8) van der Doef. M, Maes S. The Leiden Quality of Work Questionnaire: its construction, factor structure, and psychometric qualities. Psychol Rep. 1999 Dec; 85(3 Pt 1):954-62.

9) Faragher EB, Cass $M$, Cooper $C L$. The relationship between job satisfaction and health: a meta-analysis. Occup Environ Med 2005; 62:105-112. doi: 10.1136/oem.2002.006734.

10) Atefi N, Abdullah KL, Wong LP, M azlom R. Factors influencing registered nurses perception of their overall job satisfaction: a qualitative study. Int Nurs Rev, 2014 Sep; 61(3):352-60. doi: 10.1111/inr.12112. Epub 2014 Jun 5.

11) Iliceto P, Pompili M, Spencer-Thomas S, Ferracuti S, Erbuto D, Lester D. et al. Occupational stress and psychopathology in health professionals: an explorative study with the multiple indicators multiple causes (M IM IC) model approach. Stress. 2013 M ar; 16(2):143-52. doi: 10.3109/10253890.2012.689896. Epub 2012 Jun 6. 
12) Toh S, Ang E, Devi MK. Systematic review on the relationship between the nursing shortage and job satisfaction, stress and burnout levels among nurses in oncology/haematology settings. Int J Evid Based Healthc. 2012 Jun; 10(2):126-41. doi: 10.1111/j.1744-1609.2012.00271.x.

13) Iliceto $P$, Pompili M, Spencer-Thomas $S$, Ferracuti S, Erbuto D, Lester D. et al. Occupational stress and psychopathology in health professionals: an explorative study with the multiple indicators multiple causes (M IM IC) model approach. Stress. 2013 Mar; 16(2):143-52. doi:

10.3109/10253890.2012.689896. Epub 2012 Jun 6.

14) Gedro J, Wang J. Creating Civil and Respectful Organizations Through the Scholar-Practitioner Bridge. Advances in Developing Human Resources August 2013 vol. 15 no. 3 284-295.

15) Sermeus W, Aiken LH, Van den Heede K, Rafferty AM, Griffiths P, M oreno-Casbas et al. Nurse forecasting in Europe (RN4CAST): Rationale, design and methodology. BM C Nurs. 2011 Apr 18; 10:6. doi: 10.1186/14726955-10-6.

16) Aiken L, Sermeus W, Van den Heede K, Sloane D, et al Patient safety, satisfaction, and quality of hospital care: cross sectional surveys of nurses and patients in 12 countries in Europe and the United States BMJ 2012;344:e1717.

17) Forster DA, M cLachlan HL, Davey MA, Biro MA, Farrell T, Gold L, et al. Continuity of care by a primary midwife (caseload midwifery) increases women's satisfaction with antenatal, intrapartum and postpartum care: results from the COSM OS randomised controlled trial. BM C Pregnancy Childbirth 2016 Feb 3; 16:28-016-0798-y.

18) Saber DA. Frontline registered nurse job satisfaction and predictors over three decades: a meta-analysis from 1980 to 2009.Nurs Outlook. 2014 NovDec; 62(6):402-14. doi: 10.1016/j.outlook.2014.05.004. Epub 2014 M ay 28.

19) Warmelink JC, Hoijtink K, Noppers M, Wiegers TA, de Cock TP, Klomp T. et al. An explorative study of factors contributing to the job satisfaction of primary care midwives. M idwifery. 2015 Apr; 31(4):482-8. doi:

10.1016/j.midw.2014.12.003. Epub 2015 Jan 2.

20) Collins CT, Fereday J, Pincombe J, Oster C, Turnbull D. An evaluation of the satisfaction of midwives' working in midwifery group practice. M idwifery. 2010 Aug; 26(4):435-41. doi: 10.1016/j.midw.2008.09.004. Epub 2009 Sep 24. 
21) Verhoeven, C. INCAS-2 (INtegrated CAre System) a study into integrated care in the Netherlands. 2017. http:// www.incas2.nl/ accessed 23/3/17.

22) Dutch Central Committee for Research Involving Human Subjects, CCM 0. 2017. (English Version) web site. http://www.ccmoonline. $\mathrm{nl} / \mathrm{main}$.asp/English/FAQ/WMO.

23) The Royal College of M idwives. Response to the NHS Working Longer Review Call for Evidence, 2013, RCM , London.

24) Bjørka I, Samdalb G, Hansenc B, Tørstadd S, Hamilton G. Job satisfaction in a Norwegian population of nurses: A questionnaire survey International Journal of Nursing Studies, 2007. 44; 747-757.

25) Pype P, Symons L, Wens J, Van den Eynden B, Stes A, Deveugele M. Health care professionals' perceptions towards lifelong learning in palliative care for general practitioners: a focus group study. BM C Fam Pract. 2014; 15: 36.

26) Koninklijke Nederlandse Organisatie van Verloskundigen (KNOV). Hoge startsalaris verloskundigen, KNOV, 2013. Utrecht, The Netherlands.

27) Creedy D, Sidebotham M, Gamble J, Pallant J, Fenwick J. Prevalence of burnout, depression, anxiety and stress in Australian midwives: a crosssectional survey BM C Pregnancy and Childbirth BM C 2017 17:13 DOI: 10.1186/s12884-016-1212-5.

28) Yoshida Y and Sandall J. Occupational burnout and work factors in community and hospital midwives: A survey analysis. M idwifery Volume 29, Issue 8, 2013, Pages 921-926.

29) Prosser D, Johnson S, Kuipers E, Szmukler G, Bebbington P, Thornicroft G. Burnout' and job satisfaction among hospital and community-based mental health staff. The British Journal of Psychiatry. 1996, 169 (3) 334337; DOI: 10.1192/bjp.169.3.334.

30) Grol, R., \& Grimshaw, J. From best evidence to best practice: Effective implementation of change in patients' care. The Lancet, 2003; 362, 12251230.

31) Cronie D, Rijnders M, de Vries, R and Buitendijk S. M aking Evidence Available for Hospital-Based Midwives: A Systematic Examination of the Content and M ethodological Quality of Three Protocols Used in Maternity Hospitals in the Netherlands International Journal of Childbirth; 2014 Volume 4, Issue 4.http://dx.doi.org/10.1891/2156-5287.4.4.208. 
32) Grol, R. Successes and failures in the implementation of evidence-based guidelines for clinical practice. M ed Care. 2001; 39: 46-54.

33) M akabe S, Takagai J, Asanuma Y, Ohtomo K, and Kimura Y. Impact of work-life imbalance on job satisfaction and quality of life among hospital nurses in Japan Ind. Health. 2015 M ar; 53(2): 152-159.

34) Tait D, Shanafelt M, Boone S, Tan Let al. Burnout and Satisfaction With Work-Life Balance Among US Physicians Relative to the General US Population Arch Intern M ed. 2012;172(18):1377-1385.

35) Howard S, Hordacre AL, M oretti C \& Spoehr J. Investigating flexible work arrangements: For nurses and midwives in the acute hospital sector. Adelaide: Australian Workplace Innovation and Social Research Centre, 2013. The University of Adelaide.

36) Wiegers $T$, Hukkelhoven $C$. The role of hospital midwives in the Netherlands BM C Pregnancy and Childbirth 2010 10:80.

37) Warmelink C, Wiegers T, de Cock P, Spelten E, Hutton K. Career plans of primary care midwives in the Netherlands and their intentions to leave the current job Hum Resour Health. 2015; 13: 29.

38) Peterson S, Spiker B. Establishing the Positive Contributory Value of Older Workers: A Positive Psychology Perspective. Organizational Dynamics, 2005 Vol. 34, No. 2, pp. 153-167.

39) Randall-Andrews D, Dziegielewski $S$. The nurse manager: job satisfaction, the nursing shortage and retention Journal of Nursing Management, 2005,Volume 13, Issue 4 Pages 286-295.

40) Warwick C. M idwives can no longer keep services afloat Nursing Standard, 2016, volume 31 number 12 / 16 p.27.

41) Carrieri $D$. Why are so many doctors leaving the profession: is the answer one, seven or forty-two? BMJ 2015;351:h6719.

42) Sumner J \& Townsend-Rocchiccioli J. Why are nurses leaving nursing? Nurs Adm Q. 2003 Apr-Jun;27(2):164-71.

43) O'Sullivan S. Why do midwives leave? RCM M idwives J. 2002 Jul;5(7):210.

44) Visser R. Caseload working. 2010. http://vroedvrouwenradicaalrebekka.blogspot.nl/2010/11/caseload-werken.html accessed 31/1/17. 
45) Newton M, M cLachlan H, Willis K, and Forster D. Comparing satisfaction and burnout between caseload and standard care midwives: findings from two cross-sectional surveys conducted in Victoria, Australia BM C Pregnancy and Childbirth. 2014, 14:426 DOI: 10.1186/s12884-014-0426-7.

46) Sandall J: Midwives' burnout and continuity of care. Br J M idwifery 1997, 5:106-111.47) Clifford K. Who Cares for the Carers? Literature Review of Compassion Fatigue and Burnout in Military Health Professionals Journal of M ilitary and Veterans' Health, 2017. Volume 22 No. 3.

47) Ng T, Sorensen K, Eby L. Locus of control at work: a meta-analysis Journal of Organisational Behaviour Volume 27, Issue 8 December 2006 Pages 1057-1087.

48) Royal College of M idwives. RCM Caring for You Charter. 2017. http:// www.rcm.org.uk/caringforyou.html accessed 1/2/17.

49) M oran M, Banks D. An exploration of the value of the role of the mentor and mentoring in midwifery. Nurse Educ Today. 2016 M ay;40:52-6. doi: 10.1016/j.nedt.2016.02.010. Epub 2016 Feb 19.

50) Ng T, Sorensen K, Eby L. Locus of control at work: a meta-analysis Journal of Organisational Behaviour Volume 27, Issue 8 December 2006 Pages 1057-1087.

51) Saber D. Frontline registered nurse job satisfaction and predictors over three decades: a meta-analysis from 1980 to 2009. 2014, Nursing Outlook Volume 62, Issue 6, November-December 2014, Pages 402-414.

52) Basaka, R Ghoshb, A. School Environment and Locus of Control in Relation to Job Satisfaction among School Teachers - A Study from Indian Perspective. Procedia - Social and Behavioral Sciences Volume 29, 2011, Pages 1199-1208.

53) Adegoke A, Atiyaye F, Abubakar A, Auta A, Aboda A. Job satisfaction and retention of midwives in rural Nigeria. M idwifery. 2015 Oct;31(10):946-56. doi: 10.1016/j.midw.2015.06.010. Epub 2015 Jun 23.

54) Shen J, Cox A, M cBride A. Factors influencing turnover and retention of midwives and consultants: a literature review. Health Serv M anage Res. 2004 Nov;17(4):249-62.

55) Evans J, Lambert T, Goldacre M. GP recruitment and retention: a qualitative analysis of doctors' comments about training for and working in general practice. Occas Pap R Coll Gen Pract. 2002 Feb;(83):iii-vi, 1-33. 
56) Coomber B, Barriball K. Impact of job satisfaction components on intent to leave and turnover for hospital-based nurses: a review of the research literature. Int J Nurs Stud. 2007 Feb;44(2):297-314. Epub 2006 Apr 24.

57)The European Union. Working Time Directive (2003/88/EC) http://ec.europa.eu/social/main.html accessed 1/2/2017.

58) Rijks Overheid. Specifieke regels arbeidstijden zorgsector. 2010. https://www.rijksoverheid.nl/documenten/brochures/2010/09/02/specifiek e-regels-arbeidstijden-zorgsector.html accessed 1/2/2017.

59) De Vries R, Nieuwenhuijze M, Buitendijk S. What does it take to have a strong and independent profession of midwifery? Lessons from the Netherlands. Midwifery. 2013 Oct;29(10):1122-8. doi:

10.1016/j.midw.2013.07.007. Epub 2013 Aug 2. 


\section{5 \\ Experienced job \\ autonomy among \\ maternity care \\ professionals in the \\ Netherlands.}

Hilde Perdok, RM, M Sc, Doug Cronie, M A, RM, RN, Cecile van der

Speld, RM, MSC, Jeroen van Dillen, MD, PhD, Ank de Jonge, RM, PhD, M arlies Rijnders, RM, PhD, Irene de Graaf, MD, PhD François G Schellevis, MD, PhD, Corine J. Verhoeven, RM, PhD

Birth 2015, 42 (2): 156-64. 
Abstract

Objective: High levels of experienced job autonomy are found to be beneficial for healthcare professionals and for the relationship with their patients. The aim of this study was to assess how maternity care professionals in the Netherlands perceive their job autonomy in the Dutch maternity care system and whether they expect a new system of integrated maternity care to affect their experienced job autonomy.

Design: A cross-sectional survey. The Leiden Quality of Work Life Questionnaire was used to assess experienced job autonomy among maternity care professionals.

Setting: Data were collected in the Netherlands in 2015.

Participants: 799 professionals participated of whom 362 were primary care midwives, 240 obstetricians, 93 clinical midwives and 104 obstetric nurses.

Findings: The mean score for experienced job autonomy was highest for primary care midwives, followed by obstetricians, clinical midwives and obstetric nurses. Primary care midwives scored highest in expecting to lose their job autonomy in an integrated care system.

Key conclusions: There are significant differences in experienced job autonomy between maternity care professionals.

Implications for practice: When changing the maternity care system it will be a challenge to maintain a high level of experienced job autonomy for professionals. A decrease in job autonomy could lead to a reduction in job related wellbeing and in satisfaction with care among pregnant women. 
Introduction

Job related wellbeing and satisfaction is of importance both for maternity care professionals and for the women they take care of. Job autonomy, defined as the degree of control a worker has over his or her own immediate scheduling and tasks (Liu et al., 2005), is one of the conditions that influence job related wellbeing and satisfaction (Katerndahl et al., 2009). In various professional groups a linear relationship was found between experienced job autonomy and job satisfaction (Busis et al., 2017; Jerkovic-Cosic et al., 2012; Katerndahl et al., 2009; Scheurer et al., 2009). Job autonomy is of high importance as it protects healthcare professionals against somatic complaints, psychological distress in their work, and burnout (de Jonge, 1998).

Besides the positive effects for the maternity care professional, a high level of job autonomy is shown to have a positive effect on the empowerment of women and has a positive influence on the professional-patient relationship (Walsh and Devane, 2012). This can be clarified by the correlation between jobautonomy, job related stress and satisfaction of professionals, with patient satisfaction and quality of care (Forster et al., 2016).

$M$ aternity care services are shifting the focus of care from the professional and organisational interests to the interests of women and their family (Watkins et al., 2017). Organisational changes and job uncertainty can influence job conditions such as job autonomy (Hodnett et al., 2013). As the Netherlands is in the process of changing the maternity care system, this may influence the level of experienced job autonomy of professionals. Shifting towards a system of integrated care provided by professionals from multiple disciplines, will result in professionals working together in taking care of women. This might possibly influence autonomous decision making of both midwives and obstetricians in the Netherlands.

Similar to midwifery care in countries such as Canada (Canadian Association of M idwives, 2010) and New Zealand (Grigg and Tracy, 2013), the current maternity care system in the Netherlands is characterised by risk-selection. However, in contrast to these countries, in the Netherlands different professionals provide segmented perinatal maternity care. Primary care midwives in the Netherlands are independent practitioners with a legally defined sphere of practice and work in a community setting (Amelink-Verburg and Buitendijk, 2010). Primary care midwives are responsible for risk selection and autonomously provide care to women at low risk for complications during pregnancy, labour and in the post-partum period. Women at low risk for complications can choose to give birth either at home, in a hospital or in a birth 
centre. At the onset of antenatal care $86 \%$ of all women in the Netherlands receive midwife-led care (College Perinatale Zorg, 2016; Utrecht: Perined, 2016). During pregnancy and labour, women at increased risk or with a complication are referred to secondary, obstetrician-led care in a hospital setting. In this setting women are assisted by obstetricians, residents, clinical midwives (midwives who work in a hospital setting) and obstetric nurses. At the onset of labour $51 \%$ of all women are in midwife-led care and approximately $29 \%$ of all births eventually take place in primary midwife-led care (Utrecht: Perined, 2016).

Due to supposed relatively high perinatal mortality rates in the Netherlands (M ohangoo et al., 2008) the Dutch maternity care system has become the subject of debate. It has been suggested that closer collaboration between primary and secondary care would lead to better quality of care and fewer perinatal deaths (Advies Stuurgroep zwangerschap en geboorte, 2009). Some argued that reorganising maternity care and combining primary and secondary care into one system might result in better outcomes (Evers et al., 2010; Posthumus et al., 2013). Others have pleaded for experimenting with different types of organisation of care and evaluating these experiments before changing the system (Prins et al., 2014). However, although professional organisations of both obstetricians and midwives are positive regarding the integration of maternity care, and a guideline for integrated care has been published (College Perinatale Zorg, 2016), opinions differ with regard to the optimal organisational structure (Perdok et al., 2016b). A complicating factor is that historically there have been tensions between midwives and obstetricians in the Netherlands due to a power imbalance, which still plays a role now. According to van der Lee et al., the establishment of professional boundaries has undermined effective teamwork and inter-professional collaboration (van der Lee et al., 2014). This has led, in some cases to midwives and obstetricians not perceiving themselves as equals within the team (Lee, 2014).

Integrated care is expected to lead to a shift in professionals' tasks and responsibilities and more professionals taking care of women, which could affect experienced job autonomy (Posthumus et al., 2013). For a successful implementation of integrated maternity care, it is of importance that the autonomy of different professionals within the team is maintained (Perdok et al., 2016a). To evaluate the effect of new models in the maternity care system it is vital to measure experienced job autonomy in the current system. The findings are also relevant to other countries that are in the process of changing their maternity care system. 
The aims of this study were to assess how maternity care professionals in the Netherlands perceive their job autonomy and whether professionals expect to lose job autonomy in a system of integrated maternity care.

\section{Methods}

Data were used from a broad survey among professionals in maternity care including midwives, obstetricians, obstetric nurses, maternity care assistants and paediatricians.

For this study we used data from obstetricians, midwives and obstetric nurses in the Netherlands. We focused on these groups because we expect a shift in these professionals' tasks and responsibilities.

Data were collected using a self-administered online questionnaire (Survey M onkey, Palo, Alto, CA, USA), from February 2015 till M ay 2015.

The questionnaire contained 126 questions on multiple aspects of maternity care. For the present study only the questions on demographic characteristics and perceived job autonomy were used.

In the Netherlands a total of 3150 midwives (Netherlands Institute for Health Services Research (NIVEL), 2016), 959 obstetricians and 2835 nurses are active in maternity care (Intelligence group, 2017). The majority of midwives, 2231 (71\%), work in primary care and 919 (29\%), work as clinical midwives (Netherlands Institute for Health Services Research (NIVEL), 2016). The majority of Dutch obstetricians provide obstetric care but 298 are member of the Dutch Society for Obstetrics and Gynaecology (NVOG) working group perinatology and maternal diseases and presumably have obstetrics as their main field of practice.

In order to reach an appropriate sample of primary care midwives for this study, invitations were sent by e-mail (where the e-mail address could be obtained from their website) to 452 midwifery practices from a total of 532 practices (Netherlands Institute for Health Services Research (NIVEL), 2016) in the Netherlands in 2015.

To reach obstetricians, clinical midwives and obstetric nurses an e-mail was sent to a contact person of all 91 Dutch hospitals with an obstetric department. The e-mail contained information on the study and a link to the survey. Addressees in midwifery practices and obstetric departments were asked to distribute the invitation e-mail among colleagues. 
In addition to this, the Royal Dutch Organisation of Midwives (KNOV) of whom $84 \%$ of all midwives are a member, placed a notification on their website asking midwives to participate in this study. There was no restriction on the number of participants per hospital or practice.

All midwifery practices and obstetric departments received a reminder by email in M arch 2015. Only non-identifiable information was available for the researchers who analysed the data.

\section{Measures}

Job conditions were assessed with the Leiden Quality of Work Life Questionnaire for Nurses (LQWLQ-N) developed by van der Doef (van der Doef and $M$ aes, 1999). This questionnaire is a validated instrument to examine job satisfaction, of which "decision authority" is a characteristic, among nurses. The formulations of the questions were adjusted for maternity care professionals in consultation with the author of the instrument.

Job conditions were measured on a 4-point Likert-like scale ranging from 1 (totally disagree) to 4 (totally agree). Higher scores correlate with better job conditions. For the purpose of this study the domain "decision authority" was used to measure experienced job autonomy, which was defined as the mean of the five questions in this domain. This domain has five statements:

I continuously have to perform tasks I am ordered to do

In my work I am allowed to make decisions myself

I have a say in decisions related to work

I am free to choose when to do client related and non-client related tasks

I am free to perform my tasks according to my own insight.

Regarding the demographic characteristics information was collected on age, number of years of work experience and the number of working hours per week.

A steering group with representatives from obstetricians, midwives, obstetric nurses, paediatricians, clients and researchers was consulted and advised on all steps during the research process.

Ethical considerations 
The study was submitted to the medical ethics committee of VU University M edical Centre (reference number 2014/030). Ethical approval was not considered necessary according to Dutch legislation (M ETc-VUmc, 2015).

Data analysis

The data were analysed using SPSS version 24.0 (SPSS, Inc., Chicago, IL, USA).

Descriptive statistics were computed and normality of the distribution of the outcome measure was examined. The scores were calculated as the mean of the items in the domain's subscale. Participants with more than one missing value within a subscale were excluded (van der Doef and Maes, 1999).

Independent ANOVA was used to examine the level of job autonomy of the professionals and their future perspective of job autonomy. A p-value of 0.05 or lower was considered statistically significant.

M ultivariable linear regression analyses were performed to adjust for age, years of work experience and number of working hours per week, which might be associated with experienced job autonomy.

Findings

A total of 1896 professionals responded to the questionnaire, of whom 799 completed at least four questions of the domain "decision authority". Of the 91 obstetric hospital departments who were approached, respondents came from 88 departments. The number of midwifery practices from whom midwives participated was 242 ( $54 \%$ of the invited practices) and all provinces were represented in our sample. Analysis of incomplete responses in SPSS showed that data were missing completely at random (MCAR).

Table 1. Characteristics of participating maternity care professionals

\begin{tabular}{|c|l|l|l|l|l|}
\hline & $\begin{array}{l}\text { Total population } \\
n=799 \\
(100 \%)\end{array}$ & $\begin{array}{l}\text { Primary care } \\
\text { midwives } \\
n=362 \\
(45.3 \%)\end{array}$ & $\begin{array}{l}\text { Obstetricians } \\
n=240 \\
(30.0 \%)\end{array}$ & $\begin{array}{l}\text { Clinical } \\
\text { Midwives } \\
n=93 \\
(11.6 \%)\end{array}$ & $\begin{array}{l}\text { Obstetric nurses } \\
n=104 \\
(13.1 \%)\end{array}$ \\
\hline $\begin{array}{l}\text { Age in years } \\
\text { Mean (SD) }\end{array}$ & $\begin{array}{l}41.5 \\
(10.68)\end{array}$ & $\begin{array}{l}38.2 \\
(10.65)\end{array}$ & $\begin{array}{l}44.1 \\
(10.01)\end{array}$ & $\begin{array}{l}42.1 \\
(9.66)\end{array}$ & $\begin{array}{l}46.5 \\
(9.63)\end{array}$ \\
\hline $\begin{array}{l}\text { Years of work } \\
\text { experience }\end{array}$ & $\begin{array}{l}14.7 \\
\text { Mean (SD) }\end{array}$ & $\begin{array}{l}13.1 \\
(8.60)\end{array}$ & $\begin{array}{l}14.0 \\
(9.96)\end{array}$ & $\begin{array}{l}16.3 \\
(8.91)\end{array}$ & $\begin{array}{l}20.7 \\
(9.02)\end{array}$ \\
\hline
\end{tabular}




\begin{tabular}{|l|l|l|l|l|l|}
\hline $\begin{array}{l}\text { Working } \\
\text { hours/week } \\
\text { (SD) }\end{array}$ & $\begin{array}{l}40.6 \\
(14.00)\end{array}$ & $\begin{array}{l}43.4 \\
(14.84)\end{array}$ & $\begin{array}{l}47.2 \\
(9.85)\end{array}$ & $\begin{array}{l}28.8 \\
(5.53)\end{array}$ & $\begin{array}{l}26.3 \\
(5.66)\end{array}$ \\
\hline
\end{tabular}

In total 799 participants were included of whom 362 were primary care midwives, 93 clinical midwives, 240 obstetricians and 104 obstetric nurses.

The mean age of obstetric nurses was the highest with 46.5 years and the primary care midwives had the lowest mean age of 38.2 years. In line with this, the obstetric nurses had the longest work experience with nearly 20.7 compared to 13.1 years for primary care midwives. The obstetricians scored highest in the mean number of working hours with 47.2 hours of work per week.

In Table 2 the experienced job autonomy scores are presented for the different maternity care professionals. Adjustment for age, number of years of work experience and number of working hours per week showed minor changes in the regression coefficients compared to the bivariate analysis. Primary care midwives had a significantly higher score (mean 2.94 on a 4-point scale) for experienced job autonomy compared to obstetricians (mean 2.73), clinical midwives (mean 2.70) and obstetric nurses (2.61).

Table 2. Experienced job autonomy scores by professional group (means ( \pm SD) and adjusted means with $95 \%$ Confidence Interval (CI))

\begin{tabular}{|c|c|c|}
\hline & $\begin{array}{l}\text { Experienced autonomy } \\
\text { Mean (SD) }\end{array}$ & $\begin{array}{l}\text { Experienced autonomy } \\
\text { Adjusted mean* } \\
(95 \% \mathrm{Cl})\end{array}$ \\
\hline $\begin{array}{l}\text { Primary care midwives } \\
(\mathrm{n}=362)\end{array}$ & $3.07(0.40)$ & $\begin{array}{l}2.94 \\
(2.77-3.11)\end{array}$ \\
\hline $\begin{array}{l}\text { Obstetricians } \\
(n=240)\end{array}$ & $2.88(0.37)$ & $\begin{array}{l}2.73 \\
(2.53-2.92)\end{array}$ \\
\hline $\begin{array}{l}\text { Clinical midwives } \\
(n=93)\end{array}$ & $2.82(0.39)$ & $\begin{array}{l}2.70 \\
(2.53-2.88)\end{array}$ \\
\hline Obstetric nurses ( $n=104)$ & $2.73(0.38)$ & $\begin{array}{l}2.61 \\
(2.44-2.79)\end{array}$ \\
\hline
\end{tabular}


Table 3 shows the item (statement) means and total subscale score of experienced job autonomy for the different professional groups. The lowest score given by all professionals was for the statement "I am free to choose when to do client related and non-client related tasks".

Table 3. Item means and total subscale score of experienced job autonomy (means and SD)

\begin{tabular}{|c|c|c|c|c|}
\hline & $\begin{array}{l}\text { Primary care } \\
\text { midwives } n=362\end{array}$ & Obstetricians $n=240$ & $\begin{array}{l}\text { Clinical midwives } \\
n=93\end{array}$ & $\begin{array}{l}\text { Obstetric nurses } \\
n=104\end{array}$ \\
\hline $\begin{array}{l}\text { I continuously } \\
\text { have to perform } \\
\text { tasks that I am } \\
\text { ordered to do* }\end{array}$ & $\begin{array}{l}3.10 \\
(0.56)\end{array}$ & $\begin{array}{l}3.15 \\
(0.50)\end{array}$ & $\begin{array}{l}3.00 \\
(0.44)\end{array}$ & $\begin{array}{l}2.84 \\
(0.58)\end{array}$ \\
\hline $\begin{array}{l}\text { In my work I am } \\
\text { allowed to make } \\
\text { decisions myself }\end{array}$ & $\begin{array}{l}3.20 \\
(0.53)\end{array}$ & $\begin{array}{l}3.27 \\
(0.49)\end{array}$ & $\begin{array}{l}3.11 \\
(0.50)\end{array}$ & $\begin{array}{l}2.96 \\
(0.42)\end{array}$ \\
\hline $\begin{array}{l}\text { I have a say in } \\
\text { decisions related } \\
\text { to work }\end{array}$ & $\begin{array}{l}3.16 \\
(0.56)\end{array}$ & $\begin{array}{l}3.22 \\
(0.46)\end{array}$ & $\begin{array}{l}2.97 \\
(0.60)\end{array}$ & $\begin{array}{l}2.86 \\
(0.53)\end{array}$ \\
\hline $\begin{array}{l}\text { I am free to } \\
\text { choose when to } \\
\text { do client related } \\
\text { and non-client } \\
\text { related tasks }\end{array}$ & $\begin{array}{l}2.85 \\
(0.67)\end{array}$ & $\begin{array}{l}2.11 \\
(0.69)\end{array}$ & $\begin{array}{l}2.25 \\
(0.64)\end{array}$ & $\begin{array}{l}2.22 \\
(0.61)\end{array}$ \\
\hline $\begin{array}{l}\text { I am free to } \\
\text { perform my tasks } \\
\text { according to my } \\
\text { own insight. }\end{array}$ & $\begin{array}{l}3.04 \\
(0.53)\end{array}$ & $\begin{array}{l}2.65 \\
(0.62)\end{array}$ & $\begin{array}{l}2.78 \\
(0.57)\end{array}$ & $\begin{array}{l}2.74 \\
(0.48)\end{array}$ \\
\hline Total scale score & $\begin{array}{l}3.07 \\
(0.40)\end{array}$ & $\begin{array}{l}2.88 \\
(0.37)\end{array}$ & $\begin{array}{l}2.82 \\
(0.39)\end{array}$ & $\begin{array}{l}2.73 \\
(0.38)\end{array}$ \\
\hline
\end{tabular}


In Table 4 the scores for the statement "In the future I expect to lose autonomy" are presented. Primary care midwives scored highest (mean 2.43), followed by obstetric nurses (mean 2.06), obstetricians (mean 1.99) and clinical midwives (mean 1.92).

Table 4. Scores on questionnaire item "Future perspective: I expect to lose autonomy in an integrated care system" by professional group (means ( \pm SD) and adjusted means with $95 \%$ Confidence Interval (CI))

\begin{tabular}{|c|c|c|}
\hline & $\begin{array}{l}\text { Mean } \\
\text { (SD) }\end{array}$ & $\begin{array}{l}\text { Adjusted mean* } \\
(95 \% \mathrm{Cl})\end{array}$ \\
\hline $\begin{array}{l}\text { Primary care midwives } \\
(n=362)\end{array}$ & $2.61(0.78)$ & $2.43(2.13-2.73)$ \\
\hline Obstetricians ( $n=240$ ) & $2.19(0.64)$ & $1.99(1.65-2.34)$ \\
\hline Clinical midwives $(n=93)$ & $2.11(0.64)$ & $\begin{array}{l}1.92 \\
(1.61-2.22)\end{array}$ \\
\hline Obstetric nurses ( $n=104$ ) & $2.30(0.50)$ & $\begin{array}{l}2.06 \\
(1.76-2.38)\end{array}$ \\
\hline
\end{tabular}

\section{Discussion}

In our study, which relates to the current model of midwifery care in the Netherlands, primary care midwives had a significantly higher score for job autonomy compared to obstetricians, clinical midwives and obstetric nurses. Primary care midwives also scored highest with regards to their future perspective of losing job autonomy, in a system of integrated maternity care.

Literature suggests that working outside a hospital setting is related to higher job satisfaction, primarily due to higher experienced job autonomy (M cCourt et al., 2014a, 2014b; Pron, 2013). This is in line with our study, which shows that self-employed primary care midwives, who work outside the hospital, experienced the highest level of job autonomy. This corresponds with obstetricians in the Netherlands who are self-employed (mostly in peripheral hospitals) experiencing a higher level of job-autonomy compared to obstetricians employed by hospitals (mostly in academic hospitals) (Hugen, 2016). Our study shows that primary care midwives score highest in expecting to lose job autonomy in a new, integrated maternity care system. This is in contrast to clinical midwives who have a lower expectation to lose their job 
autonomy. An explanation for this could be that, since clinical midwives already work under the supervision of an obstetrician in the current system, they do not expect much change in job autonomy. Surprisingly, the obstetric nurses who also work under supervision, score second highest in the expectation to lose their job autonomy. This could be caused by the fact that nurses seem to be highly satisfied with their job, and they generally attributed this satisfaction to the autonomy they were granted through delegation of tasks (meaning an intentional transfer of clinical tasks from one professional to another healthcare professional). (Riisgaard et al., 2016). Possibly, their expectation to lose job autonomy is caused by their expectation of a change in task delegation.

The obstetricians, clinical midwives and nurses in our study scored lower on experienced job autonomy compared to the primary care midwife. This could be caused by the widespread use of protocols and a more prescriptive form of maternity care in hospitals leading to a more regulated form of practice (Coyle et al., 2001).

Even though there were differences in experienced job autonomy between the professionals, in our study all professionals scored at least 2.7 on a scale of 4 . A sense of job autonomy is of importance for professionals themselves as it can protect them from burnout (de Jonge, 1998). As well as this, a higher sense of job autonomy among midwives in midwife-led care settings is shown to have a positive effect on the empowerment of women and has a positive influence on the professional-patient relationship (Walsh and Devane, 2012).

Therefore, care must be taken to maintain a high level of job autonomy amongst all professionals when moving to a system of integrated maternity care.

Successful implementation of new staffing models requires fulfilment of certain preconditions. One of these conditions is that staff must be empowered and supported to establish their own ways of working which can increase professional autonomy (NHS National maternity review report, 2016). One example of a successful, alternative model is a self-directed nursing service "Buurtzorg" (neighbourhood care) in the Netherlands, which provides patientcentred home care. Under this model the organisation values professional autonomy and delivers care through small, local, self-managing nursing teams. Buurtzorg clients appreciate the consistent, compassionate and autonomous care. This is reflected in high levels of satisfaction in national surveys (Kreitzer et al., 2015). A recent study among nursing staff confirms that a higher degree of self-direction (self-perceived autonomy over patient care) leads to higher 
satisfaction levels (M aurits et al., 2017). Another example is caseload midwifery, as a model of care whereby childbearing women receive their antenatal-, intrapartum- and postnatal care from one midwife, which leads to higher levels of experienced autonomy and increased job satisfaction among professionals (Edmondson and Walker, 2014). As well as this caseload midwifery increases women's satisfaction with antenatal, intrapartum and postpartum care (Forster et al., 2016).

Although it has been shown that job autonomy is of importance in different maternity care systems (Forster et al., 2016; Lavender and Chapple, 2004), there seems to be tension between job autonomy and collaboration between professionals (van der Lee et al., 2016). Literature shows that good collaboration of maternity care professionals, improves the quality of care (Hunter et al., 2008). Therefore, the challenge lies in finding the balance between maintaining a high level of job autonomy among professionals and good collaboration between professionals based on the needs of women. Lack of a clear definition, consensus and coordination between practitioners, researchers and policy leaders in relation to the concept of collaboration (Perdok et al., 2014, 2016a) adds to the challenge of finding this balance.

\section{Strengths and limitations}

A strength of this study is that different maternity care professionals were included whereas most studies focus on only one professional group (Pron, 2013). In addition, we received responses from the majority of primary care midwifery practices and hospitals with an obstetric department in the Netherlands, therefore giving a reliable picture of the views of professionals.

A limitation of this study is that the exact response rate of the participants cannot be established due to the method of (snowball) sampling. M idwifery practices and obstetric departments were invited by e-mail. Individuals did not receive a personalised link to the survey and therefore no information could be traced back to the respondents. In addition with the anonymity of the respondents, no information is available on the non-respondents and possible selection bias. Due to snowball-sampling the distribution of the recruitment email depended on the willingness of the person who was responsible for the practices' e-mail. However, this was mitigated by the invitations on the professional groups' websites to participate.

The general idea that people are naturally reluctant to change must be taken into account when interpreting the results of this study. 
Furthermore, the LQWLQ was validated to measure overall job-satisfaction among nurses whereas we focused our research on the domain of job autonomy and included obstetric nurses, midwives and obstetricians. As the LQWLQ does include the characteristic decision-authority, which was used to measure experienced job autonomy, we consider this a reliable instrument for our study.

Future research considering individual elements of job satisfaction may examine a separate validation of each the domains within the questionnaire.

More research is needed to explore how to optimise collaboration between professionals in order to improve the quality of maternity care and maintain the high level of job satisfaction.

\section{Conclusions}

This study shows that there is a significant difference in experienced job autonomy between maternity care professionals. Primary care midwives working in the community experienced the highest level of job autonomy and scored highest in expecting to lose their job autonomy in an integrated maternity care system.

Since a decrease in job autonomy could have a negative impact on job related wellbeing and satisfaction among professionals and the women for whom they care, the challenge is to maintain a high level of experienced job autonomy when changing the maternity care system. Further research is needed to evaluate experienced job autonomy in a system of integrated maternity care and its effect on the wellbeing of professionals involved as well as on patient care.

\section{Ethical approval}

The study was submitted to the medical ethics committee of VU University M edical Centre (reference number 2014/030). Ethical approval was not considered necessary according to Dutch legislation (METc-VUmc 2015).

\section{Acknowledgements}

We gratefully thank van der Doef for her advice in this study and the professionals who participated in this study.

Funding Sources 
HP was supported by a grant of the Royal Dutch Organization of Midwives. The sponsor did not play a role in the collection, analysis or interpretation of the data, or in the writing of the manuscript.

Conflict of interest

The authors declare that they have no competing interests. 
References

Advies Stuurgroep zwangerschap en geboorte, 2009. Een goed begin: veilige zorg rond zwangerschap en geboorte.

M.P. Amelink-Verburg, S.E. Buitendijk. Pregnancy and labour in the Dutch maternity care system: what is normal? The role division between midwives and obstetricians. Journal of M idwifery Women's health, 55 (2010), pp. 216225

N.A. Busis, T.D. Shanafelt, C.M. Keran, K.H. Levin, H.B. Schwarz, J.R. M olano, T.R. Vidic, J.S. Kass, J.M. M iyasaki, J.A. Sloan, T.L. Cascino. Burnout, career satisfaction, and well-being among US neurologists in 2016. Neurology, 88 (2017), pp. 797-808

Canadian Association of M idwives, 2010. Position statement. Midwifery care and normal birth.

http://www.canadianmidwives.org/DATA/DOCUM ENT/CAM_ENG_M idwifery_ Care_Normal_Birth_FINAL_Nov_2010.pdf). (Accessed 1 December 2016).

College Perinatale Zorg, 2016. Zorgstandaard Integrale Geboortezorg. https://www.zorginzicht.nl/bibliotheek/integrale-geboortezorgzorgstandaard/RegisterKwaliteitsstandaardenDocumenten/Zorgstandaard_Inte grale_Geboortezorg_versie_1_1.pdf〉. Accessed 2/28 2017.

K.L. Coyle, Y. Hauck, P. Percival, L.J. Kristjanson. Ongoing relationships with a personal focus: mothers' perceptions of birth centre versus hospital care. M idwifery, 17 (2001), pp. 171-181

de Jonge, J. 1998. Job Characteristics and Employee Well-being: A test of Warr's Vitamin Model in Health Care Workers Using Structural Equation Modelling. 19. pp. 387-407.

M.C. Edmondson, S.B. Walker. Working in caseload midwifery care: the experience of midwives working in a birth centre in North Queensland. Women and Birth: Journal of the Australian College of Midwives, 27 (2014), pp. 31-36

A.C. Evers, H.A. Brouwers, C.W. Hukkelhoven, P.G. Nikkels, J. Boon, A. van Egmond-Linden, J. Hillegersberg, Y.S. Snuif, S. Sterken-Hooisma, H.W. Bruinse, A. Kwee. Perinatal mortality and severe morbidity in low and high risk term pregnancies in the Netherlands: prospective cohort study. British Medical Journal (Clinical research ed.), 341 (2010), p. c5639D.A. Forster, H.L. M cLachlan, M.A. Davey, M.A. Biro, T. Farrell, L. Gold, M. Flood, T. Shafiei, U. Waldenstrom. Continuity of care by a primary midwife (caseload midwifery) increases 
women's satisfaction with antenatal, intra-partum and postpartum care: results from the COSM OS randomised controlled trial. BM C Pregnancy and Childbirth, 16 (2016), p. 28 (016-0798-y)

C.P. Grigg, S.K. Tracy. New Zealand's unique maternity system. Women and Birth: Journal of the Australian College of Midwives, 26 (2013), pp. e59-e64

E.D. Hodnett, S. Gates, G.J. Hofmeyr, C. Sakala. Continuous support for women during childbirth. The Cochrane Database of Systematic Reviews, 7 (2013) (CD003766)

Hugen, B., 2016. Van autonomie naar zeggenschap.

https://www.erasmuscentrumzorgbestuur.nl/dynamic/media/24/documents/b art_hugenthesis.pdf. (Accessed 11 June 2017).

B. Hunter, M. Berg, I. Lundgren, O.A. Olafsdottir, M. Kirkham. Relationships: the hidden threads in the tapestry of maternity care. Midwifery, 24 (2008), pp. 132137

Intelligence group, 2017. De arbeidsmarkt van $0 \& G$ verpleegkundigen in beweging 2012. https:// www. intelligence-group.nl/nieuws/april-2012/Dearbeidsmarkt-van-0-en-G-verpleegkundigen-in-beweging. (Accessed 19 January 2017).

K. Jerkovic-Cosic, M.A. van Offenbeek, C.P. van der Schans. Job satisfaction and job content in Dutch dental hygienists. International Journal of Dental Hygiene, 10 (2012), pp. 155-162

D. Katerndahl, M. Parchman, R. Wood. Perceived complexity of care, perceived autonomy, and career satisfaction among primary care physicians. Journal of the American Board of Family M edicine, 22 (2009), pp. 24-33

M.J. Kreitzer, K.A. Monsen, S. Nandram, J. de Blok. Buurtzorg Nederland: a global model of social innovation, change, and whole-systems healing. Global Advances in Health and M edicine: Improving Healthcare Outcomes Worldwide, 4 (2015), pp. 40-44

T. Lavender, J. Chapple. An exploration of midwives' views of the current system of maternity care in England. M idwifery, 20 (2004), pp. 324-334

Lee, V.D.N., 2014. Tailoring CanM EDS for training in Obstetrics and Gynaecology in the Netherlands. 
C. Liu, P. E. Spector, S. M. Jex. The relation of job control with job strains: a comparison of multiple data sources. Journal of Occupational and Organisational Psychology, 78 (2005), pp. 325-336

E.E. M aurits, A.J. De Veer, P.P. Groenewegen, A.L. Francke. Home-care nursing staff in self-directed teams are more satisfied with their job and feel they have more autonomy over patient care: a nationwide survey. Journal of Advanced Nursing (2017)

M cCourt, C., Rayment, J., Rance, S., Sandall, J., 2014b. An Ethnographic Organisational Study of Alongside M idwifery Units: a Follow-on Study from the Birthplace in England Programme.

METc-VUmc, 2015. Beslisboom WM 0-plechtigheid. www.vumc.nl/afdelingenthemas/nietwmobeslisboom.pdf. (Accessed $18 \mathrm{M}$ ay 2016).

A.D. M ohangoo, S.E. Buitendijk, C.W. Hukkelhoven, A.C. Ravelli, G.C. Rijninksvan Driel, P. Tamminga, J.G. Nijhuis. Higher perinatal mortality in The Netherlands than in other European countries: the Peristat-II study. Nederlands tijdschrift voor geneeskunde, 152 (2008), pp. 2718-2727

Netherlands Institute for Health Services Research (NIVEL), 2016. Registration of midwives 2015 verloskunde-academie.nl/wp-

content/ uploads/2016/02/Cijfers-uit-de-registratie-van-verloskundigen-peilingjan-2015.pdf. (Accessed 25 January 2017).

NHS National maternity review report, 2016. Better births: improving outcomes of maternity services in England. https:// www.england.nhs.uk/wpcontent/uploads/2016/02/national-maternity-review-report.pdf. (Accessed 19 January 2017).

H. Perdok, L. M okkink, D.J. van, M. Westerneng, S. Jans, B.W. Mol, J.A. de. Opinions of maternity care professionals about integration of care during labor for "moderate risk" indications: a Delphi study in the Netherlands. Birth, 41 (2014), pp. 195-205

H. Perdok, S. Jans, C. Verhoeven, L. Henneman, T. Wiegers, B.W. M ol, F. Schellevis, $A$. de Jonge. Opinions of maternity care professionals and other stakeholders about integration of maternity care: a qualitative study in the Netherlands. BM C Pregnancy and Childbirth, 16 (2016), p. 188 (016-0975-z)

H. Perdok, S. Jans, C. Verhoeven, J. van Dillen, R. Batenburg, B.W. M ol, F. Schellevis, A. de Jonge. Opinions of professionals about integrating midwifeand obstetrician-led care in The Netherlands. Midwifery, 37 (2016), pp. 9-18 
A.G. Posthumus, V.L. Scholmerich, A.J. Waelput, A.A. Vos, L.C. De Jong-Potjer, R. Bakker, G.J. Bonsel, P. Groenewegen, E.A. Steegers, S. Denktas. Bridging between professionals in perinatal care: towards shared care in the Netherlands. M aternal and Child Health Journal, 17 (2013), pp. 1981-1989

Prins, M., van Dillen, J., de Jonge, A., 2014. Advantages of midwife-led continuity model of care. PM ID:25017977 157, A7070.

A.L. Pron. Job satisfaction and perceived autonomy for nurse practitioners working in nurse-managed health centers. Journal of the American Association of Nurse Practitioners, 25 (2013), pp. 213-221

H. Riisgaard, J. Nexoe, J.V. Le, J. Sondergaard, L. Ledderer. Relations between task delegation and job satisfaction in general practice: a systematic literature review. BM C Family Practice, 17 (2016), p. 168

D. Scheurer, S. M cKean, J. M iller, T. Wetterneck. U.S. physician satisfaction: a systematic review. Journal of Hospital M edicine, 4 (2009), pp. 560-568 Utrecht: Perined, 2016. , 2. Perined. Perinatale Zorg in Nederland 2015 assets. perined.nl. (Accessed 25 January 2017).

M. van der Doef, S. M aes. The Leiden Quality of Work Questionnaire: its construction, factor structure, and psychometric qualities. Psychological Reports, 85 (1999), pp. 954-962

N. van der Lee, E.W. Driessen, E.S. Houwaart, N.C. Caccia, F. Scheele. An examination of the historical context of inter-professional collaboration in Dutch obstetrical care Journal of Inter-Professional Care, 28 (2014), pp. 123127

N. van der Lee, E.W. Driessen, F. Scheele. How the past influences interprofessional collaboration between obstetricians and midwives in the Netherlands: findings from a secondary analysis. Journal of Inter-Professional Care, 30 (2016), pp. 71-76

D. Walsh, D. Devane. A meta-synthesis of midwife-led care. Qualitative Health Research, 22 (2012), pp. 897-910 
V. Watkins, C. Nagle, B. Kent, A.M . Hutchinson. Labouring Together:

collaborative alliances in maternity care in Victoria, Australia-protocol of a

mixed-methods study. BMJ open 7, e014262, (2016-014262). 


\section{6}

How good is

collaboration between maternity

service providers in the Netherlands?

Doug Cronie

Marlies Rijnders

Suze Jans

Corine J Verhoeven

Raymond de Vries

Journal of M ultidisciplinary Healthcare 2019, 12: 21-30. 
Abstract

Aims: To examine the experiences with inter-professional collaboration of maternity-service providers in the Netherlands and to identify potential enhancing and inhibiting factors for inter-professional collaboration within maternity care in the Netherlands.

Background: Good collaboration between health care professionals is a key element of safe, effective care, but creating a collaborative culture can be challenging. Good collaboration requires, among other things, negotiating different professional orientations and the organizational constraints of hierarchies and scheduling.

Good collaboration is especially important in maternity care. In the Netherlands, sub-optimal collaboration has been cited as a significant factor in maternal deaths and in adverse incidents occurring in hospitals during evenings, nights, and weekends. In spite of its importance for effective maternity care, little is known about the nature and quality of collaboration between maternity care professionals. In order to fill this gap, we examined the inter-professional collaboration within multi-disciplinary teams providing maternity-services in the Netherlands.

M ethods: Online survey of multi-disciplinary teams (consisting of hospital and primary-care midwives, doctors and carers) involved in the provision of maternity services in the Netherlands. We used a validated measure of collaboration (the Leiden Quality of Work Questionnaire) to analyse the attitudes of those involved in the provision of maternity services about multidisciplinary collaboration in their work. We used descriptive and inferential statistics to assess differences between the groups.

Results: $40 \%$ of all respondents were not satisfied with collaboration within their multi-disciplinary team. Overall, mean collaboration scores were low. We found significant differences in mean collaboration scores between professional groups. Midwives - community and hospital based - were pessimistic about collaboration in future models of maternity care.

Discussion: In the Netherlands, collaboration in maternity care is less than optimal. Poor collaboration is associated with negative consequences for patient safety and quality of care. Strategies to address sub-optimal collaboration exist; however, no one-size-fits-all approach is identified in the literature. 
Conclusion: Sub-optimal collaboration exists within the midwifery model of care in the Netherlands and the relationship between care providers is under pressure. This could affect patient safety and quality of care, according to the literature.

Key words: interprofessional communication, communication, multidisciplinary team, interprofessional teamwork, interprofessional collaboration survey, questionnaire hospital midwife, primary-care midwife, midwifery, carer, doctor, nurse, maternity-care assistant, Integrated-care. 


\section{Background.}

Optimal collaboration between professionals involved in the provision of healthcare is known to be a critical element of safe, effective care ${ }^{1-3}$ and an essential feature of effective cost-management. ${ }^{4,5}$ Collaboration among the diverse professionals involved in the delivery of maternity care can be especially difficult: the challenges involved in creating a collaborative maternity care culture transcend countries and health systems. ${ }^{6,7}$

In the Netherlands, in spite of the fact that the current Dutch midwifery model is well-regarded internationally, ${ }^{8,9}$ there are significant challenges to optimum collaboration. Maternity services in the Netherlands are organised into primary (community) and secondary (hospital) care, making collaboration and communication especially important. ${ }^{10}$

$M$ idwives are the cornerstone of maternity-service provision in the Netherlands, managing more than $60 \%$ of all births. ${ }^{11}$ While the majority of Dutch midwives work in primary care ${ }^{12}$ where the emphasis is on normal physiology of birth, almost one-third of all midwives now practise in a hospital setting, where the emphasis is more towards pathology and births no longer defined as "physiological" (the Dutch term for a healthy birth).

Both groups of midwives commonly work in isolation from each other. Midwives working in primary care have developed good working relationships with other healthcare providers within the primary care setting. ${ }^{13}$ However, we know very little about the collaboration between hospital midwives and other members of the multi-disciplinary maternity care team.

In the Netherlands, a midwife may be the only obstetric professional in attendance at a birth - be that birth at home or in the hospital. More than $40 \%$ of all births to women with a higher risk profile, birthing in hospital, are managed solely by a hospital midwives. ${ }^{11}$

Referral of birthing women from primary to secondary care often occurs during labour. ${ }^{14}$ This frequently involves the exchange of complex information in face-to-face communication between professionals who may or may not know each other, often by means of electronic patient-data systems that may not interface with each other. These factors present a serious challenge to the necessary collaboration between maternity service professionals.

In the Netherlands, sub-optimal collaboration has been cited as a significant factor in maternal deaths and in adverse incidents occurring in Dutch hospitals during evenings, nights and weekends. ${ }^{15,16}$ One response to these adverse 
outcomes has been the introduction of integrated models of care. ${ }^{17}$ It has been suggested that these models will improve communication and result in better perinatal outcomes. ${ }^{18}$ However, there is currently no evidence to support this suggestion and there is no consensus on the best way forward. ${ }^{19}$ In fact, we know very little about the nature of, and attitudes about collaboration between maternity care professionals, making it difficult to predict the effects of new models of care.

Existing studies on the subject of collaboration in maternity care have focused, for the most part, on whether perceptions between those involved are aligned $^{20}$ and what constitutes 'good' collaboration. In their international literature review, Downe and colleagues ${ }^{6}$ proposed a 'toolkit' for (establishment of) effective collaboration in maternity care. Van Helmond and colleagues ${ }^{21}$ searched the existing literature for examples of 'positive' collaboration and communication and found that there were several factors associated with good communication and collaboration. In addition, they found that parent's views were underrepresented in the literature. vd Lee et al ${ }^{22}$ evaluated collaboration between hospital obstetricians and primary-care midwives in the Netherlands as a result of inter-professional education based on a model developed for that purpose in Canada. Among other things, they found that the potential for improved collaboration with secondary care providers, such as obstetricians and paediatricians was emphasised, and a need was expressed for better, respectful communication. These studies have been useful, but they tell us little about what collaboration looks like in everyday practice or how partners-in-care feel about their collaborations. Principle aim: To examine the experiences with inter-professional collaboration within multidisciplinary teams involved in the provision of maternity-services in the Netherlands.

A secondary objective of our study was to shed light on the current situation of inter-professional collaboration within maternity services in the Netherlands, and has a wider relevance for providers of maternity services elsewhere.

\section{Methods.}

Design: We carried out a cross-sectional survey using a self-administered, online questionnaire. ${ }^{23}$

Sample: The study population consisted of all practising midwives $(n=3,150)$, obstetricians, paediatricians and residents $(n=959)$, nurses $(n=2,835)$ and maternity-care assistants $(n=9,966)$ in the Netherlands. 
For the purposes of this study we identified four categories of maternity care providers, starting with two types of midwives. A 'hospital midwife' (HM) is employed in a hospital in the secondary or tertiary-care sector; a 'primary-care midwife' (PCM) is self-employed or employed by a primary-care midwifery practice. In the third category 'carer', we included obstetric-nurses (registerednurses with an additional obstetric and gynaecology training course), general nurses (registered nurse) and maternity-care assistants (M CA). In the Netherlands, MCAs are a distinct profession, they can be employed or selfemployed, and work in different settings across primary and secondary care. ${ }^{24}$ They provide support to midwives in either setting, helping at births and providing assistance to women with basic needs following the birth.

The last category was 'doctor', consisting of obstetricians, paediatricians and residents-in-training (most commonly to be an obstetrician, general practitioner or specialist in tropical medicine). In addition, we offered respondents the option of 'other' if their occupation did not fit any of these categories.

We defined 'multi-disciplinary team' as the collaborating professionals involved in the chain of maternity service provision in the healthcare region where the respondent worked.

Data collection and analysis:

During the first week of March 2015, invitations were sent by email to 452 of the of 532 midwifery practices in the Netherlands that included an email address on their website. ${ }^{12}$ Practices received an email containing information about the study and a link to the survey. The survey was only available in Survey Monkey (via the link) from February 2015 until April 2015. Questions were numbered consecutively and the order of completion was fixed. However, respondents could move forward and backwards and change answers while completing the questionnaire. No incentives financial or otherwise were offered and participation was entirely voluntary. Participation and return of the questionnaire was deemed to be informed consent.

An email was also sent to the head of departments in all hospitals in the Netherlands with maternity-care facilities $(n=91)$ and to the national representative organisation of maternity care-assistants (knowledge centre for maternity care assistants, KCK) asking them to distribute the questionnaire among all maternity-service professionals in their institutions. 
In addition to this direct approach, we used snowball sampling. The Royal Dutch Organization of M idwives (KNOV) and the KCK placed a notification on their websites, asking all members to participate in this study. M embers were asked to distribute the recruitment email among other colleagues after completion of the survey. After four weeks, a reminder email was sent to all hospitals and midwifery practices and further reminders were placed on the website and forums frequented by maternity care professionals.

There was no restriction on the number of participants per hospital, practice, or birth centre. No specific measures were used to prevent multiple entries. Data were stored electronically in an encrypted database.

Collaboration was assessed using the Leiden Quality of Work Life Questionnaire for Nurses (LQWLQ-N). This questionnaire is a validated instrument used to examine job satisfaction among nurses. ${ }^{22}$ The questionnaire consists of ten domains (of which workplace collaboration is one). The formulation of the questions was adjusted for maternity care professionals in consultation with the author of the questionnaire.

Respondents answers were measured on a 4-point Likert scale ranging from 1 (totally disagree) to 4 (totally agree). Negatively worded questions were reverse coded for analysis.

For the purpose of this study we only used the domain 'workplace collaboration'. This domain consists of seventeen factor statements, eight related to within-organisation collaboration and eight related to within multidisciplinary team (M DT) collaboration. The remaining factor-statement from this domain relates to future collaboration within new models of care. In our study, we used the factor-statements relating to within M DT collaboration as well as the factor-statement related to future collaboration within new models of care (see figure 1).

In addition, information was collected on respondent's gender, age, profession, employment status (employed or self-employed), work environment (hospital, birth-centre or community-based), total years of experience (since qualification), total years of experience in current job, and the number of working hours per week.

The questionnaire was piloted in a group of (ten) participants drawn from all professions represented in the sample. This resulted in the simplification of two questions and the deletion of one that had been included twice in the draft questionnaire. 
Statistical methods:

IBM SPSS version 22.0 (SPSS, Inc., Chicago, IL, USA) was used for data analysis. Using the Kolmogorov-Smirnov test, data were judged sufficiently normally distributed to allow parametric testing.

We compared four groups: hospital midwives, primary-care midwives, carers, and doctors. We used multiple-imputation techniques to analyse missing data. In addition, we used descriptive statistics, chi-square, bivariate and multivariable regression. We calculated a mean score for within-M DT collaboration for each group. We combined respondents' answers to each of the eight factor statements to make a mean collaboration score for within-M DT collaboration. We then compared these scores across professions using anova pair-wise comparison of means. Higher scores correlate with better collaboration.

We dichotomized answers on the Likert items, using the categories 'disagree' and 'agree'. We used t-tests, cross-tabulation and linear regression to assess the differences in relation to collaboration between all groups. Fisher's exact test was used when more than $20 \%$ of the cells of the table had an expected count less than 5. We calculated Pearson's $r$ correlation for each factor statement within the domain against the mean collaboration score per professional group. Lastly, we used multiple linear regression to look at the effect of several independent variables on collaboration. A p-value of 0.05 or lower was considered statistically significant.

Ethical considerations:

This study is part of a larger study 25 that was submitted to the medical ethics committee of VU University M edical Centre (reference number 2014/030). The study was approved. Ethical approval was not considered necessary according to Dutch legislation. ${ }^{26}$ The authors declare no conflicts of interest.

\section{Results.}

We received a total of 4,073 responses for the MDT collaboration questionnaire. Of these 151 were excluded because the professional group of the respondent was not stated. The 'other' category was chosen by 64 respondents. Examination of the explanation of the respondents who chose 'other' to describe their profession allowed us to add most of these responses $(n=44)$ to the category 'carer'. When we could not establish occupational group, responses were excluded $(n=20)$. 
The remaining 3,902 responses were included for analysis. Of these $80 \%$ contained some missing values. However, in total no more than $12 \%$ of values were missing. $M$ issing data were found to be missing completely at random (MCAR).

When imputed data for missing cases/values were compared with complete cases the results did not significantly differ. M issing values resulted in slight fluctuations in total numbers of respondents per professional group per question. Totals are given in each table. Response rates per profession are shown in table 1 . M ost of the respondents were female (except in the category 'doctor', where $30 \%$ were male) and were not self-employed (table 1). Notable exceptions were PCM (of whom $80 \%$ were self-employed) and doctors (of whom $36 \%$ were self-employed). Significant differences were noted in the mean ages between the professional groups with PCM being the youngest (mean 38 yrs., sd 9.8) and carers being the oldest (mean 47yrs., sd 10.5).

Significant differences were also seen in the mean total years of experience and mean years of experience in current job: PCM having the least total experience (mean 13 yrs., sd 8.9) and carers having the most (mean 16 yrs., sd 10.5). Doctors reported the least number of years of experience in their current job (mean 9 yrs., sd 8.1) and carers the most (mean 11 yrs., sd 9.4). Lastly, there was a significant difference in the mean hours per week worked between the groups: carers having the lowest (mean 23 hours per week, sd 9.1) and doctors the highest (mean 47 hours per week, sd 9.9) number of working hours.

Overall, mean collaboration scores were low (table 2). The mean collaboration score (M CS) for all groups was $2.99(\mathrm{sd}=.34)$. PCM scored lowest with a M CS of 2.79 ( $\mathrm{sd}=37)$. M CS for HM (2.89 sd =.28) and doctors were also low (2.89 sd = .33). Carers had the highest M CS (3.03 sd =.32).

When MCS were dichotomized - (3-4) =satisfied, (1-2.99) =not satisfied $-40 \%$ of all respondents were not satisfied with the collaboration within the MDT. . Levels of satisfaction varied between professional groups (31-68\%). Maternity care assistants were the most satisfied (68\%), followed by doctors $(47 \%)$ and hospital midwives (44\%). Primary care midwives were the least satisfied with their collaboration (68\%).

In a pairwise comparison (independent samples t-test), the between group difference of the MCS for HM and PCM was significant $(p=0.02)$ and highly significant for the differences between HM and carers, PCM and doctors, PCM and carers and doctors and carers $(p \varangle 0.001)$. 
We found significant differences between professions on statements in the domain "within-M DT collaboration" (table 3). More than half of the PCM (compared with less than $25 \%$ of carers) disagreed with the statement, "within my multi-disciplinary team, colleagues give me emotional support in times of difficulty' (52\% PCM, 23\% carers, $p=0.001)$.

One in four PCM and HM and one in five doctors (compared with one in ten of the carers) disagreed with the statement 'within my multi-disciplinary team, colleagues offer a helping hand if necessary' $(26 \%$ PCM 25\% HM , 19\% doctors, $10 \%$ carers, $p=0.001$ ). While, more than $30 \%$ of PCM (as opposed to $6 \%$ of carers) agreed with the statement 'within my multi-disciplinary team, colleagues criticise each other in an 'annoying manner' (32\% PCM , Doctors $18 \%$, HM $15 \%, 6 \%$ carers, $p=0.001$ ).

Using a bivariate comparison of correlations (Pearson's $r$ ) we compared each individual factor statement within the MDT domain to the mean collaboration score for each of the professional groups. For $\mathrm{HM}$, the strongest correlation was the factor statement "Within my multi-disciplinary team colleagues give me emotional support in times of difficulty" $(r=0.687, p=0.001)$. For PCM and carers, the strongest correlation was "Within my multi-disciplinary team I feel valued by my colleagues" PCM ( $r=0.721, p=0.001)$ and carers $(r=0.754, p=$ 0.001). For doctors, the strongest correlation in the domain was "Within my multi-disciplinary team I trust the abilities of my colleagues" $(r=0.704, p=$ 0.001).

When all four groups were compared with each other, both groups of midwives were less confident (than doctors and carers) about future collaboration within new models of maternity service provision. For primary care midwives this difference was significant $(p=\varangle 0.001)$. While for hospital midwives the difference just failed to reach the level of significance $(p=0.06)$. Carers, on the other hand were significantly more positive than the other three groups ( $p=\varangle 0.001$ ) regarding collaboration within new models of care.

The best-fit regression models for each professional group differed slightly (table 4), although three factor-statements were significant in each model for all professional groups. These were: 'Within my multi-disciplinary team I experience other professionals more as colleagues than competitors', 'Within my multi-disciplinary team colleagues criticize each other in an annoying way', 'Within my multi-disciplinary team colleagues give me emotional support in times of difficulty'. 


\section{Discussion.}

We found that overall $40 \%$ of all respondents were not satisfied with collaboration within their multi-disciplinary team. In addition, both groups of midwives surveyed were pessimistic over collaboration within future models of maternity service provision.

With the increased use of multi-disciplinary teams, especially in maternity care, optimum-collaboration is a safety issue and one of the greatest challenges of modern-day healthcare. If collaboration is suboptimal this can lead to medical errors. Failure to communicate effectively has been cited by the American Joint Commission for Accreditation as the third most common cause of death in US hospitals. ${ }^{27}$

Other studies report findings similar to ours. ${ }^{28,29}$ Based on these findings our results can be broadly grouped into four headings related to collaboration: the presence of competition, trust in the abilities of colleagues, the need to feel valued (including sensitivity to criticism), and the importance of a "helpinghand" (including presence of emotional support).

Competition in healthcare has been found to be helpful and harmful to patient outcomes. ${ }^{30}$ Under the current system of remuneration for maternity-related care in the Netherlands, hospitals, primary-care midwives, and home-based maternity-care assistants are reimbursed separately for their services.

However, the recently published national standard for integrated care (which has been introduced with the expectation of improved quality of care $)^{17}$ Suggests that one element within integrated care is that caregivers will be paid from an integrated tariff, i.e. a lump-sum; a policy, that may lead to each party receiving less money.

In our data we see that one-in-four of the primary-care midwives agree that they see others in the MDT more as competitors than colleagues indicating that competition for resources is a sensitive issue. This is a potential source of mistrust between caregivers that can lead to harmful 'competition' for pregnant women. ${ }^{31}$

The ability to trust colleagues was also an important issue for respondents. Trust is a fundamental component of effective collaboration. ${ }^{32,20}$ Where trust is lacking, teams are likely to be less effective, as illustrated in observational studies of obstetric emergencies. 33,34

Trust is an especially important component of the Dutch model of maternitycare, where birthing women are often referred during labour. ${ }^{35}$ In our findings, 
trust in the ability of colleagues within the MDT was strongly correlated with a higher M CS. When obstacles to trust, such as competition or role ambiguity, exist, they are likely to stand in the way of optimising collaboration. A recent review of the role of American advanced nurse-practitioners (ANP) in relation to others within the MDT concluded better outcomes are achieved when ANP's have a defined role inclusive of "competencies, leadership, engagement, collaboration and advocacy". ${ }^{36}$ Under the current model of service provision in the Netherlands similar arrangements for hospital midwives may assist in reducing barriers in MDT collaboration.

The need to feel valued was significant for the carers and doctors' groups in our study. M eeting this need is seen as an essential feature for effective teamwork, as widely reported among maternity service professionals in differing settings as well as in nursing teams and in teamwork situations in general. ${ }^{37,38}$ Effective teamwork - and thus effective collaboration - requires (among others) that each member of the team values the contribution of others and that criticism is undertaken from a positive perspective. Inter-professional education, structured communication (such as using Situation Background Assessment Recommendation [SBAR] technique) and the use of no-blame incident analysis are all known to remove barriers to effective teamwork. ${ }^{17,39,40}$

Our study shows that there is room for improvement in the dynamics of multidisciplinary maternity care teams in the Netherlands. Inter-professional education is in its infancy but is promising in its scope. ${ }^{41}$ In addition, it has been shown that collaboration within health and social care can be improved by the introduction of national guidance and advice, ${ }^{42}$ such as the UK National Institute for Clinical Effectiveness (NICE). In the Netherlands, the recently formed College of Perinatal Care has just launched a national care-standard for integrated maternity care. ${ }^{17}$ While discussion is ongoing as to how this standard can be implemented, it will nevertheless be interesting to see whether this leads to improved collaboration in the future.

Lastly, the importance of 'availability of help when necessary' and 'emotional support in times of difficulty', was common to all professional groups in our survey. In each of our analyses there was a significant correlation between (the presence of) help/support and the reported score of the collaboration.

Availability of help is particularly relevant to the Dutch model of maternity care. M idwives, both in primary-care and hospital settings, tend to work in isolation, large maternity units/ hospitals are not common, and frequently there will be only one obstetric-professional in attendance (supported by a carer) at a birth. Robust protocols exist for the provision of assistance in a homebirth 
setting however, the availability of similar arrangements in hospital settings is unclear. ${ }^{43}$ In spite of encouragement by the Dutch Healthcare Inspectorate (IGZ) to do so, most maternity units do not have protocols to deal with peakpressure. $^{10}$

Our findings suggest that where practitioners report that they receive help and support from colleagues, that they are likely to score higher on optimal collaboration. Conversely, members of the MDT were less likely to report higher collaboration scores where there was a feeling that colleagues were seen more as competitors or that they had less trust in the abilities of their colleagues. Combined, these factors can lead to sub-optimal collaboration and ineffective communication, which has been shown to compromise patient safety. ${ }^{44,45}$

Strategies to improve collaboration should be an integral feature of service provision and audit. On a positive note, more inclusive solutions are beginning to emerge. Models of shared-care ${ }^{46}$ the introduction of perinatal audit and the formation of midwifery consortia ${ }^{47}$ may further help to improve collaboration.

Our survey is the first of its kind to report Country-wide findings relating to collaboration within multi-disciplinary teams involved in the provision of maternity services. We used a validated tool to report the views of professionals involved.

Our survey adds to the body of knowledge regarding collaboration within maternity services and offers insight as what is important to Dutch practitioners. Our findings mirror those described in other studies underscoring their wider international relevance.

By highlighting barriers to optimal collaboration, knowledge gained from our study may be of particular value to commissioners and planners of future service provision. Our findings suggest the following key areas of concerns for practitioners: (the presence of) competition, (lack of) trust, the need to feel valued and that the ability to help each other when necessary.

Ensuring that collaboration is optimized is a priority for practitioners and commissioners of maternity-services alike. In order to fully succeed, future models of care must reflect the concerns of service providers.

\section{Limitations.}

Due to the 'snowball' method used for sampling, the way in which participants in the study were recruited was different across professional-groups. This fact 
could have introduced a selection bias. However, we are confident that any potential for bias was mitigated by our broad general appeal for participants which appeared in the Professional Journal's and was circulated on the websites of The Professional Organisations representing our target groups.

M ost of our responses contained some missing data. Although we are confident that the missing data are randomly distributed (and therefore do not adversely affect our analyses), were we to repeat the survey we would consider redesign of the survey instrument in an attempt to minimize the chances of missing data.

In consultation with the author of the Leiden Quality of Work Questionnaire we modified the survey-instrument so that we could also include midwives and doctors. Since this did not change the tone or substance of the instrument. The modified questionnaire was not revalidated and we are confident that the (simple) modification did not affect the validity of the questionnaire.

Lastly, despite our survey instrument having the facility for respondents to add additional comment for their choice of answers, very few did so. We were therefore, unable to explore respondent's answers in-depth. A deeper understanding of the reasons for respondent's choices may improve our understanding of the challenges to optimal collaboration. We recommend further (qualitative) research into the subject.

\section{Conclusion.}

Sub-optimal collaboration exists within the midwifery model of care in the Netherlands and the relationship between care providers is under pressure. This could affect patient safety and quality of care, according to the literature.

Strategies to address sub-optimal collaboration exist. However, no one-sizefits-all approach is apparent from the literature. Prior to the introduction of new models of care, policymakers and commissioners of maternity services should investigate which strategy is the most appropriate for each multidisciplinary team in order to ensure that collaboration between care providers is optimised.

Disclosure statement: The authors have no conflicts of interest.

Copyright statement: Copyright permission to adapt and reproduce the Eight factor-statements relating to within-multi disciplinary team collaboration (Figure 1) which was used in this study, may be obtained by contacting the corresponding author. 


\section{References.}

1. M clnnes S, Peters K, Bonney A, Halcomb E. An integrative review of facilitators and barriers influencing collaboration and teamwork between general practitioners and nurses working in general practice. J Adv. Nurs. 2015 Sep;71(9):1973-85. doi: 10.1111/jan.12647. Epub 2015 Mar 3.

2. Morgan S, Pullon S, M cKinlay E. Observation of inter-professional collaborative practice in primary care teams: An integrative literature review International Journal of Nursing Studies Volume 52, Issue 7, July 2015, Pages 1217-1230.

3. Hämel $K$, Vössing $C$. The collaboration of general practitioners and nurses in primary care: a comparative analysis of concepts and practices in Slovenia and Spain. Prim Health Care Res Dev. 2017 Sep;18(5):492-506. doi: 10.1017/S1463423617000354. Epub 2017 Jun 20.

4. Lewin S, Lavis J, Oxman A, Bastías G. et al. Supporting the delivery of costeffective interventions in primary health-care systems in low-income and middle-income countries: an overview of systematic reviews. The Lancet 2008. http://linkinghub.elsevier.com/retrieve/ pii/S0140- 6736(08)61403-8.

5. Bosch $B$, Mansell $H$. Inter-professional collaboration in health care. Lessons to be learned from competitive sports Can Pharm J (Ott). 2015 Jul; 148(4): 176179. doi: 10.1177/1715163515588106 PM CID: PM C4530359.

6. Downe S, Finlayson K, Fleming A. Creating a Collaborative Culture in M aternity Care M ay 2010 DOI: 10.1016/j.jmwh.2010.01.004.

7. Ogbonnaya L, Ogbonnaya C, Adeoye-Sunday I. The perception of health professions on causes of inter-professional conflict in a tertiary health institution in Abakaliki, southeast Nigeria. Niger J M ed. 2007 Apr-Jun; 16(2):161-8.

8. Smulders B, The Place of Birth: The Dutch M idwifery System, paper was presented at the Future Birth: The Place to be Born Conference, Australia, February 1999.

9. de Vries R, Nieuwenhuijze M, Buitendijk S. What does it take to have a strong and independent profession of midwifery? Lessons from the Netherlands. M idwifery 29(2013)1122-1128. 
10. Dutch Inspectorate for Healthcare (IGZ) Risks in hospital care in the evening, night and in the weekend must be better covered [Risico's ziekenhuiszorg in avond, nacht en weekend moeten beter afgedekt] (in Dutch) 2011, IGZ, Utrecht, the Netherlands.

11. Cronie D, Rijnders M, Buitendijk S. Diversity in the Scope and Practice of Hospital-Based Midwives in the Netherlands. J Midwifery Women's Health 2012; 57:469-475 2012.

12. Kenens R, Battenburg R, Kasteleijn A. Numbers from the registration of midwives [Cifers uit de registratie van verloskundigen], Nivel, Utrecht (in Dutch) 2016.

13. M anniën J, Klomp T, Weigers T, Pereboom M . et al Evaluation of primary care midwifery in the Netherlands: design and rationale of a dynamic cohort study (DELIVER) BM C Health Services Research201212:69.

14. Offerhaus $P$, Hukkelhoven $C$, de Jonge $A$, van der Pal-de Bruin $K$ et al. Persisting rise in referrals during labour in primary midwife-led care in the Netherlands. Birth. 2013 Sep;40(3):192-201. doi: 10.1111/ birt.12055.

15. Schutte J, Steegers E, Schuitemaker N, Santema J, de Boer K, Pel M, Vermeulen G, Visser W, van Roosmalen J. Rise in maternal mortality in the Netherlands. BJOG. 2010 Mar;117(4):399-406. doi: 10.1111/j.14710528.2009.02382.x. Epub 2009 Nov 26.

16. Kramer J, Cronie D, Smit M, Schraagen J. Evaluation of M idwifery Protocols in the Netherlands; an analysis of task and responsibility agreements among hospital maternity service providers. [ Verloskundige Protocol Evaluatie Nederland; een analyse van taak en verantwoordelijkheidsafspraken van tweedelijns zorgverleners] TNO-report 031.20452; 13 (in Dutch) October 2010.

17. College Perinatal Care (CPZ). Care standard 'integrated perinatal care' [Zorgstadaard 'Integrale geboortezorg' Versie een] Version 1.0 College Perinatal Care, (in Dutch) 2015. Utrecht, the Netherlands.

18. van der Velden J, Pultrum J, Becker Hoff J. Everhardt E, et al. A good beginning: safe care around pregnancy and birth. Advice of the steering group pregnancy and birth. [een goed begin: veilig zorg rondom zwangerschap en geboorte. Advies van stuurgroep] Government Law. (in Dutch) 2009. http://www.rijksoverheid.nl/enzwangerschap-en/x-cz-2978049b.pdf/. Accessed 26th June 2016. 
19. Perdok H, Jans S, Verhoeven C, Henneman, L et al. Opinions of maternity care professionals and other stakeholders about integration of maternity care: a qualitative study in the Netherlands. BM C pregnancy and childbirth, (2016) 16(1), pp. 188-016-0975-z.

20. Romijn A, Teunissen $P$, de Bruijne $M$ et al. Interprofessional collaboration among care professionals in obstetrical care: are perceptions aligned? BMJ Quality \& Safety Online First, published on 26 September 2017 as 10.1136/ bmjqs-2016-006401.

21. van Helmond I, Korstjens I, M esman J, Nieuwenhuijze $M$ et al. What M akes for Good Collaboration and Communication in Maternity Care? A Scoping Study. International Journal of Childbirth. 2010.

22. vd Lee N, Driessen E, Scheele F. How the past influences inter-professional collaboration between obstetricians and midwives in the Netherlands: Findings from a secondary analysis Journal of Inter-professional Care, 30:1, 7176,DOI:10.3109/13561820.2015.1064876 2016.

23. van der Doef M, M aes S. The Leiden Quality of Work Questionnaire: Its Construction, Factor Structure, and Psychometric Qualities Psychological reports Volume: 85 issue: 3, page(s): 954-962 Issue published1999.

24. van Teijlingen, $E$. The profession of maternity home care assistant and its significance for the Dutch midwifery profession International Journal of Nursing studies 1990 Volume 27, Issue 4, Pages 355-366.

25. Verhoeven, C. INCAS-2 (INtegrated CAre System) a study into integrated care in the Netherlands. 2017. http:// www.incas2.nl/ accessed 23/3/17.

26. Dutch Central Committee for Research Involving Human Subjects, CCM 0. 2017. (English Version) web site. http://www.ccmoonline.nl/main.asp/English/FAQ/WMO.

27. Joint Commission on Accreditation of Healthcare Organizations (JCAHO). Sentinel event statistics released for 2014 J oint Commission on Accreditation of Healthcare Organizations; 2015.

https://www.jointcommission.org/assets/1/23/jconline_April_29_15.pdf accessed April 2018.

28. Henneman AE, Lee JL, Cohen JI. Collaboration: A concept analysis. J Adv. Nurs 1995; 21:103-9. 
29. Reiger KM, Lane KL. Working together: Collaboration between midwives and doctors in public hospitals. Aus. Health Rev 2009; 33:315-24.

30. Barros P, Werner B, Brouwer F, Thomson S and Varkevisser M. Competition among health care providers: helpful or harmful?

Eur. J Health Econ. 2016; 17: 229-233. Published online 2015 Oct 14. doi: 10.1007/s10198-015-0736-3.

31. Royal Dutch Organisation of M idwives (KNOV). Standpoint Integrated Funding [Standpunt integralebekostigen], (in Dutch) KNOV, Utrecht, 2013.

32. Costa A, Roe R \& Taillieu T. Trust within teams: The relation with performance effectiveness European J ournal of Work and Organizational Psychology Volume 10, 2010 - Issue 3 Pages 225-244 | Published online: 10 Sep 2010.

33. Siassakos D, Crofts J, Winter C, Weiner C, Draycott T. The active components of effective training in obstetric emergencies. BCOG DOI: 10.1111/j.1471-0528.2009.02178.x accepted $5 \mathrm{M}$ arch 2009. Published Online 11 May 2009.

34. M adden $E$, Sinclair $M$, Wright $M$. Teamwork in obstetric emergencies Evidence Based Midwifery: September 2011.

35. Blix E, Kumle M, Kjærgaard $\mathrm{H}$ et al. Transfer to hospital in planned home births: a systematic review, BM C Pregnancy and Childbirth 2014, 14:179 DOI:10.1186/1471-2393-14-179.

36. M clntosh D, Startsman L, and Perraud S. M ini Review of Integrated Care and Implications for Advanced Practice Nurse Role Open Nurs J. 2016; 10: 7889.

37. Baker D, Day R, and Salas E. Teamwork as an Essential Component of HighReliability Organizations. Health Serv Res. 2006 Aug; 41(4 Pt 2): 1576-1598. doi: $10.1111 /$ j.1475-6773.2006.00566.

38. Kalisch B, Weaver S, and Salas E. What Does Nursing Teamwork Look Like? A Qualitative Study. Journal of Nursing Care Quality: October-December 2009 Volume 24 - Issue 4 - p 298-307 doi: 10.1097/NCQ.0b013e3181a001c0.

39. Avery M, M ontgomery O, Brandl-Salutz E. Essential Components of Successful Collaborative Maternity Care Models: The ACOG-ACNM Project. 
Obstetrics and Gynecology Volume 39, Issue 3, September 2012, Pages 423434.

40. Vd Lee N. Tailoring CanM EDS for training in Obstetrics and Gynaecology in the Netherlands. Amsterdam. Vu University. 2014.

41. Koelewijn J. Does the SBAR-method improve handover and collaboration? Midwives Journal (TVV), march 2014.

42. Sakala C. and Corry M. Evidence-based maternity care: what it is and what it can achieve. M illbank M emorial Fund, New York, USA, 2008 ISBN 978-1887748-70-4.

43. Cronie D, Rijnders M, de Vries R, Buitendijk S. Making Evidence Available for Hospital-Based Midwives: A Systematic Examination of the Content and M ethodological Quality of Three Protocols Used in M aternity Hospitals in the Netherlands. International J ournal of Childbirth, Volume 4, Number 4, 2014, pp. 208-218(11).

44. Lyndon A., Zlatnik M., Watcher R. Effective Physician-Nurse Communication: A Patient Safety Essential for Labor \& Delivery Am J Obstet Gynecol. 2011 Aug; 205(2): 91-96.

Published online 2011 Apr 16. doi: 10.1016/j.ajog.2011.04.021

45. M artijn L, Jacobs A, Amelink-Verburg M, Wentzel R et al. Adverse outcomes in maternity care for women with a low risk profile in The Netherlands: a case series analysis.

BM C Pregnancy Childbirth. 2013; 13: 219. Published online 2013 Nov 29. doi: 10.1186/1471-2393-13-219.

46. Posthumus A, Schölmerich V, Waelput A, Vos A. et al. Bridging Between Professionals in Perinatal Care: Towards Shared Care in The Netherlands.

M aternal and Child Health Journal December 2013, Volume 17, Issue 10, pp 1981-1989.

47. van Diem M, Bergman K, Bouman K, van Egmond N, Stant D, Timmer A, et al. (2011). Perinatal audit in the North of the Netherlands: The first 2 years]. Dutch Medical Journal [Nederlands Tijdschrift voor Geneeskunde], 155(18), A2892. 


\section{Figures and Tables.}

Figure 1. Eight factor-statements relating to measure within-multi disciplinary domain collaboration *

\begin{tabular}{|l|}
\hline Mutual collaboration within my multi-disciplinary team (MDT) is good \\
\hline Within my M DT I experience other professionals more as colleagues than as competitors \\
\hline Within my M DT communication is good \\
\hline Within my M DT I trust the abilities of my colleagues \\
\hline Within my M DT I feel valued by my colleagues \\
\hline Within my M DT colleagues criticize each other in an annoying way \\
\hline Within my M DT colleagues offer a helping hand if necessary \\
\hline Within my M DT colleagues give me emotional support in times of difficulty \\
\hline I trust in good cooperation within the future \\
midwifery organisation.
\end{tabular}

* Adapted from working-relationships domain in The Leiden Quality of Work Questionnaire (vd Doef \& Maes, 1999) multi-disciplinary team' was defined as: all professionals involved in maternity-service provision within the healthcare region where you work. 
Table 1. basic characteristics of the study population.

\begin{tabular}{|c|c|c|c|c|c|c|}
\hline & $\begin{array}{l}\text { Total } \\
\text { n (\%) }\end{array}$ & $\begin{array}{l}\begin{array}{l}\text { Hospital } \\
\text { midwife }\end{array} \\
n(\%)[S D]\end{array}$ & $\begin{array}{l}\text { Primary } \\
\text { care } \\
\text { midwife } \\
n(\%)[S D]\end{array}$ & $\begin{array}{l}\text { Doctor } \\
n(\%)[S D]\end{array}$ & $\begin{array}{l}\text { Other carers } \\
\mathrm{n}(\%)[\mathrm{SD}]\end{array}$ & P value * \\
\hline \multicolumn{7}{|l|}{ Gender } \\
\hline $\begin{array}{l}\text { Male } \\
\text { Female }\end{array}$ & $\begin{array}{l}139(4) \\
3,514(96)\end{array}$ & $\begin{array}{l}4(4) \\
93(96)\end{array}$ & $\begin{array}{l}4(1) \\
386(99)\end{array}$ & $\begin{array}{l}119(30) \\
271(70)\end{array}$ & $\begin{array}{l}12(0.4) \\
2764(99)\end{array}$ & \\
\hline Mean age & & $42[9.8]$ & 38 [10.5] & $45[9.9]$ & $47[10.5]$ & $\mathrm{a}, \mathrm{b}, \mathrm{c}, \mathrm{d}, \mathrm{d}, \mathrm{e}, \mathrm{f}$ \\
\hline \multicolumn{7}{|l|}{$\begin{array}{l}\text { Employment } \\
\text { status }\end{array}$} \\
\hline $\begin{array}{l}\text { Employed } \\
\text { Self employed }\end{array}$ & $\begin{array}{l}2,979(82) \\
674(18)\end{array}$ & $\begin{array}{l}97(100) \\
0(0)\end{array}$ & $\begin{array}{l}77(20) \\
313(80)\end{array}$ & $\begin{array}{l}248(64) \\
142(36)\end{array}$ & $\begin{array}{l}2557(92) \\
219(8)\end{array}$ & \\
\hline \multicolumn{7}{|l|}{$\begin{array}{l}\text { Experience } \\
\text { profession }\end{array}$} \\
\hline Mean years & & $16[9.0]$ & $13[8.9]$ & $15[9.8]$ & 16 [10.5] & $\mathrm{a}, \mathrm{d}, \mathrm{e}, \mathrm{f}$ \\
\hline \multicolumn{7}{|l|}{$\begin{array}{l}\text { Experience } \\
\text { current job }\end{array}$} \\
\hline Mean years & & $9[7.1]$ & $10[7.9]$ & 9 [8.1] & $11[9.4]$ & $c, e, f$ \\
\hline \multicolumn{7}{|l|}{ Working hours } \\
\hline M ean per week & & $\begin{array}{l}29 \\
{[5.59]}\end{array}$ & 44 [14.87] & $\begin{array}{l}47 \\
{[9.91]}\end{array}$ & $23[9.14]$ & $a, b, c, d, f$ \\
\hline
\end{tabular}

${ }^{*} p$ value for means = each group was compared individually to all other groups giving six possible $p$ values for each comparison. Only the $P$ values for comparisons which reach the level of significance are shown. The $p$ values are lettered as follows: $a=P$ value for difference between $H M$ and $P C M, b=P$ value for difference between $H M$ and Drs, $C=P$ value for difference between $H M$ and $M C A, d=P$ value for difference between $P C M$ and Drs, $e=P$ value for difference between $P C M$ and $M C A, f=P$ value for difference between Drs and MCA. 
Table 2. Mean collaboration scores within MDT.

\begin{tabular}{|c|c|c|c|c|}
\hline Professional group & $\begin{array}{l}\text { M ean within-MDT } \\
\text { collaboration (sd) }\end{array}$ & Pvalue * & $\begin{array}{l}\text { Not } \\
\text { satisfied** }^{* *} \\
n(\%)\end{array}$ & $\begin{array}{l}\text { Satisfied } \\
n(\%)\end{array}$ \\
\hline Hospital midwives & $2.89(.28)$ & $\overline{a, c}$, & $53(56)$ & $41(44)$ \\
\hline Primary care midwives & $2.79(.37)$ & $\mathrm{d}_{\text {, }} \mathrm{e}$ & $253(69)$ & $115(31)$ \\
\hline Doctors & $2.89(.33)$ & $d, f$ & $175(53)$ & $155(47)$ \\
\hline Carers & $3.03(.32)$ & $c, e, f$ & $785(32)$ & $1631(68)$ \\
\hline All groups & $2.99(.34)$ & & $1266(40)$ & $1942(60)$ \\
\hline
\end{tabular}


Table 3. Between-group differences to individual factor statements from within MDT collaboration domain.

\begin{tabular}{|c|c|c|c|c|c|c|}
\hline & n (\%) & $\begin{array}{l}\text { Hospital } \\
\text { Midwives } \\
\text { n (\%) }\end{array}$ & $\begin{array}{l}\text { Primary Care } \\
\text { Midwives } \\
\text { n (\%) }\end{array}$ & n (\%) & $\begin{array}{l}\text { Other care } \\
\text { providers }^{\text {d }} \\
\text { n (\%) }\end{array}$ & pvalue* \\
\hline \multicolumn{7}{|c|}{ M utual collaboration within my multi-disciplinary team is good } \\
\hline Agree & $3,138(93)$ & $88(91)$ & $335(89)$ & $306(88)$ & $2,409(94)$ & e,f \\
\hline Disagree & $235(7)$ & $9(9)$ & 41 (11) & $43(12)$ & $142(6)$ & \\
\hline
\end{tabular}

Within my multi-disciplinary team I experience other professionals more as colleagues than competitors

\begin{tabular}{lllllll}
\hline Agree & $2,964(86)$ & $92(95)$ & $288(77)$ & $311(89)$ & $2,273(89)$ & $\mathrm{a}, \mathrm{d}, \mathrm{e}$ \\
Disagree & $409(14)$ & $5(5)$ & $88(23)$ & $38(11)$ & $278(11)$
\end{tabular}

Within my multi-disciplinary team mutual communication is good

\begin{tabular}{lllllll}
\hline Agree & $2890(86)$ & $77(79)$ & $281(75)$ & $281(82)$ & $2,251(89)$ & c,e,f \\
Disagree & $447(13)$ & $20(21)$ & $92(25)$ & $61(18)$ & $274(11)$
\end{tabular}

Within my multi-disciplinary team I trust the abilities of my colleagues

\begin{tabular}{lllllll}
\hline Agree & $3,146(93)$ & $87(90)$ & $342(92)$ & $290(85)$ & $2,427(96)$ & $c, d, e, f$ \\
Disagree & $191(6)$ & $10(10)$ & $31(8)$ & $52(15)$ & $98(4)$ &
\end{tabular}

Within my multi-disciplinary team I feel valued by my colleagues

\begin{tabular}{lllllll}
\hline Agree & $3,024(90)$ & $86(89)$ & $282(76)$ & $312(92)$ & $2,344(94)$ & a,c,d,e,f \\
Disagree & $281(9)$ & $11(11)$ & $89(24)$ & $27(8)$ & $154(6)$
\end{tabular}

Within my multi-disciplinary team colleagues criticize each other in an annoying way

\begin{tabular}{lllllll}
\hline Agree & $338(10)$ & $15(15)$ & $119(32)$ & $61(18)$ & $143(6)$ & a,c,d,e,f \\
Disagree & $2,96788)$ & $82(85)$ & $252(68)$ & $278(82)$ & $2,355(94)$
\end{tabular}


Within my multi-disciplinary team colleagues offer a helping hand if necessary

\begin{tabular}{|c|c|c|c|c|c|c|}
\hline Agree & $2,838(84)$ & $71(75)$ & $271(74)$ & $267(81)$ & $2,229(90)$ & $c, e, f, d$ \\
\hline Disagree & 423 (13) & $23(25)$ & $97(26)$ & 63 (19) & $240(10)$ & \\
\hline
\end{tabular}

Within my multi-disciplinary team colleagues give me emotional support in times of difficulty

\begin{tabular}{|c|c|c|c|c|c|c|}
\hline Agree & $2,308(68)$ & $45(48)$ & $176(48)$ & 198(60) & 1,889 (77) & $b, c, d, e, f$ \\
\hline Disagree & $943(28)$ & $49(52)$ & $192(52)$ & $132(40)$ & $570(23)$ & \\
\hline
\end{tabular}

*each group was compared individually to all other groups giving six possible $\mathrm{p}$ values for each factor statement. However, only the $\mathrm{P}$ values for comparisons which reach the level of significance are shown. The $p$ values are lettered as follows: $a=P$ value for difference between $H M$ and $P C M, b=P$ value for difference between $H M$ and Drs, $c$

$=P$ value for difference between $H M$ and $M C A, d=P$ value for difference between $P C M$ and Drs, $e=P$ value for difference between $P C M$ and $M C A, f=P$ value for difference between Drs and M CA. 
Table 4: linear regression model factor-statements that contribute to optimal multidisciplinary collaboration per profession.

\begin{tabular}{|c|c|c|c|c|c|}
\hline $\begin{array}{l}\text { significant factor } \\
\text { statement }\end{array}$ & $\begin{array}{l}\text { Hospital } \\
\text { midwife }^{\text {a }}\end{array}$ & $\begin{array}{l}\text { Primary care } \\
\text { midwife }^{\mathbf{b}}\end{array}$ & Doctor ${ }^{c}$ & $\begin{array}{l}\text { Other } \\
\text { carer }^{\text {d }}\end{array}$ & P value* \\
\hline & $\begin{array}{l}\text { Beta } \\
(95 \% \mathrm{Cl})\end{array}$ & $\begin{array}{l}\text { Beta } \\
(95 \% \mathrm{Cl})\end{array}$ & $\begin{array}{l}\text { Beta } \\
(95 \% \mathrm{Cl})\end{array}$ & $\begin{array}{l}\text { Beta } \\
(95 \% \mathrm{Cl})\end{array}$ & \\
\hline $\begin{array}{l}\text { Within my multi- } \\
\text { disciplinary team I } \\
\text { experience other } \\
\text { professionals more as } \\
\text { colleagues than } \\
\text { competitors }\end{array}$ & $\begin{array}{l}.305 \\
(.178, .433)\end{array}$ & $\begin{array}{l}.080 \\
(.030, .130)\end{array}$ & $\begin{array}{l}.185 \\
(.111, .259)\end{array}$ & $\begin{array}{l}.168 \\
(.141 \\
.195)\end{array}$ & $\begin{array}{l}a=<001 \\
b=<0.02 \\
c=<001 \\
d=<001\end{array}$ \\
\hline $\begin{array}{l}\text { Within my multi- } \\
\text { disciplinary team I trust } \\
\text { the abilities of } \mathrm{my} \\
\text { colleagues }\end{array}$ & $\begin{array}{l}.010 \\
(-.144, .164)\end{array}$ & $\begin{array}{l}.238 \\
(.168, .309)\end{array}$ & $\begin{array}{l}.060 \\
(-.029, .149)\end{array}$ & $\begin{array}{l}.221 \\
(.183 \\
.258)\end{array}$ & $\begin{array}{l}a=.895 \\
b=<001 \\
c=.183 \\
d=<001\end{array}$ \\
\hline $\begin{array}{l}\text { Within my multi- } \\
\text { disciplinary team I feel } \\
\text { valued by my colleagues }\end{array}$ & $\begin{array}{l}.034 \\
(-.123, .191)\end{array}$ & $\begin{array}{l}.042 \\
(-.021, .105)\end{array}$ & $\begin{array}{l}.169 \\
(.063, .275)\end{array}$ & $\begin{array}{l}.130 \\
(.092 \\
.168)\end{array}$ & $\begin{array}{l}a=.671 \\
b=.187 \\
c=.002 \\
d=<001\end{array}$ \\
\hline $\begin{array}{l}\text { Within my multi- } \\
\text { disciplinary team } \\
\text { colleagues criticize each } \\
\text { other in an annoying way }\end{array}$ & $\begin{array}{l}.163 \\
(.027, .298)\end{array}$ & $\begin{array}{l}.123 \\
(.073, .174)\end{array}$ & $\begin{array}{l}.189 \\
(.123, .254)\end{array}$ & $\begin{array}{l}.318 \\
(.292 \\
.344)\end{array}$ & $\begin{array}{l}a=.019 \\
b=<001 \\
c=<001 \\
d=<001\end{array}$ \\
\hline $\begin{array}{l}\text { Within my multi- } \\
\text { disciplinary team } \\
\text { colleagues offer a helping } \\
\text { hand if necessary }\end{array}$ & $\begin{array}{l}.155 \\
(.025, .286)\end{array}$ & $\begin{array}{l}.048 \\
(-.010, .107)\end{array}$ & $\begin{array}{l}.003 \\
(-.084, .091)\end{array}$ & $\begin{array}{l}.035 \\
(.000 \\
.071)\end{array}$ & $\begin{array}{l}a=0.20 \\
b=.107 \\
c=.943 \\
d=.052\end{array}$ \\
\hline $\begin{array}{l}\text { Within my multi- } \\
\text { disciplinary team } \\
\text { colleagues give me } \\
\text { emotional support in } \\
\text { times of difficulty }\end{array}$ & $\begin{array}{l}.129 \\
(.071, .306)\end{array}$ & $\begin{array}{l}.115 \\
(.065, .166)\end{array}$ & $\begin{array}{l}.152 \\
(.087, .218)\end{array}$ & $\begin{array}{l}.113 \\
(.086 \\
.140)\end{array}$ & $\begin{array}{l}a=002 \\
b=<001 \\
c=<001 \\
d=<001\end{array}$ \\
\hline
\end{tabular}

$* \mathrm{P}$ value for difference per profession compared to all others 
7

General Discussion 


\section{Hospital midwives: an examination of the role, diversity, and practice conditions of Dutch hospital midwives.}

\section{Aims of this thesis:}

In this thesis we explore the scope of practice and the experience of hospital midwives in the Netherlands in order to better understand the factors that influence their contribution to the Dutch maternity care system. We accomplished this by investigating what hospital midwives are doing, the protocols that guide their work, and how they experience their role within the larger system of maternity care.

Five topics were of particular interest to us. We began by surveying the existing diversity in the practices of hospital midwives in the Netherlands (chapter 2), which led us to look more closely at the content and quality of hospital protocols governing the work of hospital midwives (chapter 3 ). We then turned our attention to the differences between hospital midwives and primary care midwives with regard to their job satisfaction and their attitudes towards their work (chapter 4). Recognizing that a significant element of job satisfaction is autonomy at work, we investigated how maternity care professionals in the Netherlands perceive their job autonomy, and we explored how they thought their autonomy might be affected by the introduction of integrated maternity care (chapter 5). Lastly, given the role of hospital midwives within multidisciplinary maternity care teams, we looked how collaboration was experienced across professional boundaries by maternity service providers primary care and hospital midwives, obstetricians, nurses, and maternity care assistants - working in those multi-disciplinary teams (chapter 6).

In this chapter we reflect on our main findings, consider the strengths and limitations of our research, and describe the implications of our findings for contemporary maternity care provision in the Netherlands. We conclude by making recommendations for future research based on our findings.

\section{Discussion of main findings}

\section{Practice conditions}

Not all midwives in the Netherlands are independent (primary care) practitioners. When our study began, one in four midwives registered to practice in the Netherlands was employed in the hospital setting. It is now one in three ${ }^{1}$. In order to understand the role of the hospital midwife, it is important to have a clear picture of the distribution of births in the 
Netherlands. Seventeen percent of all births take place at home or birth centres, nearly all of which are attended by primary care midwives (general practitioners attend a few of these births). An additional thirteen percent of all births occur in the hospital under the care of a primary care midwife - these are referred to as "polyclinic births" - sometimes called "home births in the hospital" 2 . The remaining births - $70 \%$ of all births in the Netherlands happen in the hospital in "obstetrician-led care"3. These are births where expectant mothers are under the care of an obstetrician because of the presence of pathology or the need for pain relief. It is this group of women who are the potential clients of hospital midwives.

In Chapter 2 we describe the findings of our survey of the roles and practice conditions of Dutch hospital midwives. Our data show that the availability of hospital midwives and their levels of education are not uniform. Despite this, we found that hospital midwives attended the majority - 77 percent - of hospital births classified as "obstetrician-led". Interestingly, we found that 40 percent of all hospital births assigned to obstetrician-led care that occurred during the study period were managed solely by a hospital midwife. In principle, this is a positive development, as previous, large-scale studies ${ }^{4-6}$ have shown that the provision of midwifery care can lead to an improvement in selected outcome measures. Other studies confirm that the presence of midwives in hospitals reduces the level of interventions, even in populations defined as high risk ${ }^{7-9}$.

\section{Role diversity}

As noted above, we found great diversity in the role, scope of practice, educational level, and working conditions of hospital midwives in the Netherlands. In response to this lack of uniformity, the professional organisations of both midwives and obstetricians have suggested amending the current Health Practitioners Law ${ }^{10}$ to add a new registrant category (specialist register) for hospital midwives. It is thought that this would facilitate greater homogeneity in the practices of hospital midwives ${ }^{11,12}$. But not all midwives agree, creating uncertainty about the best way forward ${ }^{13}$. Furthermore, the establishment of such an amendment within the scope of the current Health Practitioners Law is proving to be complex ${ }^{14,15}$.

In order to clarify the proper place and responsibility of hospital midwives in the Dutch system, key stakeholders - including the Royal Dutch Organisation of M idwives (KNOV), the Dutch Society for Obstetricians (NVOG), the Dutch Healthcare Inspectorate (IGZ), and the Care Institute (CVZ) - must find a mutually acceptable way of using the skills of hospital midwives. Our findings 
provide important information that can be used to facilitate conversations about the future of hospital midwifery and to inform the creation of policy governing the practice of hospital midwives.

\section{Quality of protocols}

The survey described above included questions about how hospital midwives made decisions and about the nature of their responsibilities within the maternity care team. Nearly all midwives responded that they "always" or "frequently" worked according to protocols specifying their duties and responsibilities. However, when asked about the scientific background of those protocols, one-third of the respondents reported that the protocols were not up to date and that the background information, used to support the protocols, was not systematically selected and reviewed.

Our second study, described in chapter 3, looks more deeply at the protocols that are used by hospital midwives. This study was motivated by three factors: 1) the uncertainty regarding the quality of protocols we found in our earlier study, 2) the diversity in the practices of hospital midwives in the Netherlands and 3 ) emerging questions about the safety of Dutch hospitals during the evening hours and on the weekends ${ }^{16}$.

We found the methodological quality of protocols to be poor. Often, the content of the protocols was not based on the best, up to date, evidence. We also found a great deal of confusion regarding the definition of what a protocol was and what it should contain.

The lack of evidence to support protocols is not a new problem nor is it unique to the Netherlands ${ }^{17}$. But this does not diminish the need to improve the quality of protocols. We know that the use of standardized, evidence-based protocols can substantially improve health outcomes, and conversely, we know that reliance on poor protocols is associated with a significant risk of harm ${ }^{18}$.

Our survey showed that protocols may not be widely available in Dutch maternity units, which suggests that the development and use of protocols is not a high priority for providers of hospital maternity care. A consequence of this - confirmed in our survey - is the use of mono-disciplinary protocols that do not always correspond with national guidelines. One reason for the use of mono-disciplinary guidelines may be the problem of "who decides who does what? - a historical and ongoing issue in the Netherlands relating to hierarchy among professionals involved in the provision of care. While there is a strong 
tradition of autonomous midwifery in the Netherlands, there is nevertheless an historical imbalance of power between obstetricians and midwives ${ }^{19}$, a situation that has led to mistrust between the parties involved.

As we mentioned above, conflicting guidelines and protocols have the potential to do harm ${ }^{20}$ making it an urgent matter that requires resolution. This issue is acknowledged in a government report ${ }^{21}$, a conclusion of which is the encouragement to develop multidisciplinary guidelines and protocols.

Since the publication of our study, the College of Perinatal Care (CPZ) has been established in the Netherlands ${ }^{22}$. This organisation has been given responsibility to develop a cohesive strategy for the implementation of integrated care within maternity services in the Netherlands ${ }^{23}$, and true to that mission, the CPZ has produced the first integrated "care standard" in perinatal care $^{22}$. However, ongoing disagreement about what integrated care should look like ${ }^{24}$ has delayed its implementation. Future research is needed to assess whether the introduction of this care standard will bring about more standardized, evidence-based maternity care in the Netherlands ${ }^{25}$.

\section{Perceived job satisfaction and autonomy}

Despite the lack of clarity surrounding the content and process of integrated care, new integrated models of care are being introduced in the Netherlands ${ }^{22}$. These models will undoubtedly result in changes in the working patterns of midwives, changes that will affect the job satisfaction and perceived job autonomy of midwives - both primary care and hospital based - and will likely alter the nature of collaboration within the multi-disciplinary team. This significant change in the organisation of maternity care gave us the opportunity to benchmark current levels of job satisfaction and to more fully explore the attitudes of midwives and other maternity care providers regarding their work prior to changes in the system of care. Our findings are described in chapters 4 , 5 and 6.

Chapter 4 describes our study of Dutch midwives' job satisfaction. We found that midwives - both hospital and primary care - were generally satisfied with their jobs. This high level of job satisfaction was related to, among other things, the potential for development within their respective roles, a phenomenon not unique to the Netherlands. Support for professional development - for example, in the form of mentorship - is known to be particularly important for new nursing and midwifery graduates ${ }^{26,27}$. This has also been found to be true for midwifery graduates in the Netherlands ${ }^{28,29}$, but ironically, no formal programme of mentorship is mandated by the Dutch registration authority for midwives. 
Evidence also suggests that health care providers find their professional development - as measured by career progression - to be intrinsically valuable ${ }^{30}$. While we do not know if (or to what degree) this is important for Dutch midwives, we do know that professional development - including career progression - is a regular issue in the annual negotiation of the working conditions of Dutch midwives ${ }^{31}$. This strongly suggests that 'potential for development' is important to Dutch midwives.

The Netherlands, like many other countries, does require evidence of ongoing professional experience for the maintenance of professional registration ${ }^{32,33}$. However, professional experience is not the same as professional development, which is increasingly seen as essential in the careers of health service personne ${ }^{34}$ and which we found to be important for Dutch midwives. One option to remedy this would be for the Dutch registration authority for healthcare professionals (CIGB) to include the demands of the quality-register ${ }^{35}$ in the process of re-registration for all midwives. At present, the quality register - a voluntary record of certain competences, maintained by the KNOV - is more relevant to primary care midwives as all insurance companies require this as a perquisite for remuneration of care. Because they are paid by their employers, and not directly reimbursed by insurance, hospital midwives, are not currently obliged to join the quality register. Extending this requirement to all midwives would allow both primary care and hospital midwives to record evidence of professional development.

While the potential for professional development was an important aspect of job satisfaction for both hospital and primary care midwives, we found significant differences in the predictors of job satisfaction for each group. For hospital midwives, structural factors relating to employment conditions such as, (fewer) working hours per week, workplace agreements, and total years of experience were strong predictors of job satisfaction.

All hospital midwives in the Netherlands are employees of organizations and the majority work part-time, with fixed hours or shifts and little-to-no on-call hours. This is in sharp contrast to most primary care midwives who are selfemployed, work longer hours, and spend more hours on-call ${ }^{1}$. It has been suggested that the desire for more regular hours may explain why more midwives want to work in hospitals ${ }^{36}$.

Compared to hospital midwives, primary-care midwives have substantially different patterns of work. Not surprisingly, then, for them job satisfaction was related to social aspects of their work, including collaboration, work demands 
and tasks, degree of autonomy, and the influence of work on their personal lives.

\section{Importance of autonomy}

Higher levels of job autonomy, defined as the degree of control a worker has over his or her immediate scheduling and tasks $\mathrm{s}^{37}$, are significantly important to healthcare professionals. Having control over one's work is not just a matter of freedom, it also protects against somatic complaints, psychological distress at work, and burnout ${ }^{38-40}$. High levels of job autonomy among midwives have been shown to have a positive effect on the empowerment of their clients and to have a positive influence on the professional-patient relationship ${ }^{41}$. Clearly it is desirable to promote autonomy among all midwives.

In Chapter 5 we present the results of our study of the perceived job autonomy of Dutch maternity care providers - including primary care and hospital midwives, obstetric nurses, and obstetricians. Compared to other maternity care providers, we found that primary care midwives had the highest perceived level of autonomy. In addition, primary care midwives also scored highest when asked to consider the extent to which they would lose autonomy with the introduction of an integrated model of service provision.

Self- employed persons are known to have higher levels of autonomy (and job satisfaction) than salaried employees ${ }^{42}$, a phenomenon that has also been shown among primary care midwives ${ }^{43}$. There are various theories explaining why this is so. Among others, concepts such as advocacy, respect, and professional recognition are thought to be important factors ${ }^{44,45}$.

Hospital midwives had lower levels of perceived autonomy. The reasons for this remain unclear. It may be that as employees of a large organization, subject to organisational hierarchies ${ }^{46}$, the autonomy of hospital midwives is diminished. Their perceived levels of autonomy may also be affected by uncertainty regarding the position of hospital midwives in the current model of maternity care $^{11}$. Further research, to better understand the reasons for the low levels of perceived autonomy among hospital midwives, is necessary.

Another important finding of our research, briefly mentioned above, is that primary care midwives expect to lose autonomy with the introduction of new (integrated) models of care. Lacking a clear strategy to safeguard their autonomy as independent practitioners, the introduction of new models of integrated care threatens the strong profession of primary care midwifery in the Netherlands. The autonomous position of Dutch midwives has long been a 
critical and cherished feature of Dutch maternity care, admired around the world for its combination of good outcomes with minimal interventions ${ }^{47}$.

\section{Collaboration between maternity service providers}

Given the increasing numbers of hospital midwives and the importance of teamwork in new, integrated models of care, we examined how collaboration was experienced within multi-disciplinary healthcare teams (MDT's) of midwifery care providers in the Netherlands (Chapter 6 ).

Good collaboration between health care professionals is known to be a key element of safe and effective care ${ }^{48-50}$. Suboptimal collaboration can compromise patient safety ${ }^{51,52}$. Collaboration is especially important in maternity care in the Netherlands where less than ideal collaboration has been cited as a significant factor in maternal deaths and in adverse incidents occurring in hospitals during evenings, nights, and weekends ${ }^{53,54}$. We found that $40 \%$ of maternity service providers in our survey were not satisfied with collaboration within the current model of care. In addition, there were significant differences in reported satisfaction between the professional groups.

M ost of the professional groups surveyed (hospital midwives, primary care midwives, and doctors) were pessimistic when asked about their view of collaboration within future models of care. When the groups were compared, midwives - hospital based and primary care - were significantly more pessimistic than doctors about collaboration within future models of maternity care. On the other hand, other caregivers - nurses and maternity-care assistants - were significantly more positive regarding collaboration in future models of care. This level of pessimism among midwives is in line with other research regarding the introduction of integrated care in the Netherlands $s^{55}$. Our findings underscore the pressing need to find mutually acceptable ways of organizing integrated models of care.

M idwifery in the Netherlands is experiencing a sustained period of change. Substantial changes to the funding structure, manner of working, and employment dynamics are being rolled out across the country, and our survey shows that each of these is viewed as a potential threat to optimal collaboration. Collectively, they present a serious challenge to effective collaboration within the country's maternity care. Strategies to address suboptimal collaboration exist ${ }^{56}$, however, no single, suitable approach has been identified.

Our findings are academically important, adding to our existing knowledge regarding collaboration, but they are also worrisome. The data point to the urgent need for stakeholders to reach consensus on how integrated care 
should be implemented in the Netherlands. It is likely that more tailor-made strategies - i.e. strategies which are tailored to particular groups or settings - to improve collaboration are needed to ensure the success of new models of Dutch maternity care. Our research has the additional value of serving as a benchmark and a useful comparator for future research on (integrated) care in maternity services in the Netherlands.

\section{Strengths and limitations}

Data for the studies contained in this thesis were collected seven and four years ago respectively. In the intervening years, more midwives have chosen to work in hospitals ${ }^{1}$. In addition, the introduction of the national job description for hospital midwives ${ }^{57}$ along with the "care standard" for perinatal care ${ }^{22}$ and the guideline for the position of hospital midwives ${ }^{58}$ have given additional dimensions to the debate over the future of midwifery in the Netherlands. However, given the absence of a clear and acceptable way forward regarding the position of hospital midwives within the Dutch maternity care model, together with the ongoing debate within the profession regarding possible amendments to the current Health Practitioners Law (creating a new registrant category for hospital midwives), it is clear that the issues raised by our findings remain relevant to contemporary midwifery practice in the Netherlands.

Prior to our study, little was known regarding the role, diversity, or practice conditions of Dutch hospital midwives. A major strength of our research is that it calls attention to the profile of the hospital midwife and, for the first time, acknowledges her contribution to maternity care in the Netherlands. In order to gather data from a broad and representative sample of maternity care givers, we chose to use quantitative methodology. While this provided us with important data, further, qualitative examination of the issues raised will provide a more nuanced insight into the underlying views of hospital midwives.

\section{Conclusion: implications for practice and education}

From their beginning less than 50 years ago, hospital midwives have, in a relatively short period of time, brought a new dimension to Dutch midwifery practice. Our findings offer a better understanding of the dynamics of midwifery service provision in the Netherlands and, in particular, provide insight into the daily practice of hospital midwives.

Over the past few years there has been much discussion about the role of midwives in the Dutch maternity care system, and new maternity care policies have been introduced, often without good supporting evidence. Among the possible options for reform of the midwifery profession, two are commonly 
suggested: the creation of a separate, 'specialist' register for hospital midwives and the introduction of an 'integrated midwife' (one who is equipped with the education and skills to work in hospitals and primary care). Neither option is supported by a majority of midwives ${ }^{59}$, underscoring the urgent need for research to explore the views of all practicing midwives. The articulation of a clear and widely accepted vision of the future of Dutch midwifery will allow the profession to move forward together.

The introduction of integrated care and the need to better harmonize the scope of practice of hospital midwives offer the profession an opportunity to pause and reflect on the best way to promote the health and well-being of mothers, families, and midwives. This moment of unrest should be used to modernize the profession, drawing on strengths that already exist to build models of care best-suited to the future. However, it remains to be seen whether the leadership of the CPZ and collaboration with the Quality Institute ${ }^{60}$ (Kwaliteits Instituut) will lead to better quality guidelines and protocols within maternity services in the Netherlands. Without consensus between the stakeholders, however, this appears unlikely.

Women's views - which, currently, are not reflected in the content of the protocols and guidelines used in the Netherlands - are crucial to the delivery of quality care ${ }^{61}$. The CPZ should listen to what women want - in addition to using the best evidence - when suggesting best practice. In addition, the CPZ should attempt to reduce mistrust between members of different professional groups by discouraging the use of mono-disciplinary protocols and by moving the discussion from a simplistic 'who decides who does what' to one focusing on best evidence for practice.

Despite the varied practice conditions of hospital midwives, they are, in general, satisfied with their jobs. But as we noted above, differing elements of job satisfaction appear to be more (or less) important for hospital midwives than their primary care colleagues. This finding has implications for employers, who should consider (the need for) more part-time employment, structured working conditions, and incentives that encourage longer term employment.

M idwives - both hospital and primary care - fear losing autonomy and, compared to their maternity care colleagues, see less potential for collaboration within proposed, new models of care. Successful implementation of new models will require more than mere encouragement to comply. The success of any new model will likely require finding ways to empower staff and to provide support for establishing their own ways of working in order to 
increase professional autonomy ${ }^{62}$ - an important contributor to job satisfaction.

Finally, strategies such as inter-professional education, structured communication, and the use of no-blame incident analysis have been shown to be effective in promoting greater collaboration ${ }^{63,64}$. Further exploration and use of such techniques should be systematically encouraged and funded.

\section{Recommendations for future research}

The move towards integrated care presents a unique opportunity for midwives to take the lead in deciding their future. Following on from our research it is clear that we need to better understand why so many midwives are choosing to work in hospitals, and we need to examine how hospital midwives see their role(s) developing. For example, with regard to the latter, future research should explore the reasons why hospital midwives experience lower levels of autonomy (and how this can be improved). Learning more about the drivers of job (dis)satisfaction will likely help to create policies to reduce expressed levels of pessimism regarding future models of service provision.

In order to create - and demonstrate the safety and efficacy of - new models of hospital midwifery care, we need further research on the scope and sphere of practice of hospital midwives. In addition, we need to conduct in-depth, qualitative studies of the differing predictors of job satisfaction between hospital and primary-care midwives - including the factors that promote their health and wellbeing. Lacking such research, it will be impossible to establish a clear vision for the future of midwifery in the Netherlands.

Lastly, future research must uncover the reasons why so many maternity care providers are not satisfied with collaboration within maternity care and ascertain what they need in order to feel more confident regarding collaboration in new models of care. Without this, the shared goals of integrated care - to promote seamless, effective, and satisfying care - will not be realized. 


\section{References.}

1). Kenens R, Batenburg R, Kasteleijn A. Cijfers uit de Registratie van Verloskundigen (Numbers from the registration of midwives) 2017, NIVEL, Utrecht, the Netherlands.

2). 24baby. Wat is een poliklinische bevaling? (What is a polikinische birth) https://www.24baby.nl/geboorte/waar-bevallen/poliklinische-bevalling/24. Accessed May 2019.

3). Perined. Jaarboek Zorg in Nederland (Annual report of Care in the Netherlands), Perined, 2012. https://www. perined.nl/publicaties1/publicaties/jaarboeken/ Accessed April, 2019.

4). Pel M, Heres M. OBINT. A study of obstetric intervention. Academisch proefschrift (Thesis). June 1995, University of Amsterdam, Amsterdam.

5). Hatem M, Sandall J, Devane D, et al. M idwife-led versus other models of care for childbearing women (review) Cochrane Collaboration. 2009. Accessed April 2018.

6). Birthplace in England Collaborative Group. Perinatal and maternal outcomes by planned place of birth for healthy women with low risk pregnancies: the

Birthplace in England national prospective cohort study. 2011. Oxford, UK. BMJ 2011;343: d7400.

7). Wang Z, Wenchao Sun, Hong Zhou. M idwife-led care model for reducing caesarean rate: A novel concept for worldwide birth units where standard obstetric care still dominates. Journal of M edical Hypotheses and Ideas, Volume 6, Issue 1, January 2012, Pages 28-31. https://doi.org/10.1016/j.jmhi.2012.03.013.

8). Bartuseviciene E, Kacerauskiene J, Bartusevicius A. et al. Comparison of midwife-led and obstetrician-led care in Lithuania: A retrospective cohort study. Midwifery, Volume 65, October 2018, Pages 67-71. https://doi.org/10.1016/j.midw.2018.06.017.

9). M cRae DN, Janssen PA, Vedam S, et al. Reduced prevalence of small-for gestational-age and preterm birth for women of low socioeconomic position: a population-based cohort study comparing antenatal midwifery and physician models of care. BMJ Open 2018;8:e022220. doi:10.1136/bmjopen-2018022220. 
10). The Individual Professional Practice in Healthcare Law (wet BIG)

[in Dutch]: Rijksoverheid Web site. http://www.rijksoverheid.nl/.

kwaliteitvanzorg/.

11). Betlem J. Oei G. De klinisch verloskundige. Van nu en de nabije toekomst! Samen werken aan de positie van de klinisch verloskundige (the clinical midwife now and in the near future! Working together on the position of the clinical midwife), 2017, KNOV, Utrecht, the Netherlands.

12). Koninklijke Nederlandse Organisatie van Verloskundigen (KNOV) / Nederlandse Vereniging voor Obstetrie en Gynaecologie (NVOG). Eindrapport KNOV- NVOG Werkgroep Klinisch Verloskundigen (Final report KNOV-NVOG working party clinical midwives). April, 2010. Utrecht, the Netherlands.

13). Vermeulen G, Nieuwenhuijze M, van Harn M. Gespreksmemo Toekomst verloskunde opleidingen (M emo for discussion: Future of midwifery education), 15 april 2015, Amsterdam, the Netherlands.

14). Cellissen E, Engeltjes B, Rijke R, Steegers E. et al. De physician assistant klinisch verloskundige in Nederland (the physician assistant clinical midwife in the Netherlands). Nederlands Tijdschrift voor Obstetrie \& Gynaecologie vol. 131, juni 2018 www.ntog.nl.

15). Croonen H. Ruzie binnen de perinatale zorg (Argument within perinatal care). M edisch Contact 2/2014, Utrecht the Netherlands.

16). Kramer J, Smit M, Simons R, Rijnders M . Factors that Influence Patient Safety in the Evening, Night and Weekend: a Literature Study [in Dutch]. Leiden: TNO; 2009.

17). Grol, R., \& Grimshaw, J. (2003). From best evidence to best practice: Effective implementation of change in patients' care. The Lancet, 362, 12251230.

18). Hogg, W., Baskerville, N., \& Lemlin, J. (2005). Cost savings associated with improving appropriate and reducing inappropriate preventative care: Cost consequences analysis. BM C Health Service Research, 5(1), 20.

19). van der Lee N, Driessen E, Scheele F. How the past influences interprofessional collaboration between obstetricians and midwives in the Netherlands: findings from a secondary analysis. J Interprof Care. 2016;30(1):71-76. 
20). Grol R (2001) Successes and failures in the implementation of evidencebased guidelines for clinical practice. M edical Care. 39: 46-54.

21). van der Velden J. A good beginning: safe care around pregnancy and birth. Advice of the steering group pregnancy and birth. [In Dutch] Rijks Overheid. 2009. http:// www.rijksoverheid.nl/enzwangerschap-en/x-cz-2978049b.pdf/. Accessed 26th June 2016.

22). College Perinatale Zorg. Zorgstandaard 'Integrale geboortezorg' Versie 1.0 (care standard 'integrated birth care' version 1.0).College Perinatale Zorg, 2015. Utrecht, the Netherlands.

23). College Perinatale Zorg. Wat wij doen (what we do) College Perinatale Zorg, 2019. Utrecht, the Netherlands.

https://www.kennisnetgeboortezorg.nl/over-cpz/ 88-wat-we-doen.

24). Perdok $H$, Jans $S$, Verhoeven $C$, Henneman L. et al. Opinions of maternity care professionals and other stakeholders about integration of maternity care: a qualitative study in the Netherlands. BM C Pregnancy Childbirth. 2016 Jul 26;16(1):188. doi: 10.1186/s12884-016-0975-z. PMID: 27459967.

25). Goodarzi B, van der Post J, Schellevis F, de Jonge A. Eerst welke organisatie vorm het best werkt Invoering integrale geboortezorg voorbarig (First: which form of organisation works best, the Introduction of integrated care is premature). M edisch Contact 24 | 14 Juni 2018.

26). Nurses and Midwives Council (NMC). (2008) The professional code of conduct for nurses and midwives. NM C: London. http:// www.nmcuk.org/Documents/Standards/The-code-A4-20100406.pdf. Accessed Dec 2018.

27). College of M idwives of British Columbia. New register mentorship agreement. https://www.cmbc.bc.ca/wp-content/uploads/2018/12/NewRegistrant-M entorship-Agreement.pdf. Accessed Dec 2018.

28). Lawson L, Bunyan C. M idwives: the next generation. M entors play a crucial role in preparing the next generation of midwives for safe and competent practice. Dutch M idwives Journal, 4th ed. 2013.

29). M oran M, Banks D. An exploration of the value of the role of the mentor and mentoring in midwifery. Nurse Educ Today. $2016 \mathrm{M}$ ay; 40:52-6. doi: 10.1016/j.nedt.2016.02.010. Epub 2016 Feb 19.

30). Bjørka I, Samdal G, Hansen B, Tørstadd S, Hamilton G. Job satisfaction in a Norwegian population of nurses: A questionnaire survey International Journal of Nursing Studies, 2007. 44; 747-757. 
31). KNOV. Policy Rules regarding M idwifery Care in the Netherlands: tariff 2019 [In Dutch] 2018. KNOV. Utrecht. https://www.knov.nl/actueeloverzicht/ nieuws-overzicht/ detail/update-nza-beleidsregel-verloskunde2019/2362. Accessed Dec 2018.

32). Nurses and Midwives Council of the United Kingdom (NMC). Revalidation: Step-by-step guide through the process. 2018. NM C, London England. http://revalidation.nmc.org.uk/information-for-employers/index.html. Accessed Dec 2018.

33). Dutch M inistry of Health, wellness and Sport. Individual Professions for Healthcare Procedure for re-registration (In Dutch) BIG Register, the Hague, Netherlands, 2018. https:// www. bigregister.nl/herregistratie/. Accessed Dec 2018.

34). M cCarthy C, Illiffe J. Continuing Professional Development for Nurses and M idwives: A Toolkit for Developing a National CPD Framework. U.S. Centers for Disease Control and Prevention (CDC) Emory University. The Commonwealth Secretariat The Commonwealth Nurses Federation East, Central, and Southern Africa College of Nursing.

https://www.researchgate.net/publication/284032370. Accessed M ay 2019.

35). Koninklijke Nederlandse Organisatie van Verloskundigen (KNOV). Kwaliteits Register. (Royal Dutch Organisation of M idwives Quality Register), KNOV, Utrecht, the Netherlands. https://www.kwaliteitsregisterverloskundigen.nl/ Accessed April 2019.

36). Wiegers T, Hukkelhoven $C$. The role of hospital midwives in the Netherlands BM C Pregnancy and Childbirth 2010 10:80.

37). Liu C, Spector P, Jex M . 2005. The relation of job control with job strains: A comparison of multiple data sources. Journal of Occupational and Organizational Psychology, 78(3), pp. 325-336.

38). de Jonge J. 1998. Job characteristics and employee well-being: a test of Warr's Vitamin Model in health care workers using structural equation modelling. J. Organ Behav, 19(4), pp. 387-407.

39). Forster DA, M cLachlan HL, Davey M A, Biro MA, Farrell T, Gold L, et al. Continuity of care by a primary midwife (caseload midwifery) increases women's satisfaction with antenatal, intrapartum and postpartum care: results from the COSM OS randomised controlled trial. BM C Pregnancy Childbirth 2016 Feb 3; 16:28-016-0798-y. 
40). Walsh D. Devane D. 2012. A metasynthesis of midwife-led care. Qualitative health research, 22(7), pp. 897-900.

41). Walsh D. Devane D. 2012. A metasynthesis of midwife-led care. Qualitative health research, 22(7), pp. 905-910.

42). Lange T. Job satisfaction and self-employment: Autonomy or personality? Small Business Economics 38(2):165-177. ISI: 2.852 - February 2012 DOI: 10.1007/s11187-009-9249-8 Accessed Jan 2019.

43). Fenwick J, Sidebotham M, Gamble J, Creedy D. The emotional and professional wellbeing of Australian midwives: A comparison between those providing continuity of midwifery care and those not providing continuity. Women and Birth, 31 (2018) 38-43. http://dx.doi.org/10.1016/j.wombi.2017.06.013 Accessed: Jan 2019.

44). Pallant J, Dixon L, Sidebotham M , Fenwick J. Further validation of the perceptions of empowerment in midwifery scale. M idwifery 2015;31(10):9415.

45). Hildingsson I, Gamble J, Sidebotham M, Creedy D, et al. M idwifery empowerment: national surveys of midwives from Australia, New

Zealand and Sweden. M idwifery 2016;40:62-9.

46). Weggeman M, Hoedemakers C. M anaging Professionals? Don't! How to step back to go forward a continental European perspective. Warden Press, 2014, Amsterdam. ISBN: 978-94-92004-01-7.

47). de Vries R, Nieuwenhuijze M, Buitendijk S. What does it take to have a strong and independent profession of midwifery? Lessons from the Netherlands. M idwifery 29(2013)1122-1128.

48). M clnnes S, Peters K, Bonney A, Halcomb E. An integrative review of facilitators and barriers influencing collaboration and teamwork between general practitioners and nurses working in general practice. J Adv Nurs. 2015; 71(9):1973-1985.

49). M organ S, Pullon S, M cKinlay E. Observation of inter-professional collaborative practice in primary care teams: an integrative literature review. Int J Nurs Stud. 2015; 52(7):1217-1230.

50). Hämel K, Vössing C. The collaboration of general practitioners and nurses in primary care: a comparative analysis of concepts and practices 
in Slovenia and Spain. Prim Health Care Res Dev. 2017; 18(5):492-506.

51). Lyndon A, Zlatnik M , Watcher R. Effective physician-nurse communication. a patient safety essential for labor \& delivery. Am J Obstet Gynecol. 2011;205(2):91-96.

52). M artijn L, Jacobs A, Amelink-Verburg M, Wentzel R. et al. Adverse outcomes in maternity care for women with a low risk profile in the Netherlands: a case series analysis. BM C Pregnancy Childbirth. 2013;13(13):219.

53). Schutte J (2010) Safe motherhood, confidential enquires into maternal deaths in the Netherlands 1993-2005.Thesis, free university, Amsterdam, The Netherlands.

54). Dutch Inspectorate for Healthcare (IGZ). Risico's in Ziekenhuiszorg in avond, nacht en weekend moeten beter afgedekt (Risks in hospital care in the evening, night and in the weekend must be better covered); 2011, IGZ, Utrecht, the Netherlands.

55). Perdok H, Jans S, Verhoeven C, van Dillen J. et al. Opinions of professionals about integrating midwife- and obstetrician-led care in The Netherlands. M idwifery. 2016 Jun;37:9-18. doi: 10.1016/j.midw.2016.03.011. Epub 2016 Apr 1. PMID: 27217232.

56). Oxman, A., Thomson, M., Davis, D., \& Haynes, R. (1995). No magic bullets: A systematic review of 102 trials of interventions to improve professional practice. Canadian M edical Association Journal, 153(10), 1423-1431.

57). Koninklijke Nederlandse Organisatie van Verloskundigen (KNOV). KNOV. Beroepsprofiel Klinisch Verloskundige (J ob description Clinical M idwife), 2013, KNOV, Utrecht, the Netherlands.

58). Werkgroep Leidraad Stuurgroep Klinisch Verloskundige. Leidraad voor Protocol positie klinisch verloskundigen (Working Group Guideline Clinical M idwives Steering Group. Guideline for the position of clinical midwives), 2014, KNOV/NVOG, Utrecht, the Netherlands.

59). Visser R. De nieuwe kleren van de keizer (The emperor's new clothes)? TvV 2/2014. KNOV, Utrecht, the Netherlands.

60). Zorginstituut Nederland. (Care Authority, the Netherlands) M ission statement. 2016. https:// www.zorginstituutnederland.nl/overons/organisatie/missie/ Accessed April 2019. 
61). Groenen C. et al. Improving maternity care using a personal health record: study protocol for a stepped-wedge, randomised, controlled trial. Trials (2016) 17:202. DOI 10.1186/s13063-016-1326-0.

62). NHS National Maternity Review Report, 2016-last update, Better births: improving outcomes of maternity services in England.

https://www.england.nhs.uk/wp-content/uploads/2016/02/nationalmaternity-review-report.pdf [1/19, 2017].

63). van Diem MT, Bergman KA, Bouman K, et al. Perinatale audit NoordNederland: de eerste 2 jaar. (Perinatal audit in the North of the Netherlands: the first 2 years). Dutch M ed J [Nederlands Tijdschrift voor Geneeskunde]. 2011;155(18):A2892. Dutch.

64). Posthumus AG, Schölmerich VL, Waelput AJ, et al. Bridging between professionals in perinatal care: towards shared care in the Netherlands. Maternal Child Health J. 2013;17(10):1981-1989. 


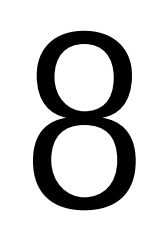

Summary/ Nederlandse Samenvatting 


\section{Summary of this thesis}

\section{Chapter 1}

The first chapter describes the background, rationale, and aims of this thesis.

The primary care midwife has long been the cornerstone of Dutch maternity care; the hospital midwife is a relatively new and increasingly important caregiver for pregnant and birthing women in the Netherlands. Twenty-five years ago, fewer than ten percent of midwives in the Netherlands were identified as hospital midwives (known as 'clinical midwives' in Dutch). Today, according to the latest available numbers, one in three midwives are employed in hospitals, making this the fastest growing segment of the profession. In spite of their growing numbers, and in spite of the fact that they are frequently called upon to care for women with complex care needs - often without direct supervision by an obstetrician - we know very little about the practice and working environment of hospital midwives.

The aim of our research was to map and critically review the practice of hospital midwives and to explore their contribution to the quality of maternity care within the context of Dutch maternity service provision (M SP). We looked at what they do and how they experience this because their experiences are (or can be seen as) another determinant for quality of care.

The objectives of our research were:

1. To describe the existing diversity in the scope and practice of hospital midwives in the Netherlands (chapter 2).

2. To examine the content and quality of the protocols for hospital midwives used in maternity hospitals in the Netherlands (chapter 3).

3. To compare hospital midwives and primary care midwives with regard to job satisfaction and attitudes towards their work (chapter 4).

4. To examine how maternity care professionals in the Netherlands perceive their job autonomy and whether their expectations about job autonomy will change in a system of integrated maternity care (chapter 5).

5. To examine the quality of collaboration between multi-disciplinary teams of maternity service providers in the Netherlands (chapter 6 ). 


\section{Chapter 2}

We know that the number of hospital midwives is growing. However, very little is known about what hospital midwives in the Netherlands actually do. We do know that there are no nationally agreed-upon multidisciplinary standards for midwifery practice in the hospital setting and that not all hospital midwives have additional training. We addressed this lacuna by describing the diversity in the scope and practice of hospital midwives. Our data come from an online survey of all hospitals in the Netherlands that gathered information about the hospital organisation, demographic information relating to hospital midwives, their experience and additional qualifications (if any), and the position of hospital midwives - in terms of duties, responsibilities and collaboration within the multidisciplinary clinical team.

We received responses from 59 of the 98 hospitals that provide maternity care in the Netherlands. One in four midwives registered to practice is employed in the hospital setting, the site of $70 \%$ of all births in the Netherlands. In theory, all those hospital births are to women transferred to secondary (hospital) care because they have an increased risk profile compared to that of women birthing in primary care (i.e., where care is provided by community midwives and general practitioners). Given that these births are no longer considered "low-risk", it is remarkable that $77 \%$ of hospital births that occurred during the study period were attended by hospital midwives, and that $40 \%$ of all hospital births in that period were managed solely by a hospital midwife. We also discovered that not all hospitals employ midwives and among those that do, not all have midwives on duty twenty-four hours a day or seven days a week.

Our respondents reported a diverse collection of duties and responsibilities, which indicated that hospital midwives have a high level of autonomy (this topic is explored further in chapter 5). M idwives in the survey had varied educational backgrounds: some midwives had no additional training beyond their initial qualification, while others reported having a masters' degree. Our study showed great differences between hospitals in the Netherlands regarding the scope of practice of hospital midwives.

Perhaps the most striking finding of our study is the degree of responsibility given to hospital midwives, who attend the majority of births referred to the hospital from primary care. This finding is important because it reveals a flaw in the records kept by Perined, the keeper of statistics regarding maternity care in the Netherlands. Because these midwife-attended hospital births occur under the supervision of an obstetrician, even when managed solely by hospital 
midwives, they are officially recorded as births done by an obstetrician. The result is an inaccurate picture of the role of midwives in the delivery of maternity care in the Netherlands. For example, in 2012 the official records report that midwives attended $30 \%(n=51708)$ of births (see https://www. perined.nl/publicaties1/publicaties/jaarboeken/) while in fact, they were actually the main caregiver at $83 \%(n=143664)$ of the total births in the Netherlands ( $n=173099)$.

\section{Chapter 3}

This diversity in role and practice conditions led us to look more closely at the content and quality of protocols governing the work of hospital midwives. The rationale for our study, undertaken in conjunction with the Dutch Healthcare inspectorate (IGZ), was a desire to explore possible factors affecting safety in hospitals. We did this by examining the content and methodological quality of hospital protocols. Three protocols - for the management of hypertensive conditions of pregnancy, post-partum haemorrhage, and fetal surveillance were selected by the Inspectorate for assessment. These protocols should routinely be available in Dutch maternity hospitals and should be based on best available evidence. The availability of evidence-based protocols is increasingly important as the Netherlands moves to new integrated models of care, where teams of providers will work together on maternity units. While these changes in the organization of care began after our research, our work nonetheless serves as an important benchmark of the guidance available to midwives working in hospital and may reflect the situation today.

A postal and internet questionnaire was sent to all hospitals with maternity facilities in the Netherlands, inquiring about the availability of these three protocols. Hospitals were asked to send copies of their protocols. All of the protocols received were systematically assessed for content and methodological quality. We measured their methodological rigour with the validated AGREE framework and we used a Likert-type scale to evaluate the level of evidence used.

We received responses from 48 of the 91 hospitals that provide maternity care in the Netherlands. The methodological quality of protocols we evaluated was poor. Using the AGREE framework, $70 \%$ of fetal surveillance protocols could not be recommended, and only one protocol from a single hospital scored "strongly recommend". There was a general paucity of evidence in the protocols assessed. An incidental finding of our research was a high degree of confusion regarding the definition of a protocol and what it should contain. 
This study shows that, at the time of our research, up-to-date, evidence-based protocols were not widely available in Dutch maternity units, and where they did exist, they were often of poor quality.

\section{Chapter 4}

Given the lack of clarity surrounding the role, practice conditions, and quality of evidence available to hospital midwives, we then turned our attention to the differences between hospital midwives and primary care midwives with regard to their job satisfaction and attitudes towards their work. This is important to know because higher levels of job satisfaction and employee-wellbeing have been identified as improving quality of care.

This chapter presents a systematic examination of the job satisfaction levels among hospital and primary-care midwives in the Netherlands. We distributed an online survey to all practicing midwives in the Netherlands, which included a validated measure of job satisfaction (the Leiden Quality of Work Life Questionnaire) -- allowing us to analyse the attitudes of hospital and primarycare midwives towards their work. The survey consisted of ten domains, each containing several "factor statements". One domain is specifically focused on job satisfaction; the other nine domains explore various elements related to job satisfaction.

In total, 508 midwives responded to our survey. One hundred and three were hospital midwives, and 405 were primary care midwives. All midwives - both primary care and hospital based - said they were satisfied with their work. However, there were significant differences between hospital and primary care midwives in the factors related to their job satisfaction. For hospital midwives, the most significant drivers of satisfaction were: the number of hours worked per week, workplace agreements, and total years of experience. For primarycare midwives, social support at work, work demands, job autonomy, and the influence of work on private life were the most significant predictors of satisfaction.

Our data confirm that midwives in the Netherlands are satisfied with their jobs overall, but that the sources of that satisfaction vary according to where midwives work - in the community or in the hospital. Given that job satisfaction also affects the quality of care (and the expressed level of satisfaction with that care), these differences are important to consider when planning workforce needs and should be used by policymakers in the Netherlands and elsewhere when planning new models of care. The observed variation in satisfaction depending on place and type of work - suggests that tailor-made strategies that respond to the different drivers of job satisfaction for community and 
hospital midwives will improve the satisfaction midwives derive from their work.

\section{Chapter 5}

Recognising that a significant element of job satisfaction is autonomy at work, we investigated how maternity care professionals in the Netherlands perceive their job autonomy and we explored how they thought their autonomy might be affected by the introduction of integrated maternity care.

We used data from the survey described in chapter 4 to compare how maternity care professionals in the Netherlands - including not only midwives (both hospital and primary care), but also obstetricians, and obstetric nurses perceive their job autonomy. These data also shed light on how a new system of integrated maternity care may affect the experienced autonomy of professionals.

A total of 799 maternity care professionals participated in the survey: 93 hospital midwives, 362 primary care midwives, 240 obstetricians, and 104 obstetric nurses. We combined respondents' answers to the factor statements from the domain 'decision authority' - contained within the Leiden Quality of Work Life Questionnaire - to calculate a mean score for experienced job autonomy. The mean score for experienced job autonomy was highest for primary care midwives, followed by obstetricians, hospital midwives, and obstetric nurses. Primary care midwives had the highest level of concern about losing their job autonomy in a system of integrated care.

Our study shows that there is a significant difference in experienced job autonomy between maternity care professionals. Job autonomy is known to be an important facet of job satisfaction. A high level of job autonomy has also been shown to have a positive effect on the professional-patient relationship.

Our data show that midwives in the Netherlands - particularly those working in primary care - were pessimistic regarding their autonomy in future models of care. Any decrease in experienced job autonomy could have a negative impact on job related wellbeing and satisfaction among professionals and the women for whom they care. The challenge when introducing new models of care is to maintain a high level of experienced job autonomy. To maintain and enhance professional autonomy, staff must be supported in establishing their own ways of working. 


\section{Chapter 6}

Good collaboration between health care professionals is a key element of safe, effective care, but creating a collaborative culture can be challenging. In chapter 6 we turn our attention to how the multi-disciplinary teams (MDTs) that provide maternity care in the Netherlands experience inter-professional collaboration. In spite of its importance for effective maternity care, little is known about the nature and quality of collaboration between maternity care professionals. To fill this gap, we used data from an online survey to identify potential enhancing and inhibiting factors for inter-professional collaboration within these MDT's. We combined respondents' answers to the factor statements from the domain 'workplace collaboration within multi-disciplinary team' - contained within the Leiden Quality of Work Life Questionnaire - to generate a mean collaboration score.

We had a relatively large sample for this study: 3653 professionals responded, including 97 hospital midwives, 390 obstetricians, 390 primary care midwives, and 2776 obstetric nurses and maternity care assistants. Forty percent of our respondents were not satisfied with collaboration within their MDT.

There were significant differences in mean collaboration scores between the professional groups. Midwives - hospital and primary care - were pessimistic about collaboration in future models of maternity care. Optimum collaboration is a safety issue and one of the greatest challenges of modern-day healthcare. Literature suggests that failing to address this issue could affect patient safety. Strategies to address sub-optimal collaboration are known to exist. However, there is no one-size-fits-all approach for addressing the issue.

As a result of this study, we know that within the current midwifery model of care, the perception of collaboration is sub-optimal. Those introducing models of integrated maternity care in the Netherlands must pay attention to the need for improved collaboration between professionals. Further research should investigate which strategy is the most appropriate for MDT's to ensure that collaboration is optimized.

\section{Chapter 7 General discussion}

M idwifery in the Netherlands is in the midst of a period of great change. Substantial alterations to the funding structure, manner of working, and employment dynamics are being introduced. In this chapter, we discuss our main findings against the background of changing models of care and in the context of the (international) literature on the practice of midwifery. We go on to examine the implications of our work for policy, future research, and maternity care practice. 
We found a large diversity in the practice of hospital midwives in the Netherlands. In addition, when we did our research, up-to-date, high quality, evidence-based protocols were not widely available in Dutch maternity units. We also found that while all midwives were satisfied with their jobs, there were important differences in the predictors of job satisfaction between hospital and primary care midwives.

Turning to the future, and in particular the introduction of integrated models of care in the Netherlands, our findings show that all midwives feared losing autonomy and were pessimistic regarding the quality of collaboration in future models of care.

We suggest that in order to succeed, future models of care must consider the existing diversity of practice and must engage all professionals in a manner that guarantees their autonomy while, at the same time, promoting greater collaboration among those professionals. Comparison with other, similarly situated professional collaborations may point to ideas that could help shape future models of care.

It is known that midwives can provide safe, effective care - even with women who do not meet the criteria for primary care. This thesis demonstrates that hospital midwives have become an important - and distinct - component of the Dutch midwifery model of care.

Our findings offer insight into the daily practices of hospital midwives, providing a better understanding of the dynamics of midwifery service provision in the Netherlands. Further research is needed, however, to determine how to better regulate the still largely unregulated practice of hospital midwifery and to learn how midwifery services - in the community and in the hospital - can best meet the needs of women. Our research, the first careful look at hospital midwifery, opens the door to future studies. We need to learn more about the views of those who benefit from the care given by hospital midwives - women and their families - and we need to examine the experiences and perspectives of the midwives who are playing this important role in Dutch maternity care. 


\section{Nederlandse Samenvatting}

\section{Hoofdstuk 1}

In Hoofdstuk 1 worden de achtergrond, de onderbouwing en de doelstellingen van dit proefschrift beschreven. De eerstelijns verloskundige is lange tijd de hoeksteen van de Nederlandse geboortezorg geweest. De klinisch verloskundige is een relatief nieuwe en een steeds belangrijker wordende zorgverlener voor zwangere en barende vrouwen in Nederland. Vijf en twintig jaar geleden was het aantal klinisch werkende verloskundigen minder dan tien procent. Volgens de meest recente cijfers, werkt momenteel één op de drie verloskundigen in het ziekenhuis en zijn zij daarmee de snelst groeiende groep binnen de verloskundige professie. Ondanks de toename in het aantal klinisch verloskundigen, en het feit dat klinisch verloskundigen met regelmaat de zorg voor zwangeren met complexe zorgvragen op zich nemen zonder directe supervisie van een gynaecoloog, weten we nog maar weinig over de inhoud en uitvoering van het werk in de praktijk of over de werkomstandigheden van deze klinisch verloskundigen.

Het doel van ons onderzoek was om de dagelijkse praktijk van het werk van klinische verloskundigen in kaart te brengen, dit kritisch te beoordelen en inzicht te krijgen in hun bijdrage aan de kwaliteit van zorg binnen de Nederlandse verloskunde. We hebben gekeken naar wat ze doen en hoe ze hun werk ervaren omdat de wijze waarop het werk ervaren wordt een determinant is (of kan worden gezien als) van kwaliteit van zorg.

De doelstellingen van het onderzoek waren als volgt:

1. Het beschrijven van de bestaande diversiteit in de reikwijdte en inhoud van het werk van klinisch verloskundigen in Nederland (hoofdstuk 2).

2. Het onderzoeken van de inhoudelijke en methodologische kwaliteit van ziekenhuisprotocollen die door klinisch verloskundigen gebruikt worden (hoofdstuk 3).

3. Het vergelijken van de arbeidssatisfactie en de werkattitude tussen klinisch en eerstelijns verloskundigen (hoofdstuk 4).

4. Te onderzoeken hoe verloskundige zorgverleners in Nederland hun professionele autonomie beoordelen en wat hun verwachtingen zijn ten aanzien van deze autonomie in een integraal zorgsysteem (hoofdstuk 5).

5. Te onderzoeken wat de kwaliteit van de samenwerking is binnen multidisciplinaire teams van verloskundige zorgverleners in Nederland (hoofdstuk 6). 


\section{Hoofdstuk 2}

Hoewel bekend is dat het aantal klinisch werkende verloskundigen stijgt, is het nauwelijks bekend wat deze verloskundigen nu eigenlijk precies doen. We weten dat er landelijk overeengekomen multidisciplinaire richtlijnen bestaan voor de verloskundige praktijk in het ziekenhuis en dat niet alle klinisch werkende verloskundigen een extra opleiding of training hebben gevolgd. Om deze kennislacune over de inhoud en de reikwijdte van het werk van klinische verloskundigen te beantwoorden is een online vragenlijst uitgezet onder alle Nederlandse ziekenhuizen. Data zijn verzameld over de organisatie van zorg binnen het ziekenhuis, demografische gegevens van klinische verloskundigen, informatie over hun ervaringen, extra gevolgde trainingen en opleidingen (indien van toepassing), en de positie van klinisch verloskundigen met betrekking tot taken, verantwoordelijkheden en samenwerking binnen het multidisciplinaire klinische team.

Negen en vijftig van de 98 Nederlandse ziekenhuizen die verloskundige zorg verlenen retourneerden de vragenlijst. Eén op de vier BIG geregistreerde verloskundigen werkt in een ziekenhuis, de locatie waar $70 \%$ van alle bevallingen in Nederland plaatsvindt. Het betreft hier in principe de bevallingen van vrouwen die overgedragen zijn aan de tweede lijn vanwege een verhoogd risico op complicaties, vergeleken met zwangere vrouwen in de eerste lijn die zorg ontvangen van eerstelijns verloskundigen en huisartsen. Het is opmerkelijk dat, gezien het feit dat deze bevallingen niet langer beschouwt kunnen worden als 'laag risico', 77\% van deze tweedelijns bevallingen (voor het merendeel) begeleid werden door klinische verloskundigen en dat $40 \%$ van deze ziekenhuis bevallingen begeleid werden door alleen een klinische verloskundige zonder enige bemoeienis van een gynaecoloog. Daarnaast laat het onderzoek ook zien dat niet alle ziekenhuizen klinisch verloskundigen in dienst hebben en dat de klinisch verloskundigen in de ziekenhuizen die dat wel doen, niet altijd 24 uur per dag en zeven dagen per week beschikbaar zijn.

De respondenten rapporteerden een grote verscheidenheid aan taken en verantwoordelijkheden van klinisch verloskundigen, waaruit een beeld naar voren komt van een hoge mate van autonomie (dit onderwerp wordt in hoofdstuk 5 uitvoerig besproken).

De verloskundigen in dit onderzoek lieten een diverse opleidingsachtergrond zien: Sommige verloskundigen hadden nooit een extra opleiding of training gevolgd naast hun initiële opleiding, terwijl anderen een masterstudie hadden gedaan. Onze studie liet een grote verscheidenheid zien tussen ziekenhuizen met betrekking tot de reikwijdte van het werk in de dagelijkse praktijk van 
klinische verloskundigen. Wellicht de meest opvallende bevinding was de mate van verantwoordelijkheid gegeven aan klinische verloskundigen in de begeleiding van het merendeel van de bevallingen die verwezen zijn door de eerste lijn, Dit is een belangrijke bevinding omdat het een onvolkomenheid in de Perined gegevens laat zien; deze door verloskundigen begeleidde bevallingen vinden plaats onder supervisie van een gynaecoloog en worden als dusdanig geregistreerd, óók wanneer de bevalling vrijwel volledig, - plaatsvindt onder begeleiding van de klinische verloskundige, zonder enige bemoeienis van een gynaecoloog -. Hierdoor ontstaat een onvolledig beeld van de rol van verloskundigen in de Nederlandse geboortezorg. Zo laten officiële cijfers uit 2012 zien dat verloskundigen $30 \%(n=51.708)$ van alle bevallingen in Nederland hebben begeleid, terwijl zij in feite de belangrijkste aanwezige zorgverlener waren tijdens $83 \%$ ( $n=143.664)$ van het totaal aantal bevallingen van dat jaar in Nederland $(n=173.099)$.

\section{Hoofdstuk 3}

Vanwege de diversiteit in de taken en verantwoordelijkheden van klinisch verloskundigen werd besloten de inhoud en kwaliteit van ziekenhuis protocollen, die leidend zijn in hun werk, te onderzoeken. Het doel van het onderzoek dat uitgevoerd werd op verzoek van de Inspectie Gezondheidszorg (IGZ), was de wens om mogelijke factoren te identificeren die van invloed zijn op de veiligheid van zorg in ziekenhuizen. Het onderzoek werd uitgevoerd doormiddel van het beoordelen van de inhoud en de methodologische kwaliteit van ziekenhuis protocollen. Op verzoek van de IGZ werden de protocollen voor het beleid bij hypertensieve aandoeningen tijdens de zwangerschap, fluxus postpartum en foetale bewaking, bij alle Nederlandse ziekenhuizen opgevraagd. Deze protocollen horen standaard in ieder ziekenhuis aanwezig te zijn en zijn in principe gebaseerd op het best beschikbare wetenschappelijke bewijs. De beschikbaarheid van wetenschappelijk onderbouwde protocollen wordt steeds belangrijker nu de zorg in Nederland verschuift naar een integraal model waarbij teams van zorgverleners samenwerken om betere geboorte zorg te kunnen leveren.

Hoewel er veranderingen in de zorg hebben plaats gevonden ná de uitvoering van dit onderzoek, zijn de uitkomsten van ons onderzoek een belangrijk benchmark wat betreft de beschikbare ondersteuning voor klinisch verloskundigen. Het is aannemelijk dat de uitkomsten van dit onderzoek nog steeds een realistische weergave van de huidige situatie zijn.

M et behulp van zowel een papieren als een digitale vragenlijst werden ziekenhuizen met een verloskundige afdeling gevraagd naar de 
beschikbaarheid van deze drie protocollen en het verzoek of zij een kopie van deze protocollen wilden opsturen. Alle ontvangen protocollen werden systematisch beoordeeld op inhoud en methodologische kwaliteit met behulp van het gevalideerde AGREE raamwerk en een likert-schaal om de wetenschappelijke inhoud te evalueren.

Wij ontvingen antwoord van 48 van de 91 ziekenhuizen met een afdeling verloskunde. De methodologische kwaliteit van de geëvalueerde protocollen was beperkt. Op basis van het AGREE raamwerk kon $70 \%$ van de protocollen met betrekking tot foetale bewaking niet worden aanbevolen en scoorde slechts één ziekenhuis protocol "sterk aanbevolen". Over het algemeen ontbrak het in de protocollen aan wetenschappelijke onderbouwing.

Een toevallige bevinding van ons onderzoek was de bestaande verwarring over de definitie van wat een protocol is en inhoudt.

Dit onderzoek laat zien dat actuele en op wetenschappelijk bewijs gebaseerde protocollen tijdens de onderzoekperiode niet of nauwelijks beschikbaar waren op de Nederlandse verloskundige afdelingen en dat, als ze al beschikbaar waren, ze van slechte kwaliteit waren.

\section{Hoofdstuk 4}

Vanwege de onduidelijkheden rondom taken en verantwoordelijkheden van klinisch verloskundigen en de beperkte kwaliteit van beschikbare protocollen die hun werk behoren te ondersteunen, is het verschil in arbeidssatisfactie en werkhouding tussen klinisch en eerstelijns verloskundigen onderzocht. Aangezien arbeidssatisfactie en werknemerswelzijn gerelateerd zijn aan betere kwaliteit van zorg is het belangrijk om hier inzicht in te hebben. Dit hoofdstuk beschrijft een systematisch onderzoek naar arbeidssatisfactie van klinisch en eerstelijns verloskundigen in Nederland. Er werd een online vragenlijst uitgezet onder alle praktiserende verloskundigen in Nederland. De vragenlijst bestond uit een gevalideerde maat voor arbeidssatisfactie (de Leiden Kwaliteit van Werk Leven vragenlijst), waarmee de mening van deze verloskundigen ten opzichte van hun werk werd geanalyseerd.

De vragenlijst bevatte tien domeinen met een aantal "factor statements" per domein. Een van de domeinen betrof specifiek arbeidssatisfactie; de overige negen domeinen betroffen verschillende elementen gerelateerd aan arbeidssatisfactie.

In totaal beantwoordden 508 verloskundigen de vragenlijst, waarvan 103 klinisch en 405 eerstelijns verloskundigen. Alle verloskundigen, zowel klinisch als eerstelijns, gaven aan dat zij tevreden waren over hun werk. Er waren 
echter significante verschillen tussen de twee groepen wat betreft de factoren die hun arbeidssatisfactie bepaalden. De belangrijkste factoren voor tevredenheid bij klinisch verloskundigen waren het aantal werkuren per week, werkafspraken (zoals protocollen) en het aantal jaren werkervaring. Sociale steun op het werk, werkbelasting, professionele autonomie en de invloed van werk op de privé sfeer, waren de belangrijkste factoren die bijdroegen aan de arbeidssatisfactie van eerstelijns verloskundigen. Onze data laten zien dat verloskundigen in het algemeen tevreden zijn over hun werk, maar dat de factoren die bijdragen aan arbeidssatisfactie verschillen op basis van waar zij werken: in de eerste lijn of in het ziekenhuis.

Aangezien arbeidssatisfactie van invloed is op de kwaliteit van de geleverde zorg en op de mate van tevredenheid over de verkregen zorg door cliënten, zijn deze verschillen belangrijk om mee te nemen bij het uitzetten van personeelsbeleid, en bij het bepalen van beleid met betrekking tot de introductie van nieuwe zorgmodellen.

De gevonden variatie in tevredenheid, afhankelijk van de plaats en het type werk, suggereert dat de arbeidssatisfactie van alle verloskundigen kan verbeteren als er meer wordt uitgegaan van op maat gemaakte strategieën die tegemoetkomen aan de verschillende factoren van arbeidssatisfactie onder eerstelijns en klinisch verloskundigen.

\section{Hoofdstuk 5}

Omdat professionele autonomie uit het onderzoek naar voren kwam als een significant onderdeel van arbeidssatisfactie, is ook onderzocht hoe verloskundige zorgverleners in Nederland hun professionele autonomie ervaren en welke effecten een integraal zorgsysteem volgens hen op deze autonomie zou kunnen hebben.

De data uit het onderzoek beschreven in hoofdstuk 4, zijn gebruikt om de ervaren professionele autonomie onder verschillende verloskundige zorgverleners, niet alleen verloskundigen maar ook gynaecologen en obstetrisch verpleegkundigen, te vergelijken. Deze data maken de mogelijke effecten van een nieuw systeem van integrale zorg op de professionele autonomie inzichtelijk.

In totaal namen 799 verloskundige zorgverleners deel aan (dit deel van) van de Leiden Kwaliteit van Werk Leven vragenlijst: 93 klinisch verloskundigen, 362 eerstelijns verloskundigen, 240 gynaecologen en 104 obstetrisch verpleegkundigen. 
De antwoorden van de respondenten op de 'factor statements' uit het domein 'Beslissingsbevoegdheid', werden gecombineerd om een gemiddelde score voor professionele autonomie uit te rekenen. Deze score bleek het hoogst voor eerstelijns verloskundigen, gevolgd door gynaecologen, klinisch verloskundigen en het laagst voor obstetrisch verpleegkundigen.

Eerstelijns verloskundigen gaven aan het meest bezorgd te zijn over het verlies van hun professionele autonomie bij de introductie van een integraal verloskundig zorgsysteem.

Onze studie laat zien dat er een significant verschil is in professionele autonomie tussen de verschillende groepen verloskundige zorgverleners. Professionele autonomie is een belangrijk onderdeel van arbeidssatisfactie, en een hoog niveau van professionele autonomie heeft een positief effect heeft op de professional-patiënt relatie.

Verloskundigen werkzaam in Nederland, vooral diegenen in de eerste lijn, zijn pessimistisch over het behoud van professionele autonomie bij de invoering van toekomstige zorgmodellen. Een afname van professionele autonomie zou dan ook een negatief effect kunnen hebben op werk-gerelateerd welzijn en tevredenheid bij professionals en op de ervaren zorg door vrouwen. Het behoud van een hoog niveau van ervaren professionele autonomie is een uitdaging bij de invoering van nieuwe zorgsystemen. Voor het behoud én het bevorderen van professionele autonomie, moeten zorgprofessionals worden ondersteund bij hun eigen manier van werken.

\section{Hoofdstuk 6}

Goede samenwerking tussen zorgprofessionals is een sleutelelement in veilige en effectieve zorg. Echter het creëren van een goede samenwerkingscultuur kan een uitdaging zijn.

In hoofdstuk 6 besteden we aandacht aan hoe multidisciplinaire teams (MDT) die geboortezorg verlenen, interprofessionele samenwerking ervaren. Ondanks het belang hiervan voor de geboortezorg, is nog maar weinig bekend over de wijze en de kwaliteit van samenwerking tussen de verschillende verloskundige zorgverleners in Nederland.

Om deze kennislacune op te vullen, hebben we de data van de eerder genoemde online vragenlijst (hoofdstuk 4) geanalyseerd om potentiele bevorderende factoren en barrières voor interprofessionele samenwerking binnen deze MDTs te identificeren.

Uit de antwoorden op de 'factor statements' uit het domein 'Werkpleksamenwerking binnen het MDT' uit de Leiden Kwaliteit van Werk vragenlijst is een gemiddelde samenwerkingsscore berekend. 
We ontvingen antwoorden van 3653 professionals, inclusief 97 klinisch verloskundigen, 390 gynaecologen, 390 eerstelijns verloskundigen en 2776 obstetrisch verpleegkundigen en kraamverzorgenden.

Veertig procent van de respondenten bleek niet tevreden over de samenwerking in het MDT.

Er waren significante verschillen in de gemiddelde samenwerkingsscores tussen de professionals. Verloskundigen, zowel klinisch als in de eerste lijn werkzaam, waren pessimistisch over de samenwerking in toekomstige modellen van verloskundige zorgverlening.

Optimale samenwerking is een veiligheidskwestie en een van de grootste uitdagingen in de huidige gezondheidszorg. De literatuur laat zien dat wanneer dit onderwerp niet wordt opgepakt, patiëntveiligheid in het geding kan komen.

Er bestaan meerdere strategieën om suboptimale samenwerking te verbeteren, echter een one-size-fits-all strategie is niet voorhanden. Onze studie laat zien dat de ervaren samenwerking niet optimaal is in de Nederlandse geboortezorg. Beleidsmakers die zich bezighouden met de introductie van integrale geboortezorg, doen er goed aan om voldoende aandacht te besteden aan de noodzaak om samenwerking tussen verloskundige zorgverleners te verbeteren.

Toekomstig onderzoek moet zich richten op welke strategieën het beste zijn om de samenwerking in M DTs te optimaliseren.

\section{Hoofdstuk 7 Algemene discussie}

De Nederlandse verloskunde ondergaat momenteel grote veranderingen. Substantiële aanpassingen in de financiering van de geboortezorg, de werkomstandigheden en de werkgelegenheidsdynamiek worden momenteel geïntroduceerd.

In dit hoofdstuk bespreken we de belangrijkste uitkomsten van dit proefschrift tegen de achtergrond van de bestaande literatuur en een geboortezorg systeem in transitie. Vervolgens bespreken we de mogelijke betekenis die de uitkomsten van ons onderzoek zou kunnen hebben op landelijk en / of regionaal beleid, toekomstig onderzoek en op de praktijk van de Geboortezorg.

Ons onderzoek liet zien dat klinisch verloskundigen bij het grootste deel van de tweedelijns bevallingen aanwezig waren en dat $40 \%$ van deze bevallingen zelfs volledig door de klinische verloskundige werden begeleid. Alhoewel dit een positieve bevinding is, omdat zorg door verloskundigen in verband wordt gebracht met minder onnodige interventies, vonden we ook een grote diversiteit in de taken, verantwoordelijkheden, werkomstandigheden en opleiding van klinisch verloskundigen in Nederland. Deze diversiteit laat de 
noodzaak zien om de regulering aan te passen die invloed heeft op de praktijk en de taakuitoefening van klinisch verloskundigen.

Ten tijden van het onderzoek, bleken er geen actuele, op wetenschap gebaseerde protocollen van goede kwaliteit beschikbaar over drie belangrijke onderwerpen op Nederlandse verloskunde afdelingen. Sindsdien is het College Perinatale Zorg (CPZ) opgericht dat onder andere als taak heeft om een samenhangende strategie te ontwerpen voor de implementatie van integrale zorg. Een van de wijze waarop het CPZ dit heeft opgepakt, is met het publiceren en implementeren van de Zorgstandaard Integrale Geboortezorg (ZIG)in 2017. Alhoewel dit aan de oppervlakte een goed idee lijkt, is onderzoek hard nodig om vast te stellen of de ZIG ook daadwerkelijk zal leiden tot verbeteringen in de geboortezorg en of de ZIG ook betere onderbouwing en ondersteuning biedt bij het werk van klinische verloskundigen.

De verloskundigen die onze vragenlijst beantwoorden, waren over het algemeen tevreden over hun werk en alle respondenten waren het er over eens dat professionele ontwikkeling een belangrijk aspect is van hun werk. $\mathrm{Er}$ bleken echter wel belangrijke verschillen te zijn in factoren die bijdragen aan arbeidssatisfactie tussen klinisch en eerstelijns verloskundigen. Structurele elementen in hun werk, bleken belangrijk te zijn voor klinisch verloskundigen, terwijl de sociale aspecten belangrijker waren voor eerstelijns verloskundigen. Deze bevindingen zijn van belang voor zowel werkgevers als zorginkopers.

Een van de meer zorgwekkende bevindingen van ons onderzoek liet zien dat het merendeel van verloskundigen zich zorgen maakt over het behoud van hun professionele autonomie bij de introductie van integrale geboortezorg modellen. De reden dat dit zorgwekkend is, is omdat we weten dat een grote mate van autonomie belangrijk is voor de werktevredenheid en het welzijn van werknemers. Ook zorgwekkend is het gerapporteerde pessimisme over de samenwerking in multidisciplinaire geboortezorgteams. Goede samenwerking is van belang voor veilige en effectieve zorg. Bijna de helft van alle respondenten in onze vragenlijst, zowel verloskundigen als artsen, waren pessimistisch over de samenwerking in toekomstige zorgmodellen.

Onze aanbeveling is daarom dat indien toekomstige zorgmodellen een kans van slagen willen hebben, er specifiek aandacht wordt geschonken aan de huidige klinische diversiteit binnen de geboortezorg en dat verloskundige zorgverleners betrokken moeten worden op een wijze die recht doet aan hun professionele autonomie én die recht doet aan het verbeteren van de onderlinge samenwerking. Professionele samenwerking op andere gebieden in de gezondheidszorg kan daar bij tot een voorbeeld dienen. 
Het is reeds bekend dat verloskundigen veilige en effectieve zorg verlenen, óók aan vrouwen die niet vallen onder criteria voor eerstelijns zorg. Dit proefschrift laat zien dat klinisch verloskundigen een belangrijk en onderscheidend onderdeel van de Nederlandse geboortezorg zijn geworden. De resultaten bieden inzicht in de dagelijkse praktijkuitoefening van klinisch werkende verloskundigen en daarmee inzicht in de dynamiek van het verloskundige aanbod binnen de Nederlandse geboortezorg.

Toekomstig onderzoek is echter nodig om te bepalen hoe de tot nu nauwelijks gereguleerde praktijk van klinisch verloskundigen verbeterd kan worden en hoe de geboortezorg, zowel in de wijk als in het ziekenhuis, het best tegemoet kan komen aan de wensen van (zwangere) vrouwen. Ons onderzoek, het eerste uitgebreide onderzoek naar de inhoud en omvang van het werk van klinische verloskundigen, is daartoe de eerste aanzet en opent de deur voor verder onderzoek. Het is daarbij belangrijk dat we meer te weten komen over de ervaring van zwangere vrouwen en hun partners, die begeleid worden door klinisch verloskundigen en meer kennis over de ervaring en perspectieven van klinisch verloskundigen zelf die tenslotte een belangrijke speler zijn geworden in de Nederlandse geboortezorg. 
9

Valorisation 
The findings of our research have important implications, not only for midwives, but also for the mothers and babies in their care. By concentrating on a hitherto under studied group (hospital midwives) our research brings new knowledge to the profession and can be used to benchmark the contribution of hospital midwives and to guide the development of policies that protect women and guide their care throughout pregnancy and birth.

\section{Relevance}

Maternity care in the Netherlands is changing. The strict delineation characteristic of the traditional model - where midwives cared for women with normal pregnancies at home and obstetricians attended to women with complications - is increasingly less defined. Over the last twenty years, the number of midwives in the employ of hospitals has grown rapidly. Hospital midwives now represent one third of all practising midwives in the Netherlands, bridging the gap between primary and hospital care. Despite their increased presence in the hospital, there has been almost no examination of the contribution of hospital midwives to maternity care.

Given the apparent desire of the government to replace the traditional form of maternity care in the Netherlands with a new integrated-care model, it is imperative, prior to change, that the contribution of each professional in the maternity care team is visible, heard and measured.

Existing research has focused on the views of primary care midwives ${ }^{1,2}$, obstetricians ${ }^{3}$ and pregnant women ${ }^{4}$. By describing the practice conditions, challenges, and opportunities faced by hospital midwives, this thesis makes a significant contribution to the body of knowledge regarding the professional groups that provide maternity care.

Our research serves as an important guide to developing policy for new models of maternity care. In these pages, we highlight the heretofore unacknowledged differences between hospital and primary care midwives and we provide evidence of what each group finds important about their work. These data offer a valuable benchmark for future studies of the profession and the maternity care system in the Netherlands. 


\section{Target groups}

Our findings relate primarily to the diversity, practice conditions, and views of hospital midwives practising in the Netherlands. As such, our work will, first and foremost, be of interest to that group. Our studies of the job satisfaction of hospital midwives, their experienced autonomy, and their attitudes toward collaboration call attention to the differences between hospital and primary care midwifery. These data are critical for acknowledging the unique and important role of hospital midwives. Hospital midwives should take note of our findings, using them to help define their place within the maternity care framework and to ensure that their contribution is recognised.

However, because hospital midwives are only one piece of the larger puzzle of maternity care, our findings have significance for the other areas of maternity service provision, including primary care midwives, other members of the multi disciplinary maternity care team, insurers, regulators, and policymakers. By serving as an 'aide memoire' regarding the contribution of hospital midwives, our research can guide the work of policy makers and purchasers of maternity services in the Netherlands. And given the unique organization of maternity care in the Netherlands ${ }^{5}$, our research - highlighting the contribution of midwives generally and hospital midwives in particular - will be of interest to a wider international audience.

Our study of diversity in the practice of hospital midwives is especially useful in focusing attention to the practice conditions of hospital midwives and has already informed debate surrounding the introduction of a new category of 'clinical midwife' to the registrant categories of the Dutch Healthcare Practitioners Law. Furthermore, our study of the content, quality, and availability of protocols in maternity care in the Netherlands found that up-todate, high quality evidence may not be readily available to hospital midwives in the Netherlands, an issue that is of critical importance for the health of mothers and babies.

Finally, by measuring the contribution of hospital midwives, our findings can be used to generate discussion regarding the introduction of practice and audit standards for hospital midwives. This would help to provide additional safety and protection to mothers and babies in our care. 


\section{Innovative character of the study}

M ost studies of midwives and midwifery in the Netherlands focus on the place of birth or primary care midwives. We chose to study hospital midwives a relatively new, fast-growing, and under-researched group within the maternity care model of the Netherlands. As little evidence regarding hospital midwives practice existed prior to our study, we began with a survey measuring the scope, breadth, and depth of the contribution of this group to maternity care in the Netherlands. This was the first such study of Dutch hospital midwives. By looking at hospital midwives as a group, we were able to establish that there is a high level of diversity in the scope and practice of hospital midwives and that the aspects of their work that hospital midwives find to be important are not the same as those that primary care midwives find important.

In the Netherlands, all hospital midwives are employees, whereas most primary care midwives are self-employed. This dynamic has generated significant differences in how hospital and primary care midwives view (elements of) their job satisfaction as well as in how they experience collaboration with other members of the care team and how they see their autonomy as professionals.

Throughout our study we used quantitative methods, comparing the two groups of midwives with each other and also with other members of the multidisciplinary maternity care team. This offered a broad perspective from which we were able to make comparisons, test hypotheses, make assumptions, and draw conclusions regarding the contribution of hospital midwives. These measures have provided new knowledge regarding this group, contributing to the wider body of midwifery knowledge.

\section{Activities}

When we began our research, very little was known about the practice of hospital midwives in the Netherlands. As pioneers in this field, we have been able to disseminate our findings at a variety of local, national and international fora. We reached out to the community of hospital midwives through the clinical midwives group of Royal Dutch Organization of M idwives (KNOV), the Dutch midwives professional journal (TVV) and via conversation with students in the Master's level clinical midwife physician assistant course (KV, M PA). We also have been involved in teaching sessions for student midwives and have 
interacted with obstetricians and other professionals involved with maternity service provision in the Netherlands.

All five of the studies included in the dissertation have been published in internationally renowned, peer-reviewed journals. Details of these and other publications are found in the Appendix of this thesis.

Following the publication of this thesis we will continue to disseminate the new and important insights gained through this study, thereby helping to raise the profile of hospital midwives in the Netherlands. In addition, we will look for new (financial) opportunities to further examine issues raised by our study. We expect our findings will contribute to the continuing discourse within the profession over the future of hospital midwives.

\section{References}

1. Collins CT, Fereday J, Pincombe J, Oster C, Turnbull D. An evaluation of the satisfaction of midwives' working in midwifery group practice. M idwifery. 2010 Aug;26(4):435-41. doi: 10.1016/j.midw.2008.09.004. Epub 2009 Sep 24.

2. Warmelink JC, Hoijtink K, Noppers M, Wiegers TA, de Cock TP, Klomp T. et al. An explorative study of factors contributing to the job satisfaction of primary care midwives. M idwifery. 2015 Apr;31(4):482-8. doi: 10.1016/j.midw.2014.12.003. Epub 2015 Jan 2.

3. van der Lee N, Driessen E, Scheele F. How the past influences interprofessional collaboration between obstetricians and midwives in the Netherlands: findings from a secondary analysis. J Interprof Care.2016;30(1):71-76.

4. Nieuwenhuijze MJ, Korstjens I, de Jonge A, de Vries R, Lagro-Janssen A. On speaking terms: a Delphi study on shared decision-making in maternity care. BM C pregnancy and childbirth. 2014;14:223.

5. De Vries. A Pleasing Birth: M idwifery and Maternity Care in the Netherlands. Philadelphia, PA: Temple University Press, 2005; Amsterdam: Amsterdam University Press, 2005. 
Appendix

List of publications

and contributing

authors

Curriculum Vitae

Word of thanks 


\section{List of Publications:}

Diversity in the Scope and Practice of Hospital-Based Midwives in the Netherlands

Doug Cronie, MA, RM , RN, Marlies Rijnders, PhD, RM , Simone Buitendijk, MD, $\mathrm{PhD}, \mathrm{MPH}$

Journal of M idwifery and Women's Health1526-9523/09 doi:10.1111/j.15422011.2012.00164.x

M aking Evidence Available for Hospital-Based M idwives: A Systematic Examination of the Content and M ethodological Quality of Three Protocols Used in Maternity Hospitals in the Netherlands

Doug J. Cronie, Marlies Rijnders, Raymond de Vries, and Simone Buitendijk INTERNATIONAL JOURNAL OF CHILDBIRTH Volume 4, Issue 4, 2014@ 2014 Springer Publishing Company, LLC www.springerpub.com http://dx.doi.org/10.1891/2156-5287.4.4.208

Are midwives in the Netherlands satisfied with their jobs? A systematic examination of satisfaction levels among hospital and primary-care midwives in the Netherlands.

Doug Cronie, MA, BSc, RM, RN, Hilde Perdok MSc RM, Corine J. Verhoeven PhD RM, Suze Jans PhD RM, Marieke Hermus MAA, RM, MSc, Prof. Dr. Raymond de Vries PhD, Dr Marlies Rijnders RM PhD

(Accepted by: BM C Health Service Research, May 2019)

How good is collaboration between maternity service providers in the Netherlands?

Doug Cronie, Marlies Rijnders, Suze Jans, Corine J Verhoeven, Raymond de Vries.

Journal of M ultidisciplinary Healthcare 2019:12

Experienced job autonomy among maternity Professionals in the Netherlands.

Perdok H, Cronie D, van der Speld C, van Dillen J, De Jonge A, Rijnders M, De Graaf I, Schellevis F, Verhoeven C.

Midwifery. 2017 Nov;54:67-72. doi: 10.1016/j.midw.2017.07.015. Epub 2017 Jul 20. 
Kramer J, Cronie D, Smit M, Schraagen J. Evaluation of M idwifery

Protocols in the Netherlands; an analysis of task and responsibility agreements among hospital maternity service providers [Verloskundige Protocol Evaluatie Nederland; een analyse van taak en verantwoordelijkheidsafspraken van tweedelijns zorgverleners]

TNO-report 031.20452;13 (in Dutch); October 2010.

Severe cardiorespiratory and neurologic symptoms in a neonate due to mepivacaine intoxication

de Groot-van der Mooren M, Quint S, Knobbe I , D. Cronie, van Weissenbruch $M$.

(Accepted by: Neonatology, June 2019) 


\section{Curriculum Vitae}

Doug Cronie was born on the 9th of November 1965 in Johnstone, Scotland. The youngest of four boys, Doug went first to Bushes Primary School and later to Paisley Grammar School. Leaving school early and moving to England at fifteen, Doug was keen to make his way in the world and initially was not too focused on further education.

Following a motorbike accident and a prolonged stay in hospital, Doug found is path and trained to become a Registered General Nurse in 1984. This was to awaken in him a passion for learning. Subsequently Doug trained as a M idwife. Qualifying in 1990 Doug worked first as a hospital midwife in the North of England before moving to London in 1995 to work as a community midwife. While there, he began what has turned out to be an ongoing journey of continuing education. First came a Batchelor's degree, with honours in M idwifery from Thames Valley University.

In 1997 he was appointed Regional Officer for the Royal College of M idwives of the UK where he spent two years consolidating his knowledge of midwifery affairs.

Following his marriage in 1998 Doug and his husband moved to the Caribbean in 1999 where he was the first male midwife in the Bahamas and then in the Cayman Islands where he obtained a M asters degree with merit in Midwifery (also from Thames Valley University).

A further move in 2005 to the Netherlands brought the challenge of a new language and desire to learn all that he could regarding the Dutch model of midwifery care. Which, in turn led to this PhD.

In 2012 Doug was appointed Senior Midwife at Sint Lucas Andreas Ziekenhuis, a tertiary hospital in Amsterdam. Since 2016, Doug works as a clinical midwife at Onze Lieve Vrouw Gasthuis in Amsterdam. In addition, he serves as a midwife member of the Dutch Midwives Disciplinary Committee (Tucht College) and is active within the KNOV, the Dutch midwives Professional Organisation.

Doug is married to Daan Huijser (and together with Ayelle and Angie Martis) they have one daughter, Bowen (2017). 


\section{Thank you/Dankwoord}

I'm finished! M any times I never thought I'd be able to say those words in the same sentence as my PhD! However, it is and I can.

Embarking on a PhD is a journey. A journey, which you don't make alone. Without the help and support of those you meet and bond with along the way, it is also one, which would be impossible to complete without their help. For that, I'm extremely grateful and I'd like to use this opportunity to thank some of them individually.

Firstly, my promotors Prof. Dr Raymond de Vries and Prof. Dr Simone Buitendijk and my Co-promotors Dr Marlies Rijnders and Dr Suze Jans.

Dear Ray, from the first time we met you've always been supportive and encouraging. Your feedback is always positive and designed to inspire confidence. Thank you for your wise words, helpful editing and for your unswerving trust and belief in me.

Dear Simone, all those years ago, you were the first to take me seriously, to listen to me and to lead me to believe that I could make something of my ideas. Despite your busy schedule, you've always made me feel that you have the time for me. Your guidance has been inspirational and your wisdom is profound.

Dear M arlies, of all those who've helped me, you've done the most! You've listened to me, encouraged me, challenged me and guided me, and all of it in the most supportive way. But more than any of that, you've become a friend. For that, I'll always be grateful. Thank you!

Dear Suze, you joined the party a little ways in but since then you've been supportive, constructive and kind. You've treated me as an equal and been positive and thoughtful in your critique.

To the members of the reading committee: Prof. Dr. Pim Teunissen, Prof. Dr. Judith de Jong, Prof. Dr. F. Stevens, Prof. Dr. Paul Lewis and Dr. M arrit Smit. Thank you for your scientific review of this thesis and for your time and willingness to take part in the public defence.

Although impossible to thank everyone else individually who's been supportive along the way, nevertheless some need particular mention.

Prof. Dr. Eileen Hutton, your guidance was particularly welcome at a time when I was wavering. 
Dr. Evelien Spelten, your kindness and support meant more than you could have known.

Dr. Ank de Jonge, Thank you for our many discussions!

Dr. Corine Verhoeven and Dr. Hilde Perdok, thank you for your collaboration.

M w M aureen Groven at M aastricht University, thank you for your procedural advice.

To all the midwives who took part in my research, you made it happen!

Thank you to my Cayman 'family', particularly Denise, Laura, Tully and Susie, Paul, Karen, Paul and Simone for providing me with the space and wise council needed to complete this work.

Special thanks to Jaimie Rogers for her help with the cover illustration (and for the privilege of allowing me to be your midwife!)

Dearest Heleen and Tineke, thank you for your enduring friendship and for being my paranimfen.

To my friends, family and colleagues, thank you for your ongoing interest and encouragement. Please know that each and every one of you (who are too many to mention) have all been instrumental in my completing this work.

Lastly, to my dearest husband, Daan. Thank you for being there through thick and thin, for your encouragement, your belief in me and for your never-ending support and also for giving me the time and space to complete this work. Without you, I wouldn't be the person I am today.

Doug. 